Florida International University FIU Digital Commons

FIU Electronic Theses and Dissertations

University Graduate School

10-29-2008

\title{
A Capability Maturity Model to Assess Supply Chain Performance
}

Heriberto Garcia

Florida International University, hgarc007@fiu.edu

DOI: $10.25148 /$ etd.FI10022514

Follow this and additional works at: https:// digitalcommons.fiu.edu/etd

Part of the Operations Research, Systems Engineering and Industrial Engineering Commons

\section{Recommended Citation}

Garcia, Heriberto, "A Capability Maturity Model to Assess Supply Chain Performance" (2008). FIU Electronic Theses and Dissertations. 191.

https://digitalcommons.fiu.edu/etd/191

This work is brought to you for free and open access by the University Graduate School at FIU Digital Commons. It has been accepted for inclusion in FIU Electronic Theses and Dissertations by an authorized administrator of FIU Digital Commons. For more information, please contact dcc@fiu.edu. 


\section{FLORIDA INTERNATIONAL UNIVERSITY}

Miami, Florida

\section{A CAPABILITY MATURITY MODEL TO ASSESS SUPPLY CHAIN PERFORMANCE}

A dissertation submitted in partial fulfillment of the requirements for the degree of DOCTOR OF PHILOSOPHY in INDUSTRIAL AND SYSTEMS ENGINEERING

by Heriberto Garcia 2009 
To: Dean Amir Mirmiran

College of Engineering and Computing

This dissertation, written by Heriberto Garcia, and entitled A Capability Maturity Model to Assess Supply Chain Performance, having been approved in respect to style and intellectual content, is referred to you for judgment.

We have read this dissertation and recommend that it be approved.

Syed M. Ahmed

Shih-Ming Lee

Martha A. Centeno

Ronald E. Giachetti, Major Professor

Date of Defense: October 29, 2008

The dissertation of Heriberto Garcia is approved.

Dean Amir Mirmiran

College of Engineering and Computing

Dean George Walker

University Graduate School

Florida International University, 2009 
(C) Copyright 2009 by Heriberto Garcia

All rights reserved. 


\section{DEDICATION}

To God, whom I serve and love.

To my family, source of love and inspiration. Thanks for your love and support through this endeavor. Thanks for helping me to be a better spouse, father and friend for you.

To my parents, who gave me the education required to be successful in the life.

To my brothers and sisters, for all your love and support during all these years. 


\section{ACKNOWLEDGMENTS}

Thanks to the members of my dissertation committee. Dr. Ronald E. Giachetti, Major Professor, thanks for all your support, advice, patience, and help through this work. I learned from you how to conduct a $\mathrm{PhD}$ research. Dr. Martha A. Centeno, thanks for introducing me into the world of research. I enjoyed your lectures and all the talks we had prior to defining my dissertation topic. Dr. Shih-Ming Lee, thanks for believing in me since the first day we met. I enjoyed the opportunity of teaching for a couple of semesters. Dr. Syed M. Ahmed, thanks for all your contributions as a member of my committee during this dissertation work.

My everlasting gratitude to my brothers and sisters in Miami, thanks for giving me so much help during my years as a PhD student. Thank you for sharing your lives with me and my family, and always being there for me. 


\title{
ABSTRACT OF THE DISSERTATION \\ A CAPABILITY MATURITY MODEL TO ASSESS \\ SUPPLY CHAIN PERFORMANCE
}

by

\author{
Heriberto Garcia
}

Florida International University, 2009

Miami, Florida

Professor Ronald E. Giachetti, Major Professor

In an overcapacity world, where the customers can choose from many similar products to satisfy their needs, enterprises are looking for new approaches and tools that can help them not only to maintain, but also to increase their competitive edge. Innovation, flexibility, quality, and service excellence are required to, at the very least, survive the on-going transition that industry is experiencing from mass production to mass customization.

In order to help these enterprises, this research develops a Supply Chain Capability Maturity Model named $\mathrm{S}(\mathrm{CM})^{2}$. The Supply Chain Capability Maturity Model is intended to model, analyze, and improve the supply chain management operations of an enterprise. The Supply Chain Capability Maturity Model provides a clear roadmap for enterprise improvement, covering multiple views and abstraction levels of the supply chain, and provides tools to aid the firm in making improvements. The principal research tool applied is the Delphi method, which systematically gathered the knowledge and experience of eighty eight experts in Mexico. The model is validated using a case study and interviews with experts in supply chain management. The resulting contribution is a 
holistic model of the supply chain integrating multiple perspectives, and providing a systematic procedure for the improvement of a company's supply chain operations. 


\section{TABLE OF CONTENTS}

CHAPTER PAGE

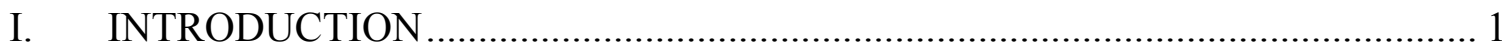

1.1 Pivotal Improvement Tools, Techniques and Methodologies .................... 5

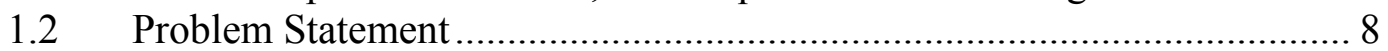

1.2.1 Problem 1: Modeling of the supply chain............................................. 10

1.2.2 Problem 2: Selecting System Improvement Strategies.......................... 12

1.2.3 Problem 3: Integrating the SCM and the core business orientation...... 14

1.2.4 Problem 4: Problem Summary .............................................................. 16

$1.3 \quad$ Goal and Specific Objectives................................................................ 16

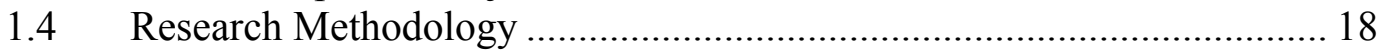

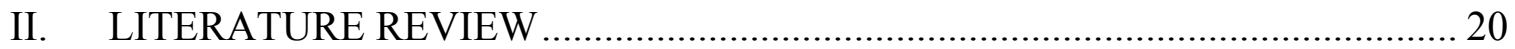

2.1 Enterprise Modeling Frameworks and Architectures.................................... 21

2.1.1 The IDEF Language........................................................................ 22

2.1.2 The GRAI Integration Methodology (GIM) ....................................... 23

2.1.3 The Zachman's framework ................................................................ 24

2.1.4 The Purdue Enterprise Reference Architecture (PERA) ……………... 25

2.1.5 The CIMOSA Framework .............................................................. 27

2.1.6 The GERAM Framework .............................................................. 29

2.1.7 Conclusions About the Enterprise Reference Architectures.................. 30

2.2 Supply Chain Models and Architectures..................................................... 32

2.2.1 Stevens' Model ............................................................................ 32

2.2.2 An Integrated Supply Chain Management Architecture......................... 34

2.2.3 Enterprise Architecture for Supply Chain Integration ........................... 35

2.2.4 Architecture for Supply Chain Integration ………………………...... 38

2.3 The Supply Chain Operations Reference (SCOR)………………………...... 42

2.4 A Supply Chain Maturity Model ............................................................... 45

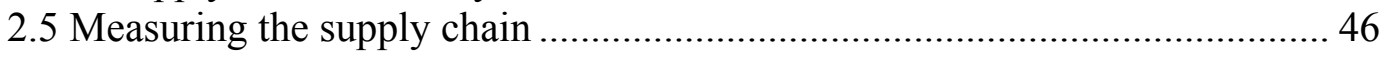

2.6 Best Practices from other disciplines applied to Supply Chain ...................... 49

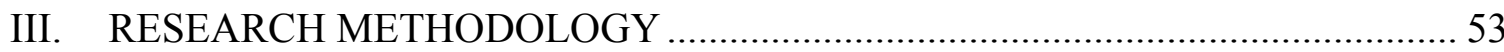

3.1 The Delphi Method as a research tool ...................................................... 55

3.2 Methodology used to get the Meta-Model Conceptualization................... 58

3.3 Detailed Description of Stage I............................................................. 59

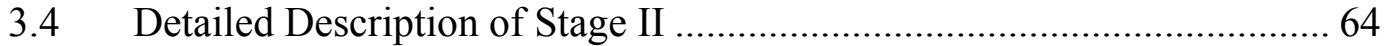

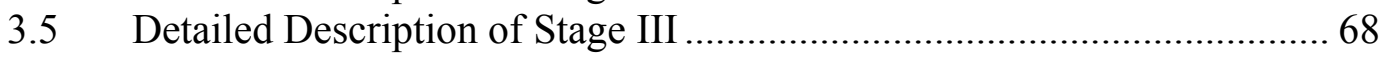

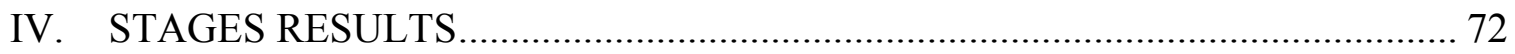

4.1 Qualification of the Experts for Stage I .................................................... 72

4.2 Summary of the Results for Stage I ..................................................... 73

4.2.1 Characterization of each Maturity Level .............................................. 74

4.2.2 Prioritization of the Key Improvement Factor in a Supply Chain ........ 76

4.3 Qualification of the Experts for Stage II................................................. 78 


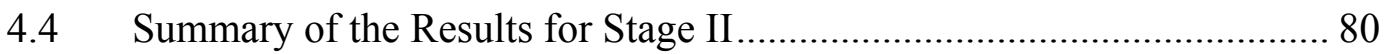

4.4.1 Validation of the Maturity Level: Undefined ........................................ 81

4.4.2 Set of Useful Improvement Tools for the Undefined Level ................. 82

4.4.3 Validation of the Maturity Level: Defined ............................................ 83

4.4.4 Set of Useful Improvement Tools for the Defined Level ...................... 84

4.4.5 Validation of the Maturity Level: Manageable....................................... 84

4.4.6 Set of Useful Improvement Tools for the Manageable Level................ 85

4.4.7 Validation of the Maturity Level: Collaborative ................................... 86

4.4.8 Set of Useful Improvement Tools for the Collaborative Level ............. 87

4.4.9 Validation of the Maturity Level: Leading ………………………........ 88

4.4.10 Set of Useful Improvement Tools for the Leading Level ...................... 89

V. THE SUPPLY CHAIN CAPABILITY MATURITY MODEL ............................... 90

5.1 Definition of the Views and Abstraction Levels in the $\mathrm{S}(\mathrm{CM})^{2}$.............. 90

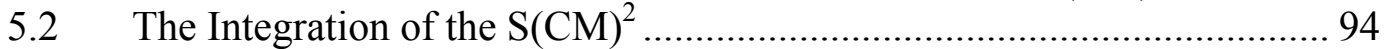

5.2.1 The $\mathrm{S}(\mathrm{CM})^{2}$ in a Tableau Form …………….................................. 95

5.2.2 The $\mathrm{S}(\mathrm{CM})^{2}$ in a graphical Form ………………............................. 98

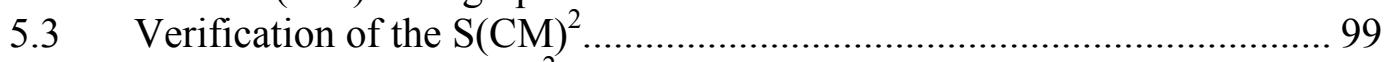

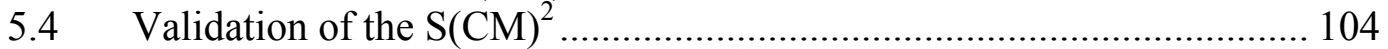

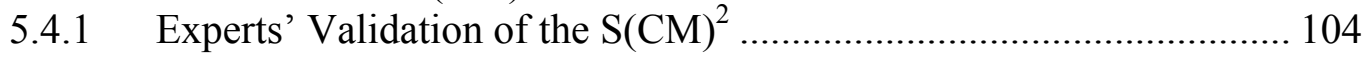

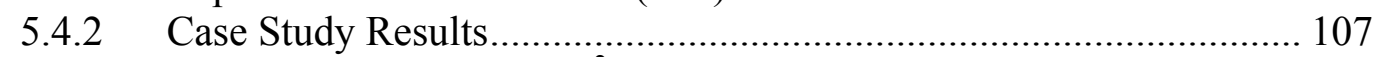

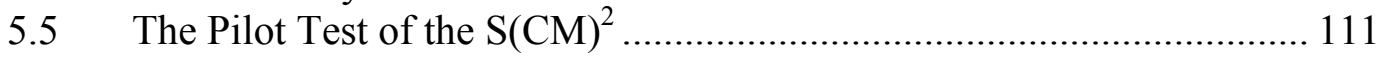

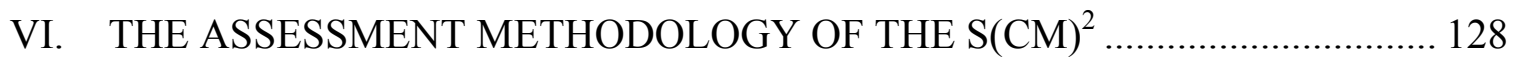

6.1 The Generalization of the Supply Chain Classification........................... 128

6.2 The Supply Chain Assessment Process ……………………………....... 130

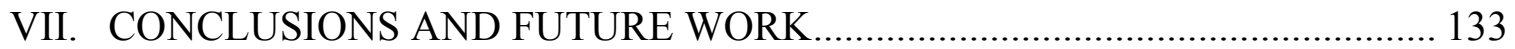

$7.1 \quad$ Research Contribution ......................................................................... 134

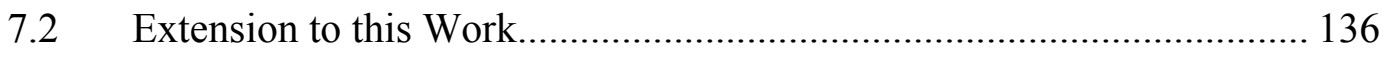

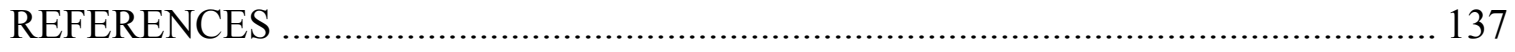

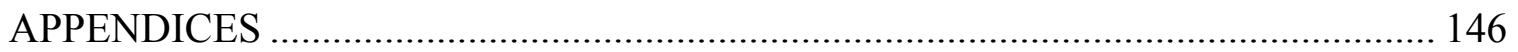

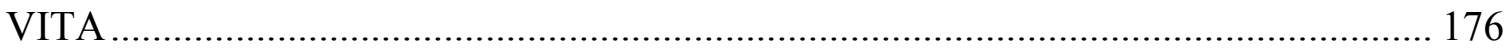




\section{LIST OF TABLES}

$\begin{array}{ll}\text { TABLE } & \text { PAGE }\end{array}$

Table 1: Comparison among Supply Chain Architectures. ....................................... 41

Table 2: Type of Business Represented in the Stage I............................................ 73

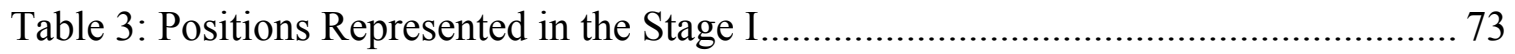

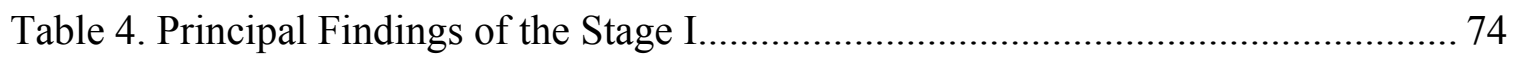

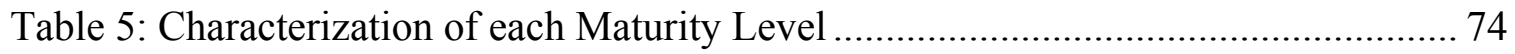

Table 6: List of Key Improvement Factors ........................................................... 76

Table 7: Prioritization of Improvement Factors for Maturity Level .............................. 77

Table 8: Key Improvement Factor for each Maturity Level..................................... 78

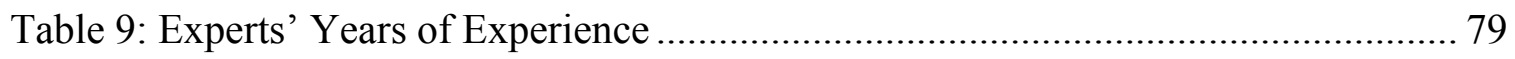

Table 10: Type of Business Represented in the Stage II ............................................ 79

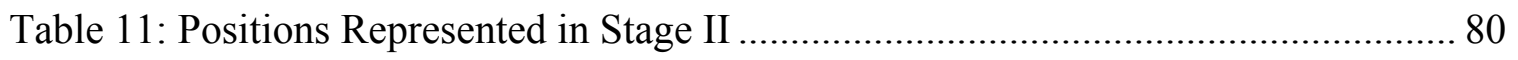

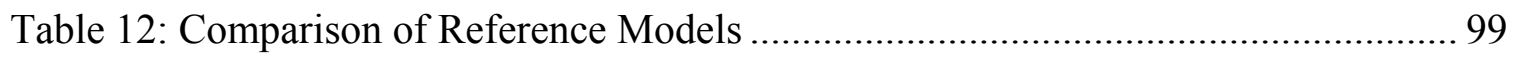

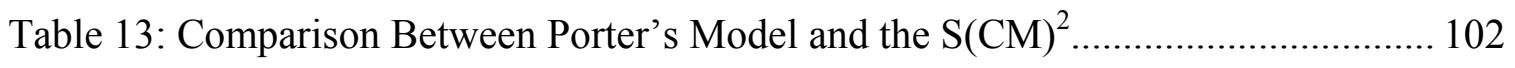

Table 14: Information of the Experts consulted to Validate the $\mathrm{S}(\mathrm{CM})^{2} \ldots \ldots \ldots \ldots \ldots \ldots \ldots . . . . . . . . .105$

Table 15: Answers Obtained Through the Validation Sheet ....................................... 106

Table 16: Expected Answers for the Case Study .................................................... 108

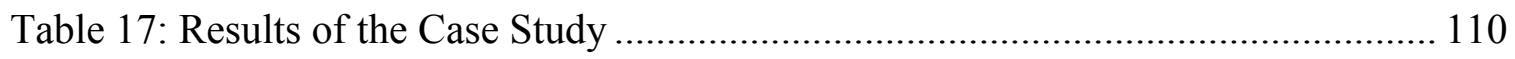

Table 18: Distribution of the Case Study Answers................................................. 111

Table 19: Assessment Questionnaire for the view Suppliers....................................... 113

Table 20: Assessment Questionnaire for the view Production .................................... 116

Table 21: Assessment Questionnaire for the view Inventory Systems......................... 118 
Table 22: Assessment Questionnaire for the view Customers.................................... 120

Table 23: Assessment Questionnaire for the view Human Resources ......................... 122

Table 24: Assessment Questionnaire for the view Info. Sys. \& Technology ................. 123

Table 25: Assessment Questionnaire for the view Performance Measurement ............. 125 


\section{LIST OF FIGURES}

FIGURE

PAGE

Figure 1: Supply Chain Macro-Level Representation ............................................... 4

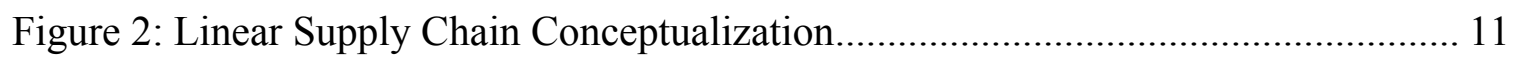

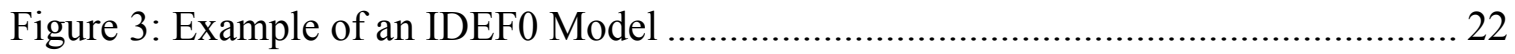

Figure 4: GIM Modeling Framework and Conceptual Model..................................... 23

Figure 5: Zachman's Framework for Enterprise Architecture .................................... 25

Figure 6: Models and tools involved in the PERA Life-cycle ..................................... 26

Figure 7: Definition of the Concepts for the Manufacturing Case ................................ 27

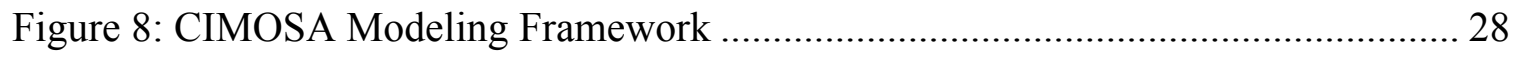

Figure 9: GERA, the Reference Architecture of GERAM ....................................... 30

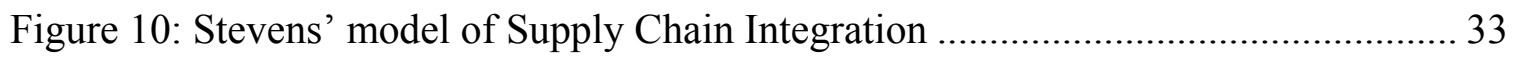

Figure 11: Integrating and Managing Business Processes across the Supply Chain....... 35

Figure 12: Member Enterprise Value Analysis (Chandra and Kumar, 2001) ................. 36

Figure 13: A Collaborative Supply Chain Member Architecture .................................... 37

Figure 14: Architecture for an Integrated Supply Chain Enabling IT ............................ 39

Figure 15: The SCOR Model-Based Supply Chain Infrastructure ................................ 42

Figure 16: The Business Process Orientation Maturity Model..................................... 46

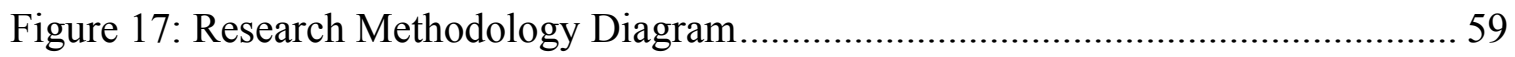

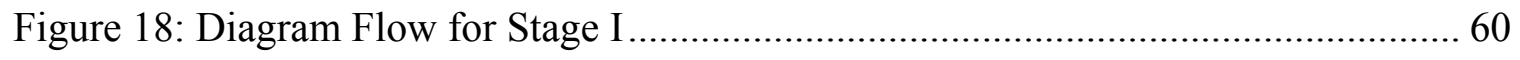

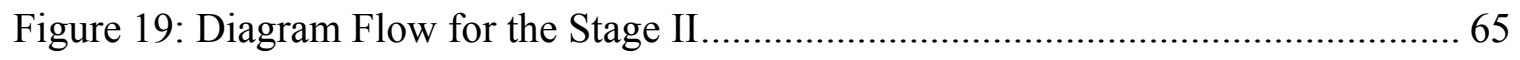

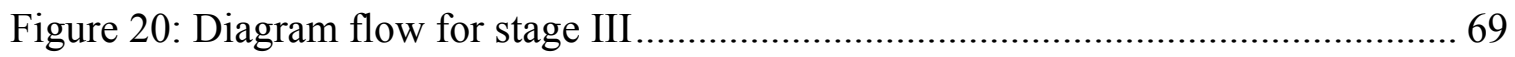

Figure 21: Acceptance of the Definition for the Undefined Level ............................... 82 
Figure 22: Acceptance of the Definition for the Defined Level .................................. 84

Figure 23: Acceptance of the Definition for the Manageable Level ............................. 85

Figure 24: Acceptance of the Definition for the Collaborative Level ............................ 87

Figure 25: Acceptance of the Definition for the Leading Level ................................. 88

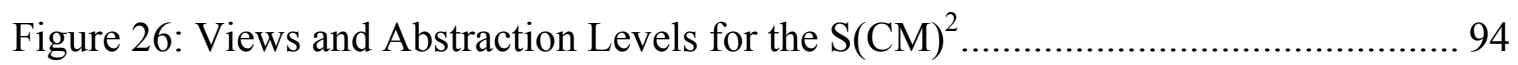

Figure 27: The Supply Chain Capability Maturity Model Framework .......................... 95

Figure 28: Example of a Maturity Level of $\mathrm{S}(\mathrm{CM})^{2}$ in Tabular Form............................ 96

Figure 29: Example of a Maturity Level of $\mathrm{S}(\mathrm{CM})^{2}$ in Tabular Form (b) ...................... 97

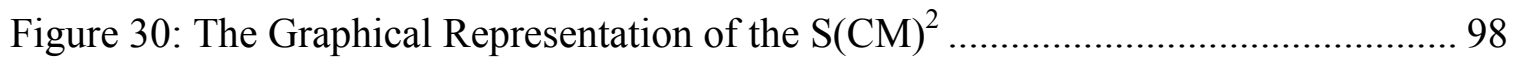

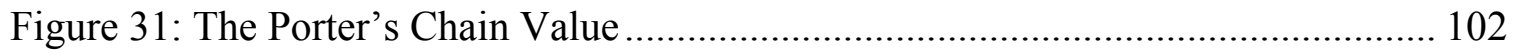

Figure 32: View Customer, Level Manageable .................................................. 108

Figure 33: Radar Graph for the View Suppliers .................................................. 115

Figure 34: Maturity Levels for each view Assessed .............................................. 127

Figure 35: Supply Chain Assessment Report ........................................................ 129

Figure 36: The $\mathrm{S}(\mathrm{CM})^{2}$ Assessment Methodology ................................................... 130

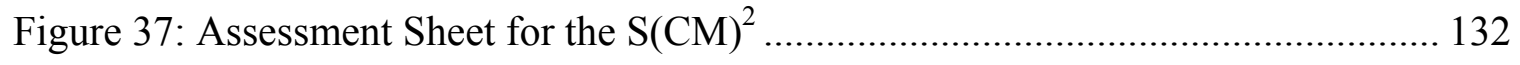




\section{CHAPTER I}

\section{INTRODUCTION}

In an overcapacity world, where customers have many similar products to satisfy their needs, enterprises are looking for new approaches and tools that can help them not only to maintain, but also to increase their competitive edge. Companies like Wal-Mart, Dell, Toyota, and Southwest Airlines are constantly seeking new methods and tools to allow their processes to be faster, cheaper and better than those of their competitors (Hammer, 2002). ERP systems, Supply Chain Management (SCM), Logistic, Valuebased Management, Lean Manufacturing, Six Sigma, and Balance Scorecard are among the strategic concepts that have been frequently used to improve competitiveness (Hammer, 2002b). However, these concepts have not provided a comprehensive perspective of the enterprise; they rather tend to focus on a single perspective or portion of the enterprise.

These partial views are not unexpected, given the fact that solutions to company's problems are frequently initiated at the department level. Not until the 1990's did many companies have the technological means to develop methods and tools with a more holistic view. Now, companies need to rethink their vision about their principal market strategy. Customers have become more demanding, and they seek the "latest" product or service at a low price, at the right place, at the right time, and with the highest quality in the market (Chin et al. 2004). Thus, innovation, flexibility, quality, and service excellence are required to, at the very least, survive the on-going transition that industry is experiencing from mass production to mass customization (Caputo et al. 2003). 
Engaging in holistic enterprise modeling and analysis requires great investment, cultural change, and a very deep commitment from the improvement project owner. Moreover, the amount of information needed for a holistic view must be considered carefully because, if it is not controlled, it may drown the vision itself. Thus, it is important to develop methodologies and tools that enable enterprise modeling by capturing the relationships that exist among subsystems.

Previous efforts have mostly been partial views, and the very few that tried a more integrated approach have failed because they needed a lot of time to model the system, validate the model, and analyze the results obtained (Chan et al. 2002). Nevertheless, the need for holistic modeling and analysis is real and critical. There is a need to move the approaches, which use partial views, toward holistic methodologies using crossdisciplinary integrated views (Svensson, 2003). This research contributes to satisfying the need of a holistic enterprise modeling methodology, which is an enterprise representation useful to analyze, improve, and document the enterprise processes through several views, decomposition levels and disciplines.

This research develops a Supply Chain Capability Maturity Model, hereafter abbreviated $\mathrm{S}(\mathrm{CM})^{2}$. The $\mathrm{S}(\mathrm{CM})^{2}$ is intended to model, analyze, and improve supply chain management operations for an enterprise, which is part of one or several supply chains. Regarding the definition of a supply chain, so far, there is no unique definition supply chain. A supply chain may be defined in terms of management processes, operations, functions or a management philosophy (Tyndall et al. 1998). 
Depending on functions, organizations, and industries, the complexity of a supply chain leads to different points of analysis and definitions of what supply chain management $(\mathrm{SCM})$ is. This situation creates a lack of standard terminology and improvement opportunities in terms of which the key performance indicators within a supply chain system are (Kasi, 2005). At the same time, this lack of a standard definition creates a dangerous ambiguity when a supply chain is analyzed. Excluding important supply chain processes in the definition may create a bias in the analysis and modeling of the system, and in how the implementation of improvement approaches may influence enterprise strategy and performance (Mentzer et al. 2001).

One of the many Supply Chain Management definitions is the one provided by La Londe and Masters (2004), “A Supply Chain is a set of independent firms of retailers, transportation companies, suppliers, and wholesalers passing materials forward by manufacturing a product and placing it in the hands of a customer." In other words, SCM is an integrating function, which links major business functions and business processes within and across an enterprise to achieve a higher performance for all involved parties. At a macro level, a supply chain can be represented as shown in Figure 1, in which it is easy to see that a supply chain is an integrated economic and operational system, with bidirectional links to corporate strategies. Additionally, an enterprise might be part of many supply chains generating a logistic network.

Even though, the existing definitions of SCM call for an integration of the supply chain, this has not yet been widely achieved. The exceptions are the companies with huge negotiation power or world-wide trademarks, such Wal-Mart or Dell, which have attained sophisticated supply chain integration. While these larger companies have good 
integration, most of their immediate suppliers are not integrated with the second tier suppliers (NIST,1999).

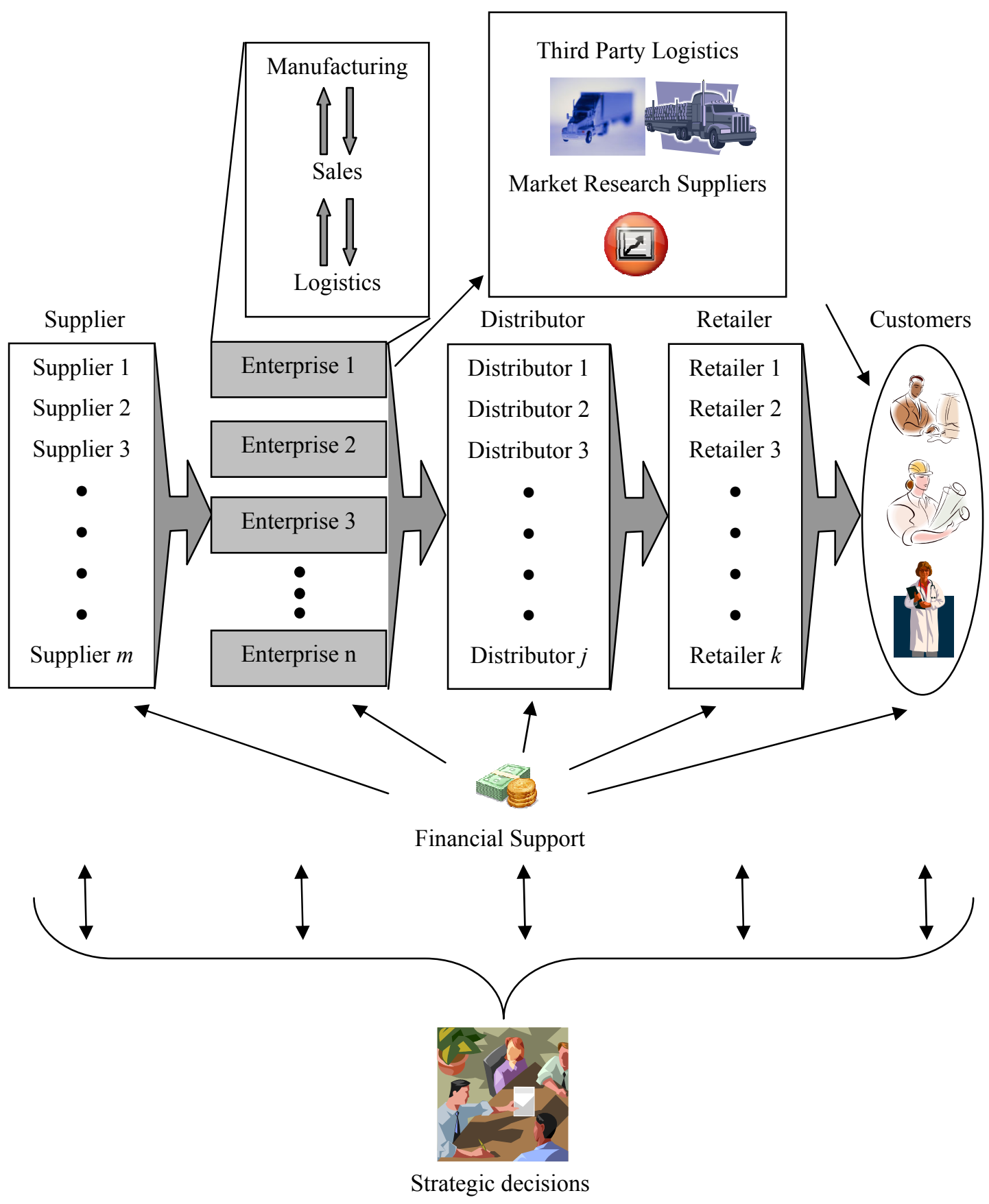

Figure 1: Supply Chain Macro-Level Representation 
For those enterprises looking to improve their supply chain, there is much advice available. Unfortunately, the abundance of existing improvement methods could create confusion in regards to prioritizing what to analyze and improve first: the processes, the tools, the model or the methodology. These facts make the supply chain improvement process more difficult. This research does not have the objective to develop a universal definition of Supply Chain, but it provides a meta-model, that is a model of models, useful for the improvement of an enterprise performance vis-à-vis the supply chain(s) of which it is a member.

The remainder of this chapter provides definitions of pivotal concepts used in this research. It also describes the problem being addressed, its importance, and what part of the problem this research has addressed. Chapter 2 presents a review of previous efforts regarding the evaluation, diagnosis, modeling and analysis of supply chain operations. Chapter 3 explains the methodology used to generate the $\mathrm{S}(\mathrm{CM})^{2}$ conceptualization, which includes the Delphi Method as a pivotal tool to model the supply chain elements. Chapter 4 presents the results obtained from the Delphi Method. Chapter 5 explains the $\mathrm{S}(\mathrm{CM})^{2}$ model and its verification and validation results. Chapter 6 provides an assessment tool and an example of how to use the meta-model to assess a supply chain. Finally, Chapter 7 includes the research conclusions and recommendations for future research.

\subsection{Pivotal Improvement Tools, Techniques and Methodologies}

There are many improvement tools, techniques and methodologies claimed by enterprises to be best practices. Improving a system in an enterprise may involve the use 
of best practices to reach some performance level. A "Best Practice" is a specific process or group of processes, which has been recognized as the best method for conducting an action by the leaders in the field (Lawes, 2006). These best practices in some cases are not well-documented or defined because they consider only a partial picture of the problem or do not present a solid, scientific basis to confirm they are widely applicable (Davies and Kochhan, 2002). An important challenge for any enterprise is to customize the best practice to fit its organization and environment. Three widely accepted improvement processes which integrate several best practices are the Capability Maturity Model Integration (CMMI), Lean Thinking, and the Supply Chain Operation Reference (SCOR) model.

The Capability Maturity Model Integration (CMMI) is a product of the Carnegie Mellon Software Engineering Institute. The model defines six maturity levels based on Crosby's maturity grid (Gack and Robinson, 2003). The CMMI defines the best practices related to the development and maintenance activities in a software or system product lifecycle. The six capability levels are named Incomplete, Performed, Managed, Defined, Quantitatively Managed, and Optimizing. The great success and wide adoption of CMMI have motivated and increased the development of similar frameworks in different disciplines, such as supply chain (Bunting et al. 2002).

Similar to the CMMI, there are models and frameworks designed to evaluate and improve the enterprise-wide supply chain performance and management; most of them highlight distribution logistics and inventory management processes (Huang et al. 2005). A recent process reference model is the Supply Chain Operations Reference Model (SCOR), which may eventually become an industry standard (Huang et al. 2004). SCOR 
is a framework for modeling, evaluating and improving enterprise-wide supply-chain performance and management processes (Stewart, 1997). The SCOR framework was developed by the Supply Chain Council (www.supply-chain.org). The SCOR model groups all the management processes related to the supply chain in five abstract processes called Plan, Source, Make, Deliver, and Return and each of these processes is decomposed into four levels of detail: Top Level, Configuration Level, Process Element Level and Implementation Level.

The SCOR model provides a framework to describe, measure, and evaluate supply chain configuration by considering the key processes, but SCOR does not define how to improve the supply chain performance. Therefore, enterprises need to implement tools and measurement systems, not provided by the SCOR model, to reach a specific performance level in enterprise collaboration, decision making, and project team development (Lockamy III and McCormack, 2004b).

Additionally, for successful implementation, the enterprises should have good information systems, which are not defined by the SCOR model (Stewart 1997). Thus, it is necessary to develop a parallel model to complement the SCOR model, especially to define the improvement path according to the enterprise's maturity level. A more indepth analysis of the SCOR model is presented in chapter 2 .

Lean Thinking is a philosophy oriented to minimize the non-value added activities as perceived by customers (Vitasek et al. 2005). Lean Thinking is implemented through several tools and techniques such as Kaizen, Just in Time, 5S, and modeling tools like value stream mapping among others. Recently, Six Sigma concepts have been 
incorporated into the Lean Sigma approach looking to improve the process flow with the lean concepts and reduce process variations with Six Sigma tools (Ferrin et al. 2005). These lean tools might be part of the $\mathrm{S}(\mathrm{CM})^{2}$ model due to their orientation to improve process performance, such as lead time, through waste elimination.

Similar to these improvement processes, the Supply Chain Capability Maturity Model $\mathrm{S}(\mathrm{CM})^{2}$ may help to make strategic decisions to improve the performance of an enterprise from a supply chain perspective, considering key business processes to improve the enterprise supply chain(s). Depending on the "maturity level" of each company, the $\mathrm{S}(\mathrm{CM})^{2}$ provides a toolbox with several best practices oriented to increase the performance of an enterprise regardless of its size. With the contents of the toolbox, an enterprise may measure, design and improve its processes with respect to the overall supply chain. As a consequence, the logistic networks are optimized, enabling cost reduction in transport and storage. Also, some other key variables respond faster, leading to higher customer satisfaction (Lummus et al., 2001; Stank and Goldsby, 2000).

\subsection{Problem Statement}

One of the most important problems in supply chain management is the uncertainty inside the processes and systems. Uncertainty in demand, pricing, quality, inventory levels, and lead time among others, causes inefficient processes and non-value added activities. The more uncertainty throughout a process, the more inefficiencies and waste there will be in the process (Van der Vorst and Beulens, 2002). Reducing uncertainty is difficult due to the complexity of the supply chain. 
The complexity of the supply chain is determined by the size of a supply chain and the nonlinear relationships among the supply chain decision variables. For instance, lead times, inventory levels, and demand are nonlinear supply chain elements because they are directly affected by erratic human behavior and the quality of market information (Chatfield et al. 2004). One of the most studied effects of these nonlinear relationships is the bullwhip effect, which is a demand distortion in the supply chain. This effect causes big inventories, poor service, customers loss, and a bad utilization of the distribution and production capacities (Lee et al. 1997).

Nowadays, there are several tools intended to help users to understand and improve the supply chain processes and functions considering these nonlinear relationships; for example, modeling and improvement of supply chain processes using simulation (Van der Zee and Van der Vorst, 2005), regression analysis (Chen et al. 2000), and system dynamics (Angerhofer and Angelides, 2000), among others.

Even though these efforts prove the usefulness of these tools, they only seek to solve a particular problem in one section of the supply chain, rather than in the whole system. Considering the large scope of supply chain management, the next paragraphs briefly describe some of the problems enterprises encounter when they attempt to diagnose, model, analyze, and improve a supply chain. These problems are:

\section{Modeling of the Supply Chain}

2. Selecting system improvement strategies

3. Integrating the SCM and the core business orientation 


\subsubsection{Problem 1: Modeling of the supply chain}

One of the main objectives of a supply chain model is to understand the whole system performance by decomposing the supply chain into more simple elements. The decomposition or simplification process generates manageable system pieces which allow an easier evaluation and improvement of the complex system (Kosanke and Zelm, 1999). However, due to the complexity and nonlinear relationships within the supply chain processes, it is a challenge to include important elements such as synergy, process alignment and market dynamics in an enterprise model because their behavior could change dramatically over time (Li et al. 2002). These supply chain modeling challenges related to the inclusion of qualitative, dynamic and nonlinear elements in a model, highlight the relevance of integrates several supply chain models in a meta-model with a cross-disciplinary perspective.

The supply chain must be managed using effective modeling tools that enable analysis of multiple and interdependent production processes. However, because of the modeling complexity of a supply chain, the analyses have been done from one point of view at a time, such as the information technology (Shapiro, 2001), Business Process Orientation (Lockamy III and McCormack, 2004) or inventory management (Lee et al. 1997).

Making decisions about supply chain improvements without adequate crossdisciplinary-view analyses may lead to regrettable decisions, resulting in waste of time, money, and market position. Furthermore, the word "chain" is somewhat misleading 
because it conveys an image of a set of links with interrelated functions and a simple process flow, as shown in Figure 2.

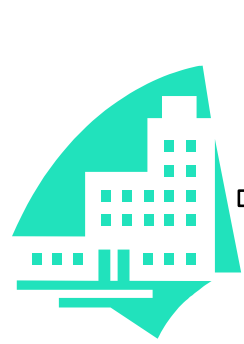

Supplier
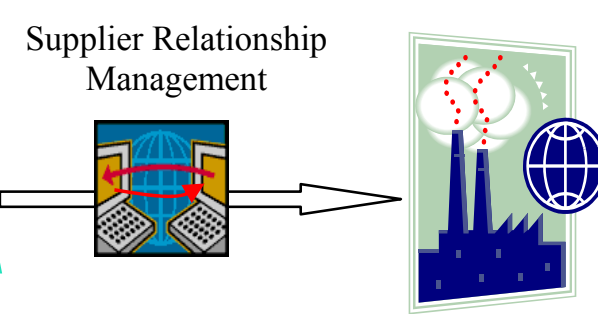

Enterprise Resource Planning

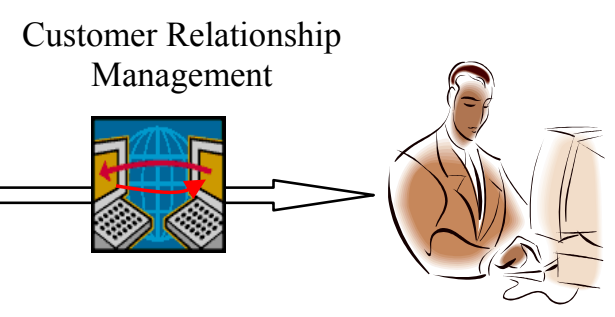

Customer

Figure 2: Linear Supply Chain Conceptualization

This visualization is clear and simple, but it is not a good one, because an enterprise has more than one supplier and more than one customer. Moreover, an enterprise can be part of many supply chains. Nowadays, companies need to rethink their vision about a supply chain from a linear series of functional activities that add value to their products, to a network of links where the links can interact in a variety of modes, as needed for their own process, (peer-to-peer, hierarchical, parent-to children, etc.) (Sengupta, 2004).

Even though there are many enterprise reference models in the literature able to provide a comprehensive enterprise perspective, it is difficult to define a single model or modeling technique capable of satisfying the supply chain modeling needs for all relevant elements of an enterprise. Examples of these enterprise reference models are CIM Open System Architecture (CIMOSA) (Kosanke et al. 1999), Zachman's framework for Enterprise Architecture (Zachman, 1999), and the Generic Enterprise Reference 
Architecture and Methodology (GERAM) (Bernus and Nemes, 1997). Even though these models and tools are widely accepted, they were not developed considering the supply chain systems needs but information systems or computer integrated manufacturing needs among others; later evolving in enterprise architectures or frameworks (Noran, 2003). One advantage of these architectures is that they provide a common language for all the stakeholders (Whitman et al. 2001). In contrast, since supply chains use different terminologies, it is complex to implement one using these kinds of models. Moreover, these models represent a snapshot of an enterprise excluding important supply chain elements such as dynamic modeling, strategic decision process, or change management (Yu et al. 2000b).

Even though general enterprise models were not developed to meet the supply chain needs, it is possible to use their modeling concepts to design a supply chain model for the design of business systems (Rollins et al. 2003). These modeling opportunities have been exploited by the $\mathrm{S}(\mathrm{CM})^{2}$ to provide a meta-model with a cross-disciplinary scope and using common supply chain terminology. Thus, it was possible to analyze particular supply chain problems, such as product distribution, inventory management or collaboration from different perspectives.

\subsubsection{Problem 2: Selecting System Improvement Strategies}

Nowadays, there are many different candidate solutions to supply chain problems. Information systems solutions (Motwani et al. 2000; Markus et al. 2000; Davenport and Brooks, 2004); Lean thinking solutions including value stream mapping, just-in-time, or lean manufacturing (Phelps et al. 2004; Vitasek et al. 2005); Operations research tools 
such as simulation (Chan et al. 2002; Van der Zee and Van der Vorst, 2005); and so on. The abundance of possible solutions complicates the decision making process. Which tool or set of them would provide the best solution to a specific supply chain problem? How will the tool be implemented? In a set of tools, which will be implemented first? How are they going to interact? The selection and implementation of any given tool does not guarantee an improvement in the supply chain cost or lead time.

For example, a common information system solution is to implement Enterprise Resource Planning (ERP). Even though ERP systems may provide software standardization improvements, from a supply chain perspective, ERP rarely provides significant benefits in information integration (Braganza, 2002). For this reason, many enterprises stop ERP projects on account of the few benefits obtained for the management time and the financial costs invested. Moreover, most of the ERP solutions have a Material Resource Planning System (MRPII) as their core module. MRPII, on its own, is not necessary for the best planning and scheduling solutions in any enterprise (Rollins et al. 2003). The companies that reach best investment returns after implementing ERP solutions are those that had implemented, previously or in parallel, strong continuous improvement programs like Total Quality Management (TQM) or Six Sigma (Miller, 2004).

The latter highlights the necessity of implementing a set of solutions in a particular progression to improve a supply chain instead of a single solution tool. In an attempt to overcome these challenges, the $\mathrm{S}(\mathrm{CM})^{2}$ provides guidance about how to select the required tool, through suggestion of a set of tools for supply chain processes according to the maturity level and a specific view. 


\subsubsection{Problem 3: Integrating the SCM and the core business orientation}

Enterprises constantly are making decisions about make or buy from an outside enterprise or a sister business unit. Some considerations influencing the decision are the prevention of possible speculations on price and the impact on company profits, or the prevention of knowledge outflow to their competitors (Argyres, 1996). In the 1980's, enterprises were concerned about how far, upstream or downstream, they should integrate vertical activities into a supply chain for a good or service. This vertical integration enabled them to control the quality and performance of all the value-added processes within the enterprise's productive system, from the end of the chain to the customer delivery (Harrigan, 1986).

However, vertical integration has been strongly questioned in regards to the actual benefits in global competition. Open markets pressure companies to adopt better market disciplines implying a reduction of their product catalogs and the breaking of vertical links (Kakabadse and Kakabadse, 2000). Vertical integration motivation was difficult to maintain, which lead to criticism about why an enterprise should maintain or develop vertical integration instead of comprehensive contracting agreements with outsider providers (Argyres, 1996). While the 1980's were dominated by enterprise acquisitions and fusions, in the 1990's a change started to take a perpendicular direction. The horizontal integration was motivated by the reorientation to the enterprise core business (Timm, 1993).

Organizations redirect their skills and capabilities to high value-added activities and trust their non-value activities to outsourcing enterprises (Harland et al. 2005). Scholars 
and practitioners argue that the core business should stay in-house while non-core activities may be outsourced. The outsourcing debate has changed from whether to outsource to what and how to outsource (Kakabadse and Kakabadse, 2000). Therefore, enterprises need to concentrate their efforts only in their strengths or core competences and outsource all those activities which a partner can do better. Consequently, companies should search for and use third-party alliances with the best in the market of all the outsourced processes (Sengupta 2004).

This paradigm change implies some challenges in the supply chain integration, among them the tendency to outsource information systems such that an enterprise may obtain capabilities not available or feasible in-house (Kole, 1983). Even though information systems by themselves have some problems as discussed in the last point, outsourcing it generates a new problem related with the supplier development. As more outsourcing providers emerge, service quality and the nature of the relationship customerprovider become more and more important (Grover et al. 1996).

Regarding this problem, $\mathrm{S}(\mathrm{CM})^{2}$ provides a road map to improve the supply chain processes. This road map considers both the benefits of the vertical integration into the three initial levels, related to internal enterprise processes, and the benefits of the horizontal integration into the last two levels, related to develop collaboration and integration within supply chain members. In other words, the $\mathrm{S}(\mathrm{CM})^{2}$ suggests tools to improve and integrate internal supply chain processes at low maturity levels and integration between enterprises processes or external collaboration at the advanced maturity levels for each model view. 


\subsubsection{Problem 4: Problem Summary}

Considering all the problems described in points one to three, any advance in supply chain integration models, using a cross-disciplinary point of view, represents a useful tool or methodology to increase the performance of an enterprise. Given the modeling complexity, a single model, concept, or tool is not capable of representing a comprehensive perspective of the enterprise. Therefore it is necessary to integrate several models, concepts and tools in a model of models or meta-model.

In spite of the fact that there being many researchers working in the supply chain management field, there is room for different scopes, specially using a systemic point of view to model, analyze, and improve a supply chain. Additionally, many other disciplines may contribute with concepts, models, methodologies, and approaches that may be applied to improve the enterprise performance (Stock, 1990). Considering the relevance of information systems in the supply chain performance, tools or models from this field may be used as the foundation for a new supply chain model, as is the case of the Capability Maturity Model Integration (CMMI) developed by the Carnegie Mellon Software Engineering Institute. ( http://www.sei.cmu.edu/cmm ).

\subsection{GOAL AND SPECIFIC OBJECTIVES}

The goal of this research is to provide a cross-disciplinary perspective of an enterprise's supply chain performance by developing a Supply Chain Capability Maturity Model $\left(\mathrm{S}(\mathrm{CM})^{2}\right)$. This meta-model integrates several best practices, methodologies, concepts, and tools from different knowledge areas in order to increase the performance of an enterprise in a supply chain system. The integration of models provides an 
improvement road map in several maturity levels for the enterprise supply chain processes, proving modeling tools useful to analyze the processes from a holistic point of view. This goal has the following objectives.

1. To Identify of key factors that affect supply chain processes through literature review and practitioner's experience applying the Delphi method. This helps define each maturity level and its particular scopes.

2. To Identify of the best practices available to improve the key factors (objective 1), clarifying how to find opportunity areas and how to reach the next maturity level from a holistic point of view. This provides enterprises with a toolbox according to each maturity level and the starting point to improve its "as-is" business process.

3. To Define of key views to model supply chain processes for evaluating the improvement reached through the implementation of the best practices. Once an improvement project starts, it is necessary to evaluate its benefits in the supply chain.

4. To Develop of an assessment tool to determine if a company adheres to the best practices. Considering not only a "yes or no" evaluation, but a more detailed and documented way to identify matches and discrepancies.

Thus, to meet these objectives, the $\mathrm{S}(\mathrm{CM})^{2}$ is a meta-model which includes:

- An improvement road map describing five maturity levels for the enterprise supply chain processes, proving modeling tools useful to analyze the processes from a cross-disciplinary point of view, and to improve the enterprise 
performance vertically within the company processes and horizontally within enterprises in the supply chain.

- A diagnostic tool to evaluate the "as-is" state of the enterprise and assign the enterprise a maturity level. For example, the SCOR model uses a scorecard gap analysis for this diagnostic purpose (Huang et al. 2005).

- A continuous improvement system. The diagnostic tool is used as a continuous improvement guide for the enterprise. This tool considers the impact of the suppliers and customers in the enterprise profits and offers some possible solutions to several of the problems related to them.

\subsection{ReSEARCH Methodology}

The research has been conducted in three stages: Review of literature, Integration of models, and Development of the $\mathrm{S}(\mathrm{CM})^{2}$. The first stage was a thorough literature review about supply chain key factors and supply chain models. The literature review enabled designing the survey of the Delphi Method applied in a first round. The objective of this stage was to reach a consensus about what a supply chain is and the taxonomy of the $\mathrm{S}(\mathrm{CM})^{2}$ regarding each maturity level. The second stage included the integration of models, tools, and concepts available to improve the enterprise supply chain in a draft meta-model, and the improvement and validation process through the Delphi method. Finally, the third stage developed the $\mathrm{S}(\mathrm{CM})^{2}$ and an assessment tool based on it, such that an enterprise may use this tool as a level of classification, useful as a starting improvement point. 
The Delphi method has been used as a modeling tool, because it is a research tool oriented to obtaining a consensus from a group of experts with anonymous interactions between them, avoiding thus confrontations and eliminating influences (Okoli and Pawlowski, 2004). The panel of experts required for the Delphi method was composed of academicians and practitioners in supply chain processes from different knowledge areas. Chapter 3 explains in depth how the Delphi method is used to build the $\mathrm{S}(\mathrm{CM})^{2}$ and the sequence of activities required to do so. 


\section{CHAPTER II}

\section{LITERATURE REVIEW}

In the last decades, a lot of research related to enterprise modeling frameworks and supply chain improvement tools has been published. Recent publications present supply chain problems and how to solve them by recognizing the importance of the multiple stakeholder perceptions (Sengupta, 2004), implementing operation research tools such as simulation (Hicks, 1999), or using frameworks for modeling the supply chain (Appelquist et al. 2004). These concepts, tools, and frameworks include modeling, analysis, or attempts to explain the complexity behind the enterprise systems, which are not similarly defined by each knowledge area.

Likewise, several frameworks have been developed to provide an open architecture for general enterprise modeling. Frameworks such as Zachman's, IDEF, GIM, CIMOSA, PERA and GERAM are commonly reported in research related to enterprise modeling (Whitman et al. 2001, Dewhurst et al. 2002, Barber et al. 2003). These models represent an enterprise through different views explaining, describing, and dealing with the complex activities of an enterprise (Yu et al. 2000). In spite of the variety of modeling scopes, the inherent complexity and dynamic behavior of the supply chain problems do not to allow identify a unique tool, model, methodology, or philosophy able to improve any supply chain process.

These general models were not necessarily developed in a supply chain context, and they are typically static representations of a process found in the supply chain. GERAM, 
for instance, does not make statements about how a process should be done. On the other hand, supply chain models, which were developed within a supply chain context, do not provide a clear road map to improve the supply chain or to react in front of market or customer behavior changes. The following pages present a literature review of some concepts, tools, strategies, and frameworks used to improve the supply chain and modeling enterprise processes. Also, several contemporary best practices, which can be merged and integrated to define a meta-model to assess the processes and performance of enterprises in the supply chain have been included.

\subsection{ENTERPRise MODELING FraMeWORKS AND ARCHITECTURES.}

Enterprise modeling frameworks and architectures provide a better understanding of the enterprise's complexity. The partitioning and simplifying enterprise processes can be studied through a common modeling language and methodology (Kosanke and Zelm, 1999). These frameworks and architectures represent a system at a particular point of time or describe the life of the systems according to developmental phases or improvements such as definition, development, operation and maintenance (Noran, 2003). Also, they provide systematic methods to capture business objectives and to display the structure of how the information and material flow are related to the enterprise's organization (Yu et al. 2000); and the knowledge any enterprise requires to do reliability analysis easier and more accurate (Yu et al. 2000b). Following are several widely accepted modeling frameworks and architectures. 


\subsubsection{The IDEF Language}

One of the oldest and most respected modeling frameworks is IDEF0 (Integrated Computer Aided Manufacturing Definition). IDEF0 is a function modeling method which allows a hierarchical representation useful to analyze processes at multiple levels of abstraction. An example of an IDEF0 model with two hierarchical levels is shown in Figure 3.

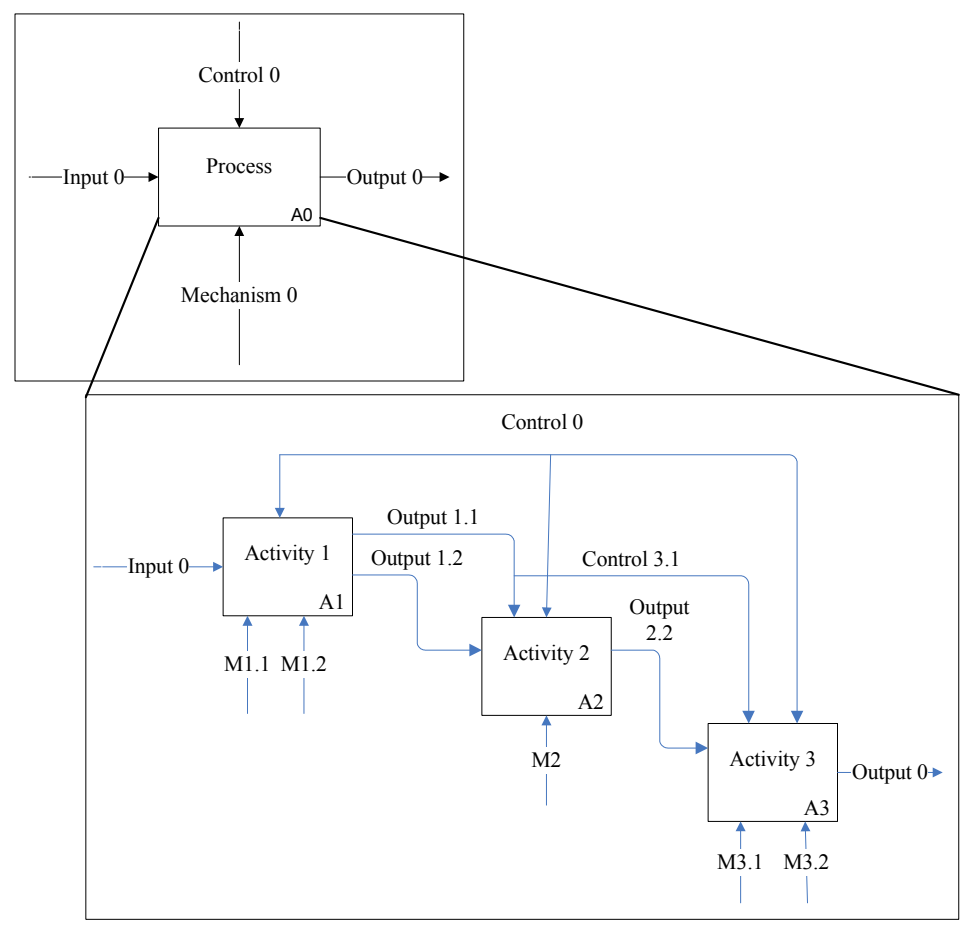

Figure 3: Example of an IDEF0 Model

IDEF0 uses a modeling diagram considering four elements; inputs, controls, outputs and mechanisms. It also allows mapping those functional relationships to represent what activities are performed within an enterprise process (Lin et al. 2002). IDEF0 has been criticized for having an inflexible modeling environment since its design is oriented to process mapping not to dynamic modeling. Its control and input elements are commonly misunderstood, and there is a lack of perspective (Dewhurst et al. 2002). 


\subsubsection{The GRAI Integration Methodology (GIM)}

The GIM emphasizes the organizational structure of an enterprise and the associated decisional system of production systems. The general objective of this integration methodology is the analysis of the current production systems in order to detect the weak points of the system. This diagnosis allows to design alternative system conceptions and to support their comprehension (Zülch et al. 2001).

GIM builds on several static business mapping techniques like entity relationship diagrams and IDEF0, and it also focuses on decision system analysis of the enterprise (Mertins and Jochem, 2005). The GIM views are informational, decisional, physical, and functional. The GIM life-cycle consists on analysis, design, and implementation (Bernus and Nemes, 1997). Even though GIM adds an important decision perspective, the weaknesses of IDEF0 in terms of operational modeling are sustained (Dewhurst et al. 2002). Figure 4 shows the Modeling Framework and Conceptual Model of GIM (Zülch et al. 2001, Bernus and Nemes, 1997).

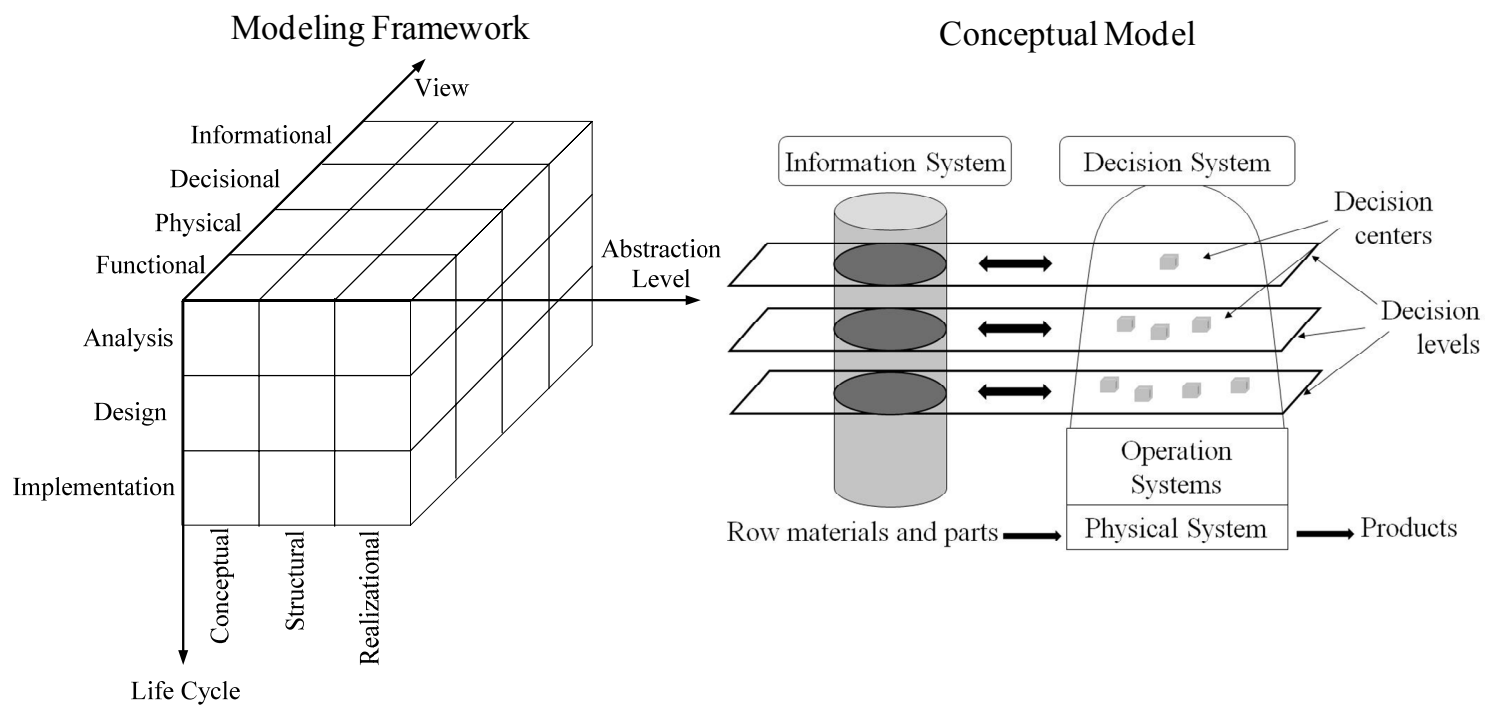

Figure 4: GIM Modeling Framework and Conceptual Model 


\subsubsection{The Zachman's framework}

This framework was developed by John Zachman and published in 1987. It was initially designed to develop information systems, and later evolved in some extensions and formalizations to a framework for enterprise architecture (Noran, 2003). Zachman's framework provides a common language for the enterprise; useful to develop any project and solve any problem in a methodological road map. Zachman's framework also provides essential distinction to areas ignored by conventional system design such as strategy, design, or documentation (Whitman et al. 2001).

A factor of acceptance of this framework resides in the logical structure for modeling the enterprise from different perspectives such as the planner's perspective, the owner's perspective or the designer's perspective, in such ways that these perspectives can be analyzed, observed, and mapped form different views or dimensions considering data, functions, or people. As a result a matrix of explicitly differentiable elements is obtained (Zachman, 1999).

The complete perspectives of the framework are: Scope (Planner's Perspective), Enterprise Model (Owner's Perspective), System Model (Designer's Perspective), Technology Model (Builder's Perspective), and Detailed Representation (Subcontractor's Perspective). Each of these perspectives is analyzed from different views or dimensions which answer basic modeling questions. These dimensions are: Data (What?), Function (How?), Network (Where?), People (Who?), Time (When?), and Motivation (Why?).

Analyzing an enterprise through this framework provides a methodology to help enterprises to manage change, and to guarantee integration and process alignment with 
dependency, coherence and traceability (Pereira and Sousa, 2004). Figure 5 shows Zachman's modeling framework for enterprise architecture (Noran, 2003).

\begin{tabular}{|c|c|c|c|c|c|c|}
\hline & \multicolumn{6}{|c|}{ Views } \\
\hline & What & How & Where & Who & When & Why \\
\hline $\begin{array}{c}\text { Scope } \\
\text { (Planner's) }\end{array}$ & & & & & & \\
\hline $\begin{array}{l}\text { Enterprise Mod } \\
\text { (Owner's) }\end{array}$ & & & & & & \\
\hline $\begin{array}{l}\text { System Model } \\
\text { (Designer's) }\end{array}$ & & & & & & \\
\hline $\begin{array}{l}\text { Technology } \\
\text { Model } \\
\text { (Builder's) }\end{array}$ & & & & & & \\
\hline $\begin{array}{c}\text { Detailed } \\
\text { Representation } \\
\text { (Subcontractor'? }\end{array}$ & & & & & & \\
\hline $\begin{array}{l}\text { Functioning } \\
\text { Enterprise }\end{array}$ & Data & Function & Network & People & Time & Motivation \\
\hline
\end{tabular}

Figure 5: Zachman's Framework for Enterprise Architecture

Even though Zachman's framework does not apparently include a life-cycle definition, the view "When" may be used to define it. This view is related to the functioning enterprise "Time”, implying temporality and succession (Noran, 2003).

\subsubsection{The Purdue Enterprise Reference Architecture (PERA)}

The PERA architecture recognizes the relevance of human judgment and decision making to merge special management requirements, such as innovation and creativity, with design. PERA helps to define a hierarchy arrangement in such way that dependency on human understanding, judgment, and decision making required for a successful implementation is minimized ( $\mathrm{Li}$ and Williams, 2002). PERA includes the bases for the 
representation of human tasks on information systems, distinguishing between those performed by humans and those performed by the system. This is achieved by defining a level of automation such that elements as mission, vision, and values are human tasks in systems which are not automated (Whitman et al. 2001). The PERA views are manufacturing, human and organizational, and information. The PERA life-cycle involves identification, concept, definition, functional design, detailed design, construction, operation and maintenance, renovation or disposal, and legal dissolution (Saenz and Chen, 2004). Figure 6 shows the PERA life-cycle according to Li and Williams (2002).

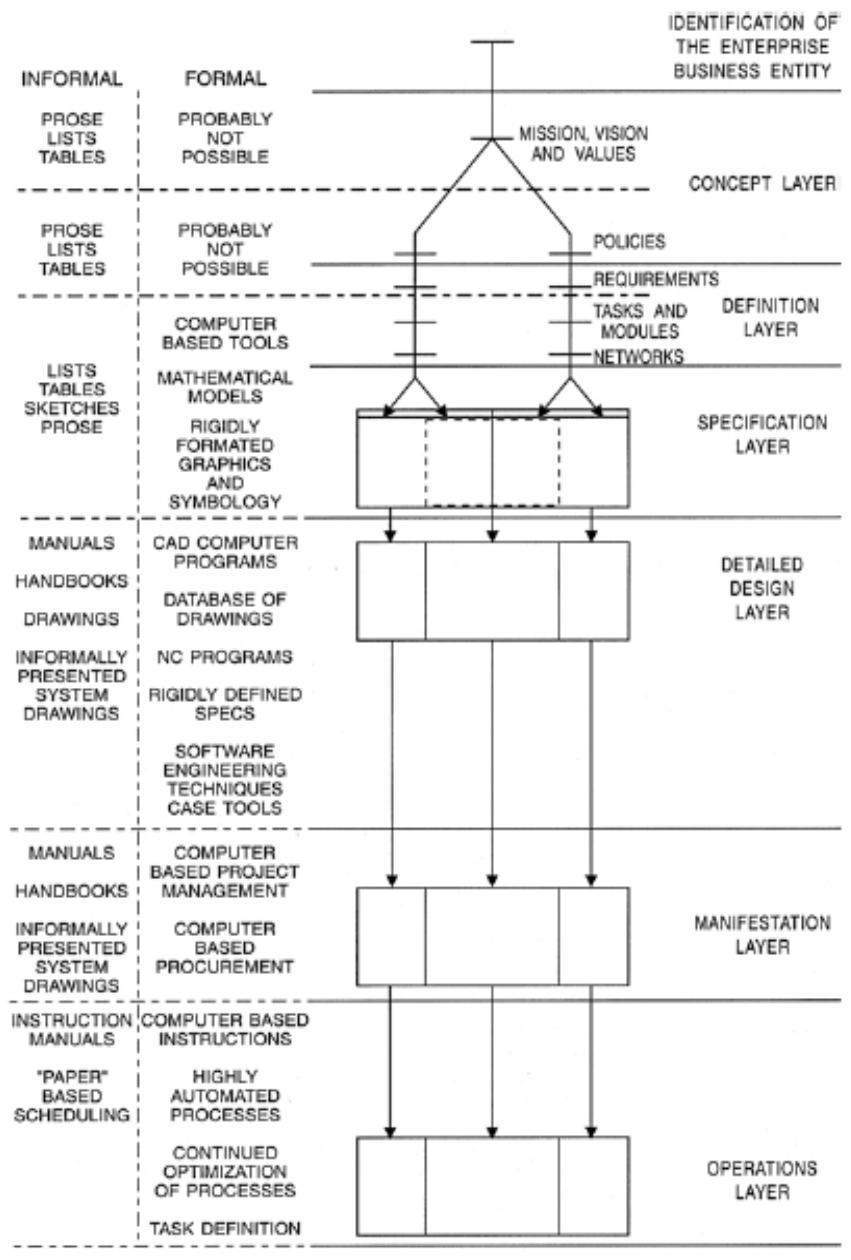

Figure 6: Models and tools involved in the PERA Life-cycle 
Figure 7 shows a definition for the manufacturing case for the concept, definition and specific design layers (Williams, 1998). A challenge in the application of this architecture is the bottom-up construction focus, which starts defining the basic elementary tasks, in order to group them into activities that meet the strategic objectives (Chalmeta et al. 2001).

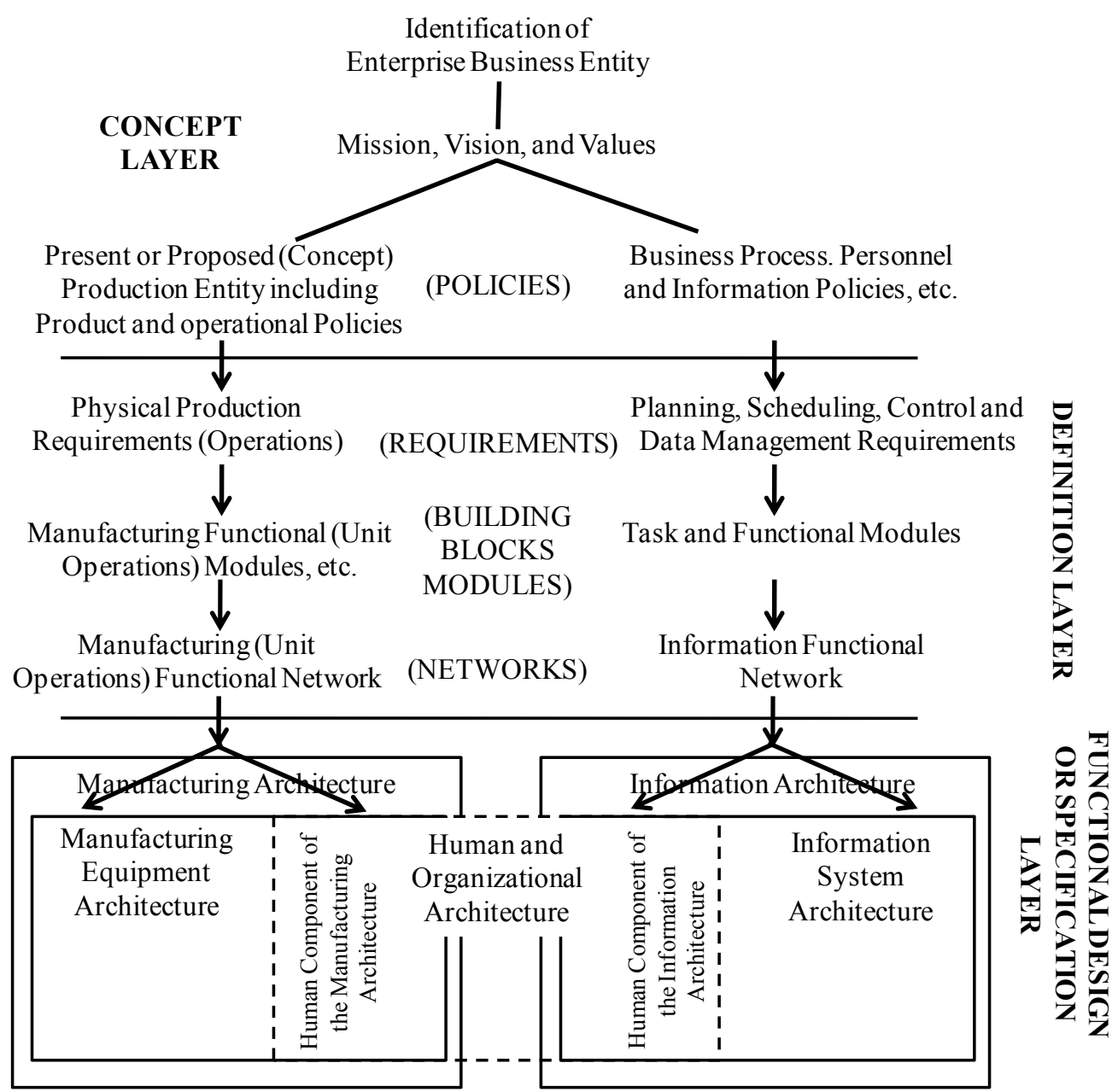

Figure 7: Definition of the Concepts for the Manufacturing Case

\subsubsection{The CIMOSA Framework}

The Computer Integrated Manufacturing Open System Architecture (CIMOSA) was developed by the ESPIRT consortium AMICE. In essence, CIMOSA takes the best 
concepts of IDEF and GIM among other frameworks (Barber et al. 2003). CIMOSA is based on a process-oriented modeling approach providing an architecture, which facilitates the descriptive modeling of an enterprise operation. CIMOSA represents an enterprise's system from a general to a particular model passing through a partial model for every view (ESPIRT Consortium AMICE, 1993). Figure 8 shows the CIMOSA modeling framework (Saenz and Chen, 2004).

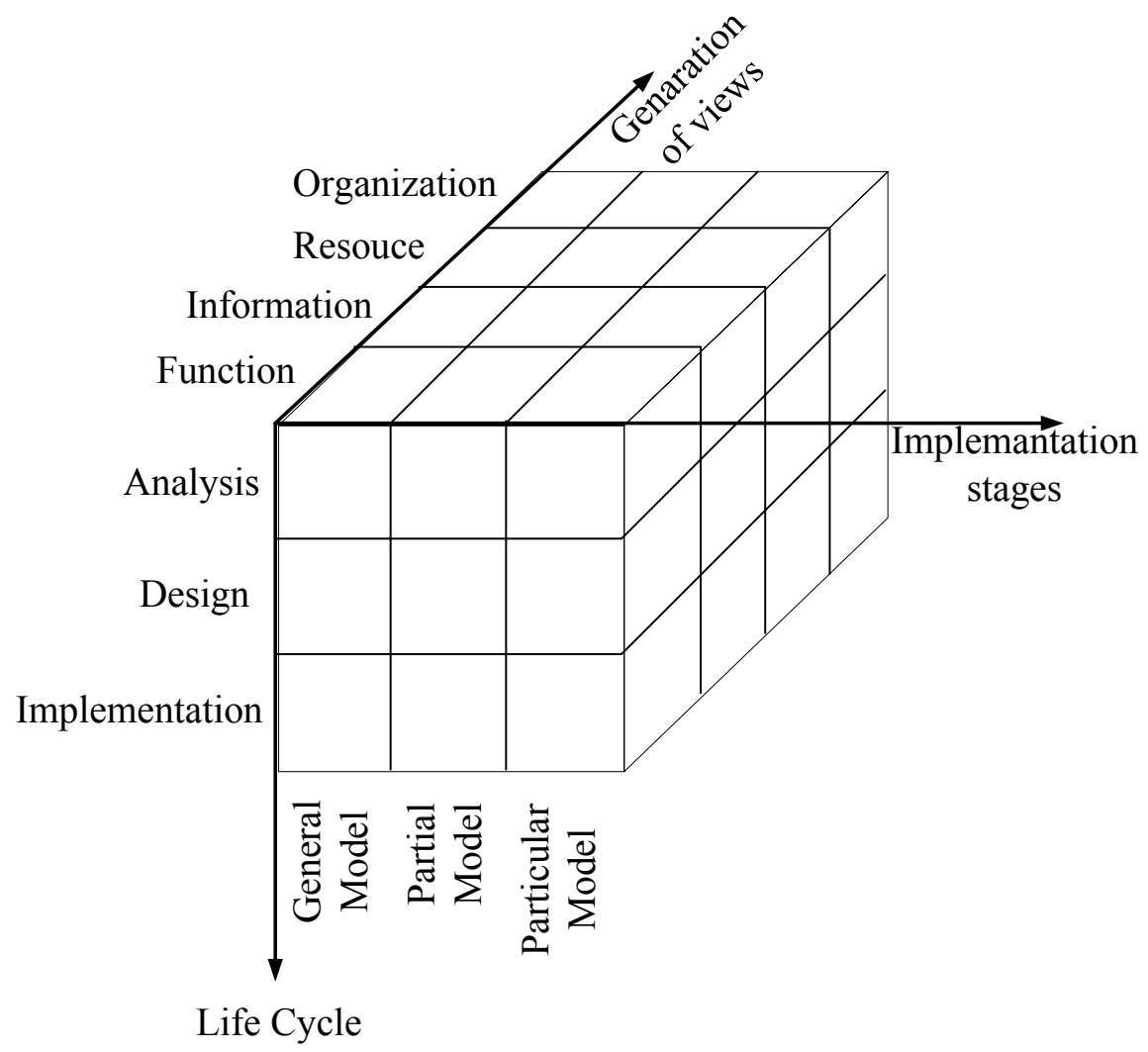

Figure 8: CIMOSA Modeling Framework

Initially, CIMOSA does not populate a life-cycle with unique processes, but defines basic phases independently from the modeling methodology in use; these basic phases consist on requirement definition or analysis design, design specification, and 
implementation or detailed design (Chalmeta et al. 2001), which are the same as GIM's. CIMOSA's views are developed according to the CIM's manufacturers' requirements (Whitman et al. 2001). A couple of examples of views are function, information, resource, and organization (Saenz and Chen, 2004) or decision, function, resource, and information (Chalmeta et al. 2001).

However, CIMOSA includes neither a method to solve possible modeling inconsistencies among views nor a method to build a dynamic integrated model (Chalmeta et al. 2001). Since CIMOSA is a static model, it is insensitive to changes in business objectives; thus, just a partial model has been done when the market conditions change. Even though this partial model may be useful for a while, market changes invalidate it quickly, requiring to start again the modeling activities (Yu et al. 2000). Moreover, CIMOSA does not clearly represent strategic decisions and operational rules (Yu et al. 2000b).

\subsubsection{The GERAM Framework}

The Generalized Enterprise Reference Architecture and Methodology (GERAM) builds on several architectures, generalizing and integrating the best elements. GERAM provides a methodology for enterprise engineering from PERA and GIM, a system lifecycle from PERA, and modeling tools from CIMOSA (Mertins and Jochem, 2005). GERAM life-cycle is found in one component of the architecture called GERA, the lifecycle phases are: Identification, concept, requirements, preliminary design, design, detailed design, implementation, operation, and decommission (Noran, 2003). The GERAM methodology focuses more on the implementation process than in the model 
structure. For instance, integration of the models for the strategic, tactical, and operational decision levels are not clearly explained (Barber et al. 2003). Figure 9 shows the reference architecture of GERAM, called GERA.
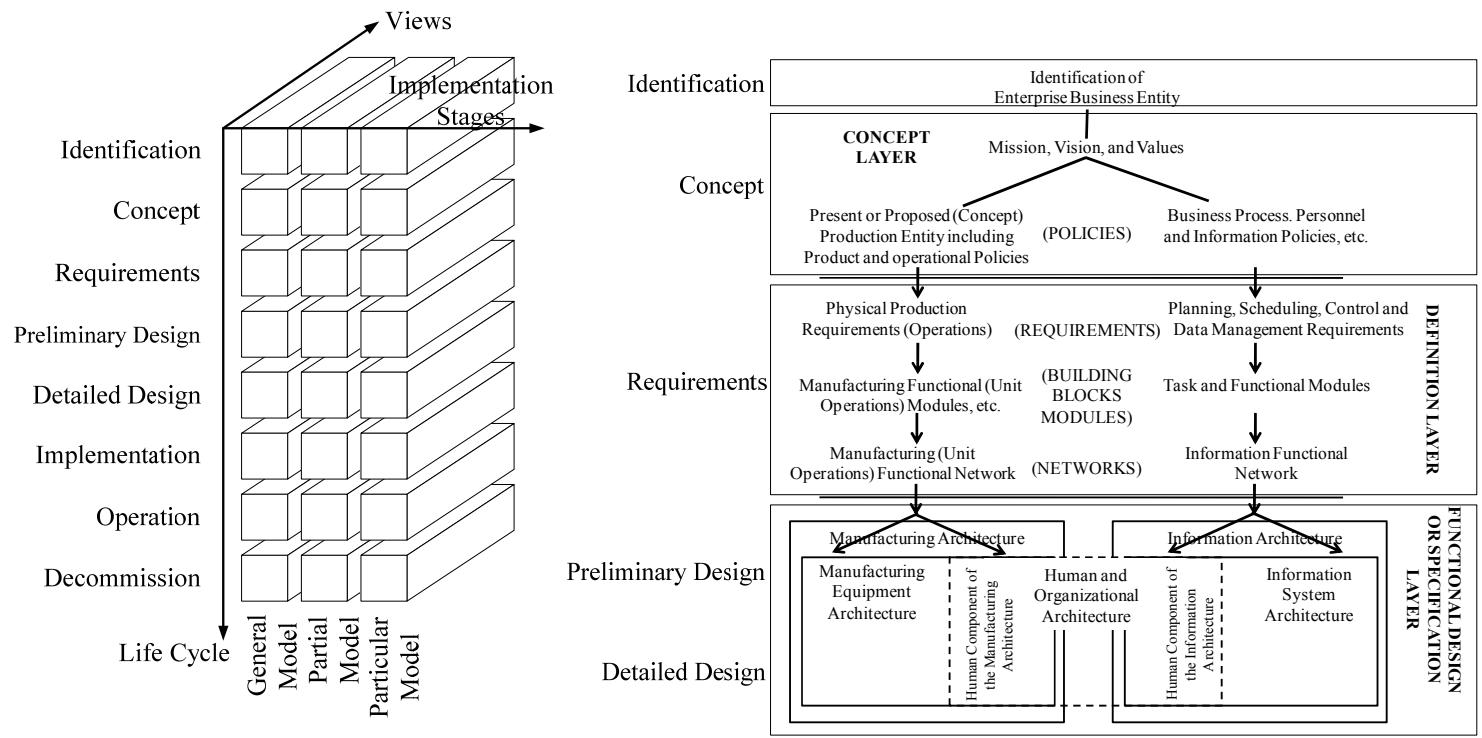

Figure 9: GERA, the Reference Architecture of GERAM

\subsubsection{Conclusions About the Enterprise Reference Architectures}

From the literature review it is possible to summarize conclusions and common characteristics of these frameworks and architectures, as follows:

1. Models provide a detailed taxonomy of the concepts related to enterprise activities, systems and stakeholders, not only by identifying them, but also by defining how to document them. The models accomplish this in a common language for all the users of the framework or architecture, making it easier to have a comprehensive understanding of the enterprise activities, processes and systems. 
2. Models provide a clear differentiation among their views, perspectives, and modeling elements; therefore, it is possible to build partial models of the enterprise processes and then integrate the views in a complete framework or architecture.

3. Models consider the time variable as a dimension for analysis, IDEF0 and Zachman frameworks considering a snapshot of the modeled system. GIM, CIMOSA, PERA, and GERAM provide, at least, basic considerations for modeling the life of a system through a life-cycle implementation.

4. Each model has been developed and designed according to the needs of a specific knowledge area such as computer integrated manufacturing or information systems and then evolved to general models.

5. None of the frameworks specifically reviewed address any dynamic modeling requirements. Because these frameworks use static models for enterprise representation, they may be insensitive to market or strategic changes.

6. Users should understand enterprise architectures and frameworks. Therefore, a common modeling language for the stakeholders should be used or developed as part of the implementation methodology.

Similar to the enterprise frameworks discussed here, there are frameworks and architectures specifically developed to supply chain modeling, analysis and integration. The next section describes some of these supply chain frameworks and architectures. 


\subsection{Supply Chain Models AND ARCHITECTURES.}

Chapter 1 discussed several problems related to supply chain, advantages and disadvantages of vertical and horizontal integration; modeling and visualization of a supply chain; and the impact of information systems on the supply chain. Whether an enterprise belongs to a unique supply chain or to many, the enterprise should take advantage of the possible vertical and horizontal integrations for its operations. In order to obtain the greatest benefit, enterprises need to know how the processes work or should be designed; to do this, a modeling framework or tool is required. This framework could provide structure to facilitate the integration of the supply chain components, detailing a methodology for structural and systems integration for several supply chain levels (Samaranayake, 2005). The following are some modeling tools, frameworks and architectures developed to fit these needs.

\subsubsection{Stevens' Model}

Stevens (1989) developed a stage-based model for supply chain integration. He argues that an integrated supply chain will be able to deal with dynamic market issues such as mass customization, short lead-time, agility and leanness. His model highlights technology and infrastructural development as critical factors to achieve supply chain integration, which takes place in stages. These stages are Baseline, Functional Integration, Internal Integration, and External Integration. The stages are focused on first integrating the internal enterprise processes, in the three initial stages, before integrating the external supply chain processes in the last stage. 
The model looks similar to a waterfall development model that is used in systems information projects. It starts from a baseline of processes integrated through technology efforts. Once the technology integration is achieved, the second stage of integration is concerned with the functions. This integration is based on enterprise organization. The third stage aims at internal integration to the enterprise's function, based on attitude concepts; that is, a focus on human capital. Finally, stage four is concerned with an external integration of suppliers, enterprise, and customers (Stevens, 1989). Figure 10 shows Stevens' model. Even though Stevens' model does not define a life-cycle, such as the enterprise architectures discussed previously did, the four stages may be considered as the time line or history of the integration process.

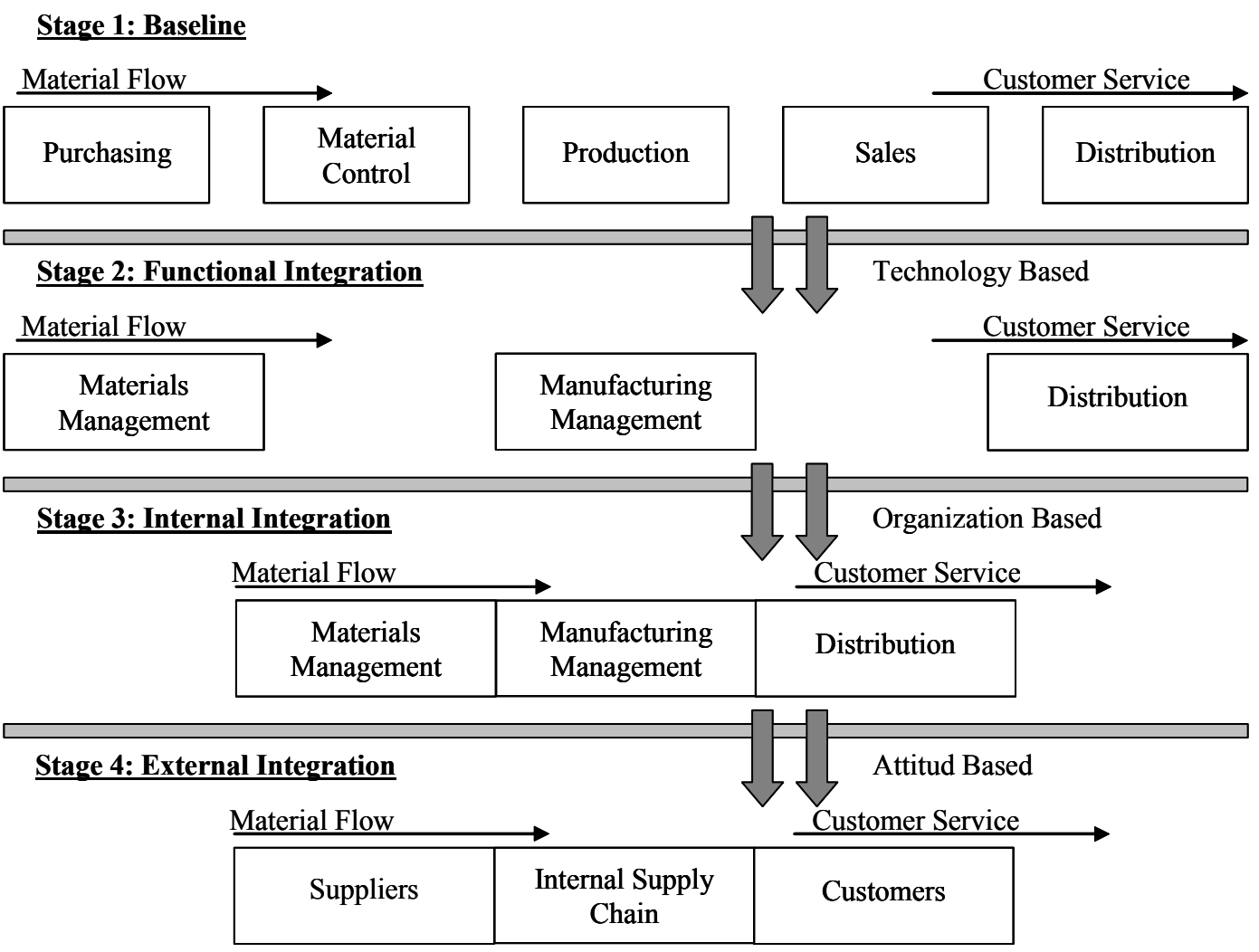

Figure 10: Stevens' model of Supply Chain Integration 


\subsubsection{An Integrated Supply Chain Management Architecture}

In the last years, a significant market change took place in the industry. Enterprises, rather than isolated companies, competed as a supply chain against other supply chains. Nowadays; the success of an enterprise frequently depends on how well-integrated the enterprise is within a network of partner relationships. This market change has caused an evolution and strengthening of the enterprise relationships, passing from a relationship based on key business processes linked within enterprises, to becoming supply chain business processes linked across the intra-company and inter-companies boundaries (Lambert et al. 1998).

A model which includes these relationships is the architecture of supply chain management presented by Cooper et al. (1997), which includes key supply chain business processes; and flows of information and product, over a supply chain network structure. This architecture highlights six key processes within an enterprise: Purchasing; Logistics; Marketing and Sales; Production, Research and Development; and Finance. Processes are integrated within several tier suppliers and several customers or end customers through the key supply chain processes of Customer Relationship Managements, Demand Management, Procurement and Returns, among others (Cooper et al. 1997). This architecture is shown in Figure 11. Similar to the enterprise architectures, this model is static since it does not explicitly include a time line or development history. Moreover there is no clear interaction and division among the key enterprise processes and the supply chain business processes. Thus, it is difficult to identify a matrix of differentiable elements such as those used by enterprise architectures. 


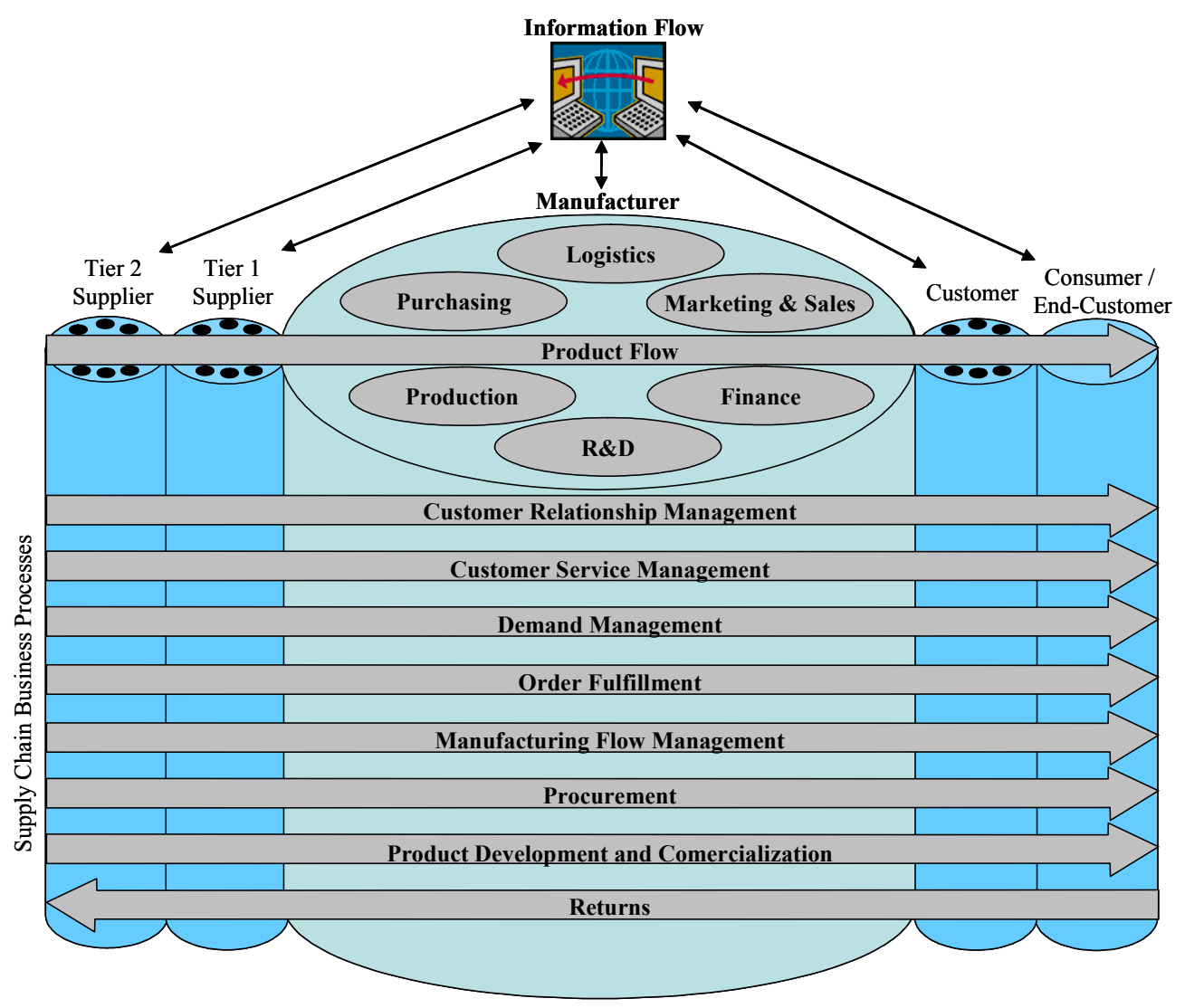

Figure 11: Integrating and Managing Business Processes across the Supply Chain

\subsubsection{Enterprise Architecture for Supply Chain Integration}

Based on an enterprise value analysis, Chandra and Kumar (2001) identified five key perspectives and four views to represent the interactions between the members of a supply chain. The perspectives defined are Marketing and Sales, Inbound Logistics (i.e., receiving and warehousing), Plant Operations (i.e., manufacturing, product assembly, and inspection), Outbound Logistics (i.e., warehousing and shipping), and Service (i.e., organization and management). The views defined are Procurement, Technology Development, Information Management, and Others. Figure 12 shows the resulting matrix after the value analysis. 


\begin{tabular}{|c|c|c|c|c|}
\hline & Procurement & $\begin{array}{c}\text { Technology } \\
\text { Development }\end{array}$ & $\begin{array}{l}\text { Information } \\
\text { Management }\end{array}$ & Others \\
\hline Marketing and Sales & $\begin{array}{l}\text { Buy advertising } \\
\text { Campaigns } \\
\text { Buy sales } \\
\text { promotions }\end{array}$ & $\begin{array}{l}\text { Consumer market } \\
\text { research } \\
\text { Incorporate market } \\
\text { needs in the product }\end{array}$ & $\begin{array}{l}\text { Forecast demand and } \\
\text { sales } \\
\text { Sales analysis } \\
\text { Track product } \\
\text { performance }\end{array}$ & $\begin{array}{l}\text { Coordinate order } \\
\text { processing }\end{array}$ \\
\hline $\begin{array}{l}\text { Inbound Logistics } \\
\text { (Receiving, } \\
\text { warehousing, } \\
\text { inventory control, } \\
\text { production planning) }\end{array}$ & $\begin{array}{l}\text { Procure end-products } \\
\text { Procure raw } \\
\text { materials for } \\
\text { assembly and } \\
\text { packaging }\end{array}$ & & $\begin{array}{l}\text { Receive and track } \\
\text { raw materials and } \\
\text { end-products }\end{array}$ & $\begin{array}{l}\text { Manage store of raw } \\
\text { materials and end- } \\
\text { products }\end{array}$ \\
\hline $\begin{array}{l}\text { Plant Operations } \\
\text { (Manufacturing, } \\
\text { inspection, product } \\
\text { assembly, product } \\
\text { packaging) }\end{array}$ & & & & $\begin{array}{l}\text { Quality Inspection of } \\
\text { finished products } \\
\text { Assemble end- } \\
\text { products } \\
\text { Package end- } \\
\text { products }\end{array}$ \\
\hline $\begin{array}{l}\text { Outbound Logistics } \\
\text { (Warehousing, } \\
\text { inventory control, } \\
\text { shipping) }\end{array}$ & $\begin{array}{l}\text { Procure shipment } \\
\text { modes }\end{array}$ & & $\begin{array}{l}\text { Inventory control of } \\
\text { finished product } \\
\text { Track and report } \\
\text { shipments }\end{array}$ & $\begin{array}{l}\text { Select shipment and } \\
\text { routing modes } \\
\text { Consolidate order for } \\
\text { a carrier }\end{array}$ \\
\hline $\begin{array}{l}\text { Service } \\
\text { (Organization and } \\
\text { management) }\end{array}$ & & & $\begin{array}{l}\text { Manage inventory } \\
\text { carrying, quality, } \\
\text { back order, and } \\
\text { opportunity cost } \\
\text { Analyze cost } \\
\text { variance }\end{array}$ & $\begin{array}{l}\text { Guarantee shipment } \\
\text { schedules }\end{array}$ \\
\hline
\end{tabular}

Figure 12: Member Enterprise Value Analysis (Chandra and Kumar, 2001)

The intersection of perspectives and views represents a set of relevant actions for the enterprise supply chain. Even though this matrix does not show the relevant actions for all the intersections among perspectives and views may be used as a quick reference to assess the supply chain integration of an enterprise. Based on this matrix, they developed the architecture of a cooperative supply chain member enterprise. They recognize that the design, modeling, and implementation of a supply chain system is a complex endeavor. The more cohesively tied the business processes of the members in the supply chain are, the more coordination they will have. Greater coordination makes it possible to have easier development of the supply chain elements, such as information 
management, plant operation, and logistics, through a set of principles, strategies, policies, and performance metrics included in decision making models.

Figure 13 defines the collaborative supply chain architecture for a supply chain member. This architecture shows a decomposition model for a supply chain member with the following relationships. A member enterprise $M_{E_{j}}$ has 1 to " $n$ " business " $B$ ", a business block $\mathrm{M}_{\mathrm{E}_{\mathrm{j}}}^{\left(\mathrm{B}_{\mathrm{j}}\right)}$ has 1 to "n" processes "P", and a process block has 1 to "n" activities "A". The transformation from material to final product takes place at the activity level, while the order life-cycle occurs at the business level, involving business processes required to process the order such as marketing, sales, product design, production planning, and so on. The control sequence occurs at both inter and intra levels to implement independent organizational goals, policies, and objectives (Chandra and Kumar, 2001).

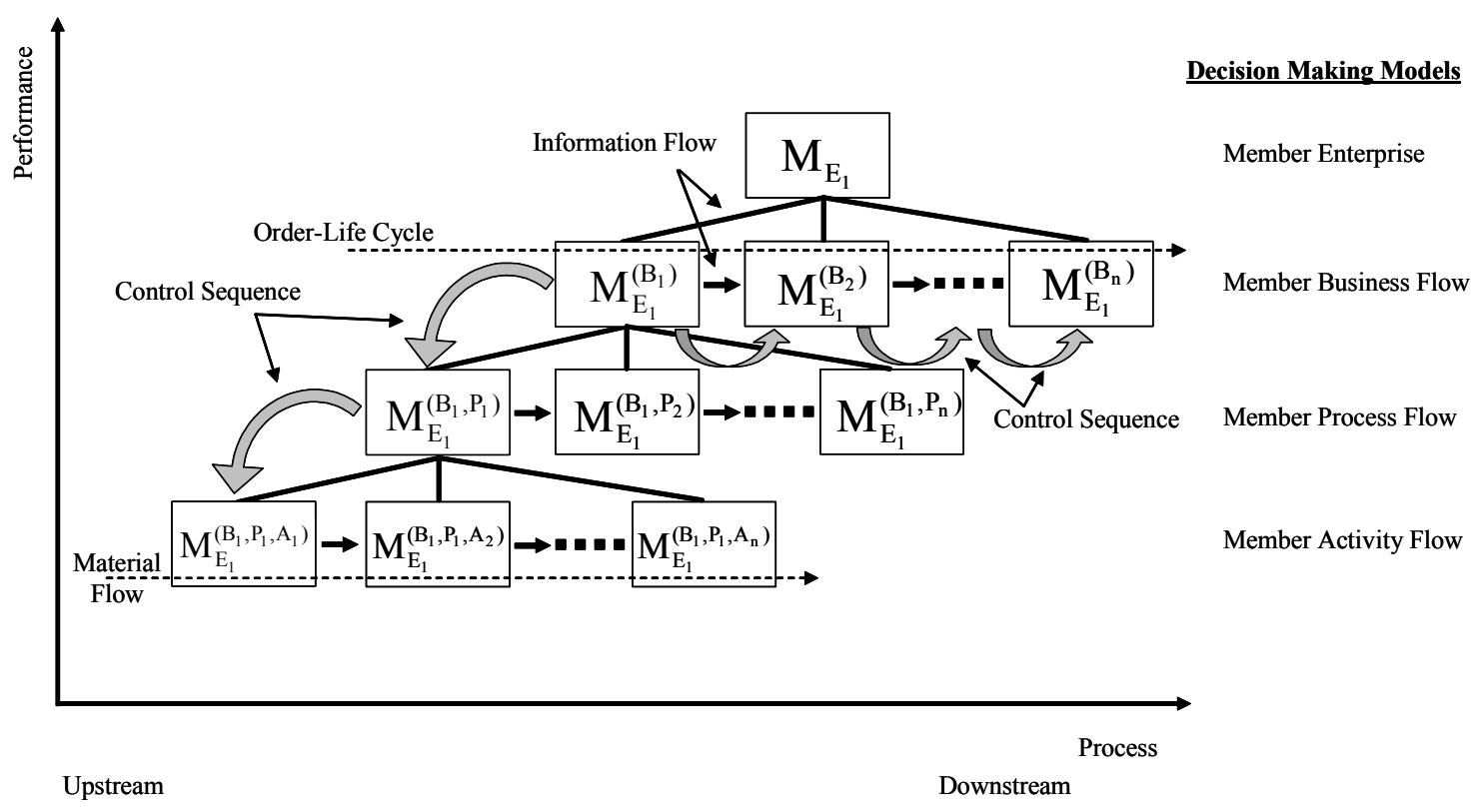

Figure 13: A Collaborative Supply Chain Member Architecture 
Even though this member architecture includes an order life-cycle, it is not defined as an enterprise life-cycle. Additionally, the architecture requires a value analysis as a starting point, which changes from the customer's point of view and over the time. Finally, for the decomposition levels, it is not clear how to represent a whole system, where an activity can belong to more than one process, or one process which belongs to many business blocks.

\subsubsection{Architecture for Supply Chain Integration}

Siau and Tian (2004) argue that an integrated supply chain must include completeness, security, flexibility, scalability, and interoperatibility. Considering these elements, they analyzed how Information Technology (IT), based on eXtensible Markup Language (XML), Common Object Request Broker Application (COBRA), .NET, and Semantic Web among others, can be used as enabling technology in order to fulfill the information requirements for integration (Siau and Tian, 2004).

Based on the simplified architecture for supply chain the architecture of an integrated supply chain was developed as is shown in Figure 14. The architecture includes internal and external communication with the supply chain enterprises, and emphasizes the relevance of the design and information system capable of interacting with different technologies, platforms, and decision support systems.

Finally, they define five critical elements which an integrated supply chain must have from the Information Technology point of view:

- The IT system covers all the supply chain as a whole.

- The IT subsystems may be independent among them. 
- The IT may provide strategic, analytical and decision support functions, not only operational management functions.

- The IT may be interoperable and may be able to integrate systems within the company and within companies.

- The IT may to provide a dynamic integration.
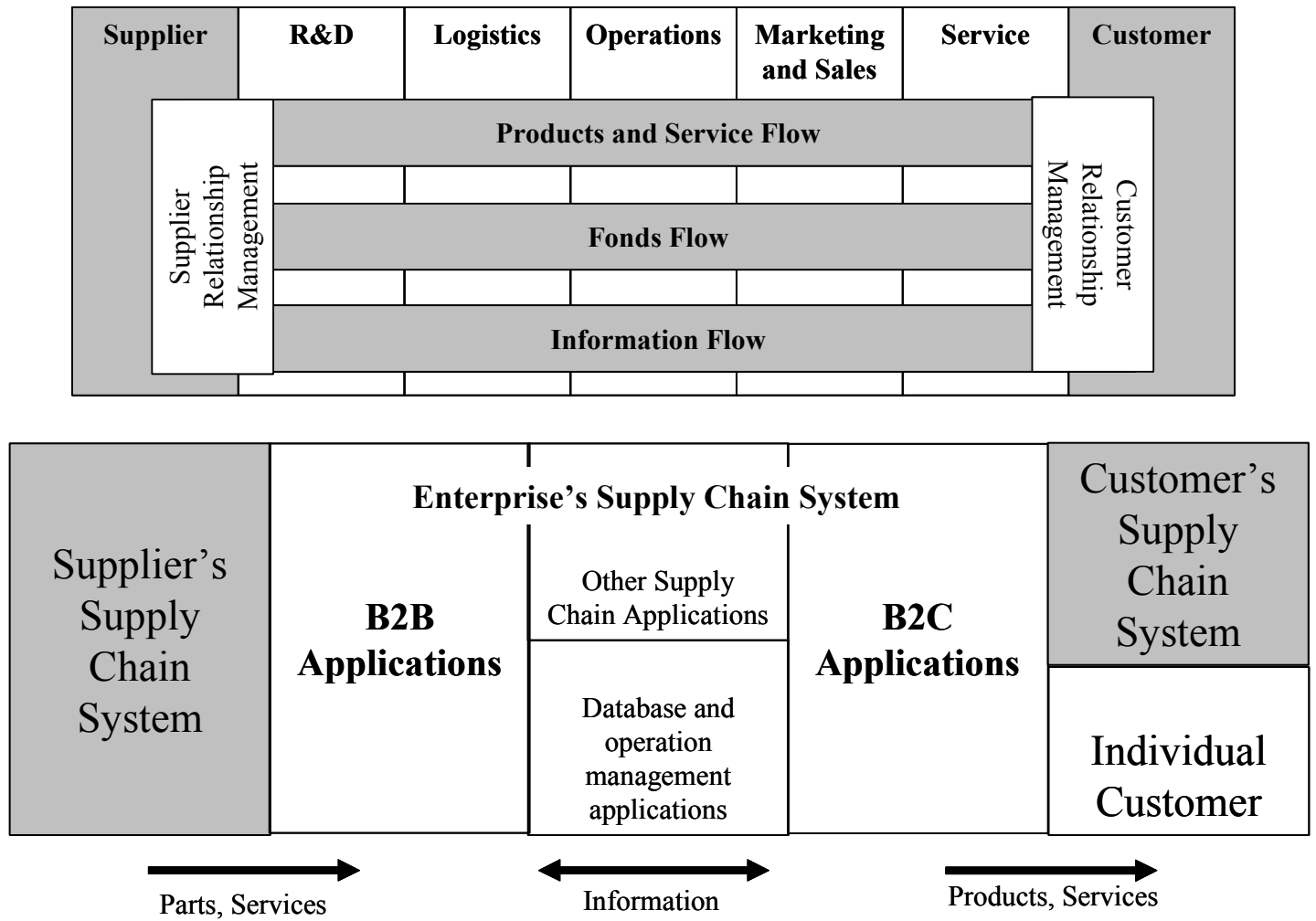

Figure 14: Architecture for an Integrated Supply Chain Enabling IT

From these examples of supply chain integration models and architectures, opportunities, conclusions and common characteristics are summarized as follows:

1. Models and architectures cover not only an enterprise system but also the integration of some companies in a supply chain. 
2. Models attempt to understand the relationship among supply chain elements through various kinds of analyses and points of view such as Business Processes, Value Analysis or Information Technology.

3. Models provide a categorization of the key supply chain concepts although they are not as clearly defined as was done in the enterprise models. For example, they do not separate the supply chain into views, perspectives, and dimensions the way enterprise models do.

4. Models use common terminology in the supply chain area, making it easier to have a comprehensive understanding of the supply chain activities, processes and systems.

5. The Supply chain models analyzed do not include life-cycle development as the enterprise models reviewed.

6. Models include several flows; some of them are similar, such as information, materials, services and funds across a supply chain system.

7. Supply chain models show different decomposition levels; some of them are high architectures but do not provide a clear road map for system improvement.

8. Supply chain models differentiate among enterprise elements such as logistics, research and development, sales, purchasing, and service; and supply chain business processes such as customer relationship management and supplier relationship management.

Table 1 shows a comparison among the architectures in terms of enterprise elements, supply chain business processes, enabling elements and flows. The column of Enterprise 
Business Process contains the processes represented in the model as internal processes, while the second column contains the supply chain business process, which implies the interaction among enterprises processes.

Table 1: Comparison among Supply Chain Architectures.

\begin{tabular}{|c|c|c|c|c|}
\hline Model & $\begin{array}{c}\text { Enterprise Business } \\
\text { Processes }\end{array}$ & $\begin{array}{c}\text { Supply Chain Business } \\
\text { Processes }\end{array}$ & Enabling Elements & Flows \\
\hline $\begin{array}{l}\text { Stevens } \\
(1989)\end{array}$ & $\begin{array}{l}\text { Purchasing, Material } \\
\text { Control, Production, } \\
\text { Sales, and } \\
\text { Distribution } \\
\end{array}$ & $\begin{array}{l}\text { Materials Management } \\
\text { and Distribution }\end{array}$ & $\begin{array}{c}\text { Technology, } \\
\text { Organization, and } \\
\text { Attitude }\end{array}$ & $\begin{array}{c}\text { Materials and } \\
\text { Customer Service }\end{array}$ \\
\hline $\begin{array}{l}\text { Copper et } \\
\text { al. (1997) }\end{array}$ & $\begin{array}{l}\text { Purchasing, Logistics, } \\
\text { Marketing and Sales, } \\
\text { Finance, R\&D, and } \\
\text { Production }\end{array}$ & $\begin{array}{l}\text { CRM, Customer Service } \\
\text { Management, Demand } \\
\text { Management, Order } \\
\text { Fulfillment, } \\
\text { Procurement, Product } \\
\text { Development and } \\
\text { Commercialization, and } \\
\text { Returns } \\
\end{array}$ & $\begin{array}{c}\text { Physical \& } \\
\text { Technical } \\
\text { Management } \\
\text { Components and } \\
\text { Managerial \& } \\
\text { Behavioral } \\
\text { Management } \\
\text { Components } \\
\end{array}$ & $\begin{array}{l}\text { Information, } \\
\text { Manufacturing } \\
\text { Management, and } \\
\text { Product }\end{array}$ \\
\hline $\begin{array}{l}\text { Chandra } \\
\text { \& Kumar } \\
(2001)\end{array}$ & $\begin{array}{l}\text { Marketing and Sales, } \\
\text { Inbound Logistics, } \\
\text { Plant Operations, } \\
\text { Outbound Logistics, } \\
\text { and Service (Member) }\end{array}$ & $\begin{array}{c}\text { Marketing and Sales, } \\
\text { Inbound Logistics, Plant } \\
\text { Operations, Outbound } \\
\text { Logistics, and Service } \\
\text { (Group) }\end{array}$ & $\begin{array}{c}\text { Procurement, } \\
\text { Technology } \\
\text { Development, } \\
\text { Information } \\
\text { Management, and } \\
\text { Others } \\
\end{array}$ & $\begin{array}{l}\text { Material } \\
\text { (Activity), } \\
\text { Process, order } \\
\text { life-cycle } \\
\text { (Business) and } \\
\text { Information } \\
\end{array}$ \\
\hline $\begin{array}{l}\text { Siau \& } \\
\text { Tian } \\
(2004)\end{array}$ & $\begin{array}{l}\text { R\&D, Logistics, } \\
\text { Operations, } \\
\text { Marketing and Sales, } \\
\text { and Service }\end{array}$ & $\begin{array}{c}\text { Customer and Supplier } \\
\text { Relationship } \\
\text { Management }\end{array}$ & $\begin{array}{c}\text { B2B and B2C } \\
\text { systems, Database } \\
\text { and Operational } \\
\text { Management } \\
\text { applications }\end{array}$ & $\begin{array}{l}\text { Parts, Products, } \\
\text { information, and } \\
\text { services }\end{array}$ \\
\hline
\end{tabular}

Almost all the reviewed models use different processes in each column, except Chandra and Kumar's model, which considers the same business process but at two different levels, as internal and external process. The last two columns show the enabling elements and flows represented in every model. Even though there are many more similar frameworks and architectures, one of them has been growing in acceptance and implementation. This is the SCOR, analyzed in the following section. 


\subsection{The SuPPly Chain OPERATIONS REFERENCE (SCOR)}

The SCOR model is a cross-functional framework, which integrates the concepts of business process reengineering, benchmarking, and process measurements. The SCOR model offers a structured process to improve the supply chain (Holmberg, 2000). This initiative of the Supply-Chain Council has grown in popularity and reported successful implementations and contributions from the Supply-Chain Council members, practitioners, and consultants. The SCOR model was developed to improve the supply chain effectiveness of enterprises, providing a common process oriented language on its five decision areas Plan, Source, Make, Deliver, and Return (Lockamy III and McCormack, 2004b). The supply chain structure based on the SCOR model is shown in Figure 15 (adapted from Huang et al., 2004).

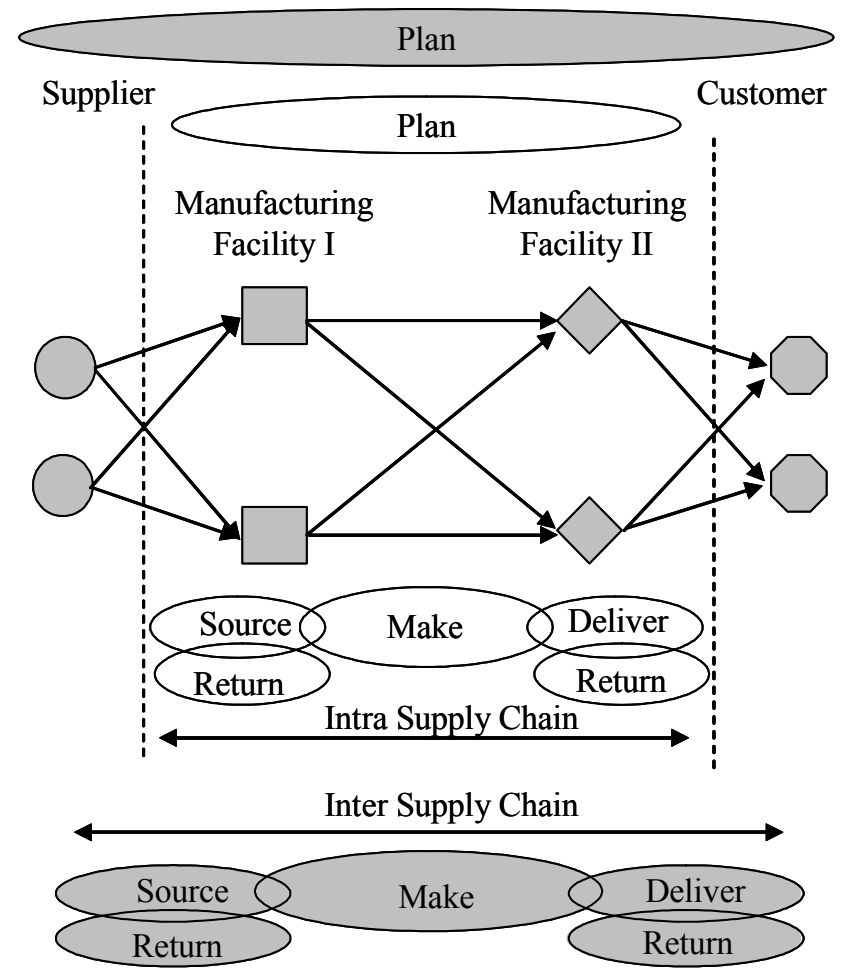

Figure 15: The SCOR Model-Based Supply Chain Infrastructure 
The SCOR model is deployed in three levels of process details (Lockamy III and McCormack, 2004b).

Level one, the top level, is related to process types and defines the scope and contents of the model, implying the definition of the core management processes for the decision areas Plan, Source, Make, Deliver, and Return. At this level is the set of competition performance targets.

- Level two, the configuration level, is related to process categories and provides a set of core process categories. This level describes the characteristics linked to the process types deployed within the core processes previously defined in level one. Also, this level defines process categories because of the relationship between a core management process and a process type.

- Level three, the process element level, is related to the enterprise fine tuning. It defines the ability of a company to compete successfully in a specific market. This level consists of process element definitions; process element information, input, and output; process performance metrics, best practices, systems capabilities to support best practices; and general systems and tools.

- Level four is the implementation. This level is not included in the model scope.

Even though the SCOR model has been used as a framework for integrated supply chain management by Supply-Chain Council members like Nabisco, Procter \& Gamble, and UPS logistics, it is important to highlight that the model does not provide a unique solution for the improvement of the supply chain. The SCOR model does not offer a step-by-step procedure to improve the supply chain management and must be supported 
by efficient systems and information technology, not defined by the model (Stewart, 1997). Moreover, According to the Supply Chain Council, SCOR does not include the processes involved in sales administration, technology development, product and process design and development, and some post-delivery technical support. Also SCOR assumes, but does not explicitly address several processes such as: training, quality, and information technology (IT) administration (non-SCM).

In spite of SCOR is widely accepted, some research is making up the SCOR model shortcomings. There is a lack of change management considerations through improving market analysis, processes synchronization, and the use of network modeling tools to support change management decisions (Huang et al. 2004). Other disciplines like Soft Systems methodology and Systems Thinking have been used to improve the model, which is strong on technical dimensions, but weak on social dimensions (Holmberg, 2000). These two disciplines can strengthen the modeling process and define a clear process vision before starting reengineering efforts. In other words, there must be understanding of the problem, the interaction between stakeholders, and understanding how they could respond if a process is changed (Kasi, 2005).

On the other hand, one of the strengths of the general enterprise modeling frameworks, like CIMOSA, PERA, and GERAM, is that it includes an implementation element on its life-cycle. GERAM, for example, focuses on the implementation process rather than the model structure (Barber et al. 2003). Although every model may be improved, the SCOR model exclusion of an implementation phase may allows being confused by a complex definition of the model. Moreover, the implementation process requires some metrics in order to evaluate the benefits achieved. SCOR does not define 
clearly whether an enterprise performance metric is outstanding or not. Even though the model provides performance metrics, it is not clear how a company can use those metrics to obtain a supply chain performance measure able to evaluate a continuous improvement process or benchmark with other enterprises (Huang et al. 2004). Considering these improvement opportunities in the SCOR model, the next section reviews a couple of models developed to provide a supply chain maturity path for enterprises.

\subsection{A Supply Chain Maturity Model}

Regarding the improvements on supply chain modeling mentioned in the last section, McCormack et al. (2002) published the Supply Chain Management Maturity Model based on Business Process Orientation. After that, Lockamy III and McCormack (2004)

published a research paper with the same scope. This model conceptualizes how to include the SCOR model in their maturity model. However, based the maturity model only in the SCOR and Business Process Orientation induce a lack of competition, consideration, and innovation. Moreover, the research study was validated over a member list of the Supply Chain Council, the creators and promoters of the SCOR model; thus, the results could be biased.

On the other hand, one interesting concept included in the model is the relationship shown between the enterprise process capability and the maturity level of the enterprise processes. The assumption behind this relationship implies that the more maturity level the enterprise process has, the more capable it is (Lockamy III and McCormack, 2004). This relationship also implies that the maturity taxonomy is directly related to the 
enterprise process performance. The proposed model has five maturity levels shown in Figure 16 (Lockamy III and McCormack, 2004).

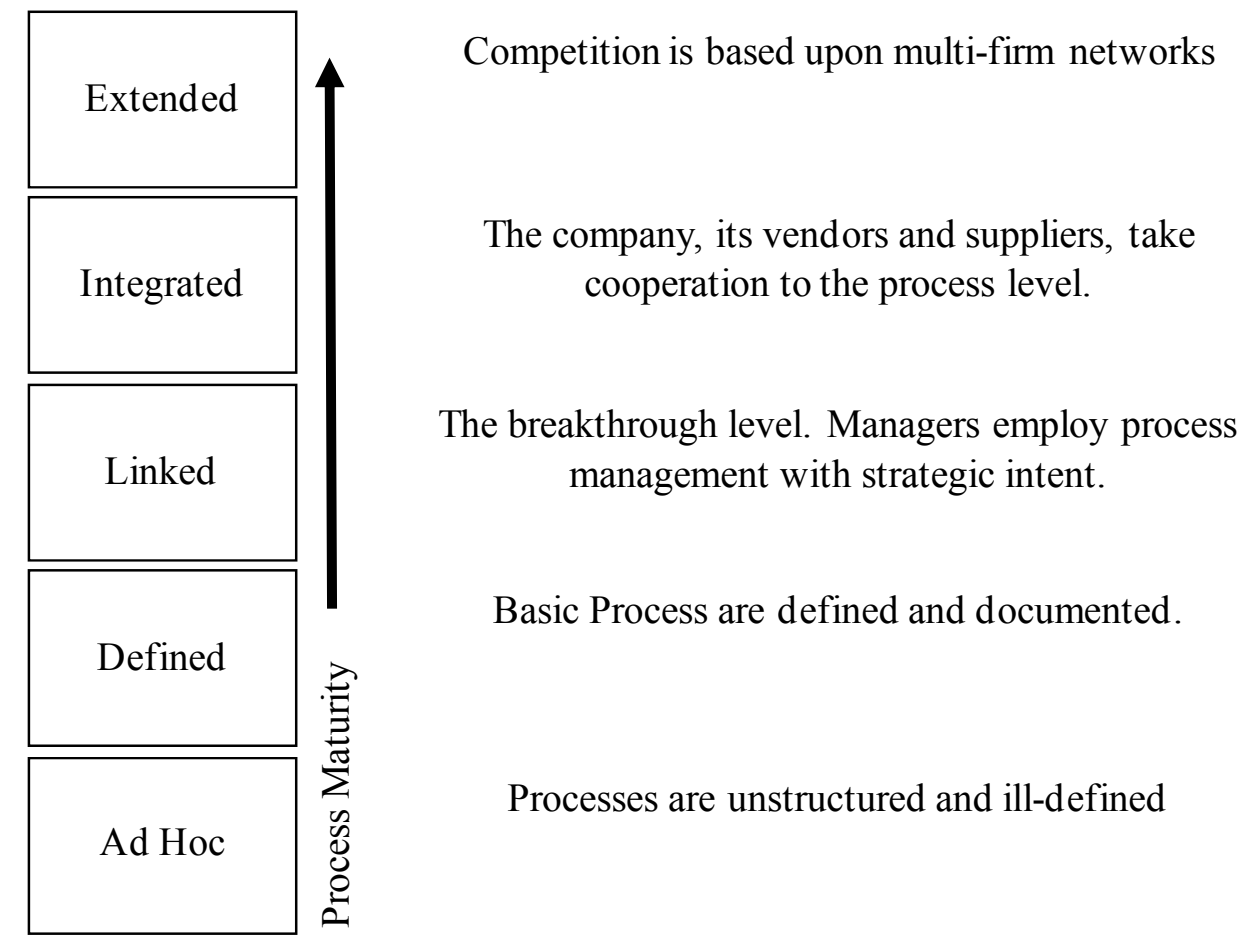

Figure 16: The Business Process Orientation Maturity Model

\subsection{MEASURING THE SUPPLY CHAIN}

One important problem related to the supply chain improvement process is the development of measurement systems. These systems should evaluate the benefits obtained from an improvement or make a comparison with some defined performance level. For instance, it should show the demand management capability, the process and product standardization, the cross-enterprise collaboration (Vitasek et al. 2005) as well as work in process inventories and lead time (Phelps et al. 2004). 
Due to the supply chain modeling complexity, it is difficult to define a performance measurement system in a way that such system integrates the whole performance of the supply chain. However, there are enterprise models and references widely accepted which provide indicators and metrics like CIMOSA (Kosanke et al. 1999), IDEF0 (Lin et al. 2002), GERAM (Bernus and Nemes, 1997), or SCOR (Huang et al. 2004). An inappropriate metric for the supply chain performance will result in failure to meet the customer's expectations due to the gap between the enterprise metrics and the customer value perception (Lambert and Pohlen, 2001).

In the literature, there are many attempts oriented to address the performance measurement system problem. Gunasekaran (2001) defines two reasons to improve the measuring systems in a supply chain; first, the lack of a balanced approach, and second, the lack in a clear distinction between measures at the operational, tactical, and strategic levels (Gunasekaran et al. 2001).

Holmberg (2000) applied the system thinking approach to model the supply chain in order to define a measuring system. The System Thinking approaches are oriented to define a system considering quantitative and qualitative criteria. They help to conclude that the system performance is more than the sum of all its processes performance. His research proposed linking the SCOR model to the Balance Scorecard to define integral metrics for the supply chain performance measure (Holmberg, 2000). Holmberg identifies several typical measurement problems: Strategy and measurements are not connected; a biased focus on financial metrics; too many isolated and incompatible measures; and the lack of supply chain context. Once again, the relevance of defining a model or at least the common boundaries for a supply chain in order to establish the 
metrics is emphasized by this author. In spite of, the fact that a company has an SRM or a CRM, there is no guarantee they will be compatible in measures or information storage within the systems of the other companies in the supply chain (Motwani et al. 2000).

A similar attempt to develop supply chain modeling and metrics in an integral way is proposed by Lambert and Pohlen (2001). They propose a framework to capture the performance across the whole supply chain considering the interaction between the corporate supply chain performance and the need to differentiate the supply chain in an enterprise in order to obtain a competitive advantage among others key factors. The framework provides a seven-step methodology, as follow:

- Map the supply chain

- Analyze each link mapped

- Develop profit and loss statements

- Realign supply chain process to achieve performance objectives

- Establish non-financial performance measures

- Compare across firms and

- Replicate these steps at each link in the supply chain

Apparently the framework proposed by Lambert and Pohlen (2001) is a generic framework, but they use a Customer Relationship Management and a Supplier Relationship Management as a link between the whole supply chain. However, not all the enterprises in a supply chain have this kind of systems. 


\subsection{BEST PRACTICES FROM OTHER DISCIPLINES APPLIED TO SUPPLY CHAIN}

There are many possible approaches to be used to improve the performance of an enterprise in the supply chain. Because of the complexity of the supply chain, it is possible to develop improvement procedures with different scopes, views, or impacts, both inside and within companies. Compared to other academic disciplines such as sociology or philosophy, logistics and supply chain are younger and with limited heritage of empirical research and theory development. Moreover, much of the recent research has its origins in theories from older disciplines, mainly from marketing, management, and engineering (Stock, 1997). The following are examples of recent research about the best practices of other disciplines applied to logistics and supply chain.

The contemporary best practices such as Lean Thinking and Six Sigma have contributed to improve the enterprise performance in the supply chain and the logistics process. A lean production system synchronizes demand and replenishment, which are very important inputs for a good supply chain performance measuring system. Supply chain waste activities may be inventories and overproduction (Kerr, 2002). Tools like the Value Stream mapping might be used for mapping an enterprise's supply chain process as a whole, by first mapping all the "as-is" enterprise supply chain processes involved directly with lead time. After that, it will be necessary to use a set of mapping and modeling tools in order to obtain the "to-be" enterprise supply chain process in a way that it describes the process in an comprehensive and universal form (Phelps et al. 2004). The benefits obtained from lean adoption in the sample enterprise used by Phelps (2004) were $20 \%$ of reduction on WIP inventory and $45 \%$ of reduction in lead time. Similarly, Vitasek et al. (2005) define six core characteristics for a lean supply chain: demand 
management capability; waste and cost reduction; process and product standardization; industry standards adoption; cultural change competency; and cross-enterprise collaboration.

Similar to the lean thinking approaches, there are Six Sigma principles which can be used for assessing the supply chain performance. Two principal issues related with supply chain improvements are the business process synchronization and the process variability reduction in key areas like distribution cost, stock levels, information management or demand forecast. These issues might be controlled and improved using six sigma concepts through controlling those decision making processes which impact in the enterprise's performance such as purchasing, pricing fluctuations and inventory management; thus developing continuous improvement through a Six Sigma Supply Chain (Garg et al. 2004).

On the other hand, since supply chain performance is directly linked to information systems performance, much of the research focuses on Six Sigma approaches applied to software development. The supply chain software has been challenged due to the fast increase of customers' requirements of information management oriented to making decision processes related with inventory, delivery or production. Even though many other approaches have been tried out such as the ISO9001 and ISO12204, the failure rate of projects is high. Therefore, among others, Six Sigma for software and the CMMI approaches emerge as a good opportunity to improve software implementation and performance (Gack and Robinson, 2003). 
There have been other attempts in regards to software development. For instance, Gack and Robinson (2003) integrates Six Sigma for software, CMMI, Personal Software Process, and Team Software Process as a set of complementary tools overlapping concepts and providing better results than a single implementation of one of them. Additionally, there are several combinations of CMM with other methodologies or tools. For instance, McGuire and McKeown (2001) provide a 5 step methodology for adopting $\mathrm{CMM}$ in an ISO environment. One of these steps is a gap analysis considered in the SCOR model; another step establishes a metrics program such that a scorecard from the Balanced Scorecard conceptualization or the SCOR model may be used. Similarly, Murugappan and Kenni (2003) use CMM and Six Sigma in order to meet business goals. They argue that Six Sigma and the CMM levels 4 and 5 are synergistic since CMM provides a good infrastructure to apply the Six Sigma techniques.

Therefore, other methodologies or concepts from different fields might be used to improve this process capability in a supply chain, such that the Six Sigma concepts of variability reduction and control can be used in order to improve lead time and delivery processes capability in a supply chain (Grag et al. 2004). In the same way, Lean concepts can be used to provide effectiveness and efficiency to the process by eliminating waste activities and all non-value-added tasks in the process through demand management capabilities, waste and cost reduction, process and product standardizations, industry standard adoption, cultural change competency and cross enterprise collaboration (Vitasek et al. 2005).

Considering all these different improvement scopes, it is possible to conclude there is a trend to integrate several techniques, tools, models and methodologies in order to assess 
the processes of enterprises in the supply chain. However, which tool, technique, methodology or set of them must be implemented first? Is some supply chain system preferred for improvement initiatives? Is there some improvement route for the supply chain assessment? Which supply chain improvement is first required? All these questions have no unique answer. Moreover, depending on the current state of the supply chain system, the possible actions might be different.

Therefore, the improvement road map provided by the $\mathrm{S}(\mathrm{CM})^{2}$ may help to define the best improvement process for an enterprise interested in assessing its processes in the supply chain. The following chapter shows the methodology applied in the S(CM $)^{2}$ conceptualization. 


\section{CHAPTER III}

\section{RESEARCH METHODOLOGY}

The previous chapters discussed several challenges related to building a supply chain model. Considering these challenges of modeling the supply chain and based on the literature review, it was concluded that a good meta-model would adhere to the following general characteristics:

1. Provide a clear description about the model foundations. The $S(C M)^{2}$ should describe how it was developed and how it is different from other models. Thus, the $\mathrm{S}(\mathrm{CM})^{2}$ requires a supply chain management definition obtained from practitioners and academicians. This definition is used as a starting point to generate the model.

2. Categorize the different areas of analysis that the model needs to address in a supply chain. The $\mathrm{S}(\mathrm{CM})^{2}$ requires the input of practitioners and academicians to define several views or dimensions, abstraction levels or perspectives; and a defined life-cycle to represent the complexity of the system, similarly to the representation used by the enterprise architectures discussed in the literature review.

3. Provide a clear description regarding the supply chain process assessment tool of the model. The general enterprise architectures reviewed describe how to improve the enterprise's processes after the enterprise model is done. Thus, the 
$\mathrm{S}(\mathrm{CM})^{2}$ should provide a list of key supply chain factors for each life-cycle stage, useful to assess a supply chain process through the model life-cycle.

4. Provide a clear description regarding the definition of an improvement road map. Generally, a model of an enterprise process is used to represent, analyze, and improve this process. Similarly, the $\mathrm{S}(\mathrm{CM})^{2}$ should provide a set of tools, techniques, and methodologies for an enterprise to define an improvement path based on the relevance of the factor at each stage.

Considering these characteristics, it was necessary to use a methodology that enabled the inclusion of different points of view; and quantitative and qualitative elements in a supply chain model. The quantitative elements should include inventory, products, raw material, and all the tools, techniques, and models useful to analyze, control, and improve the benefits for the enterprise. The qualitative elements include market and customer behavior, human capital, and information systems among others. Regarding the supply chain processes, the quantitative and qualitative elements are mixed. For instance, in the literature, there are some works about how to improve the sales process through a single tool like forecasting or a combination of tools from other methodologies like Value Stream Mapping and Business Process Reengineering over the critical process activities (Vitasek et al. 2005).

Similarly, there are other works about how to measure and control a supply chain process. There are some frameworks adapted from other tools like the Balance Scorecard or SCOR, which have been proposed to measure the enterprise performance in a supply chain (Brewer and Shep, 2000). However, neither the SCOR nor the Balanced Scorecard 
models are comprehensive for a supply chain; actually, they fail to model important questions: What are the competitors doing? and How is it going to impact my metrics? (Neely et al. 1997). Thus, improving the supply chain processes depends on the scope of who is in charge of this project. Different people use different approaches based on their experience and knowledge. Therefore, it is necessary to include and consider in the meta-model conceptualization the point of view and experience of several people, who are directly and indirectly linked to a supply chain process, either academically or practically.

This chapter describes the methodology used in the development of the supply chain capability maturity meta-model and how these requirements are met in the model conceptualization and development. Furthermore, it describes how the meta-model was analyzed, improved and validated by academicians and practitioners of the supply chain field. The next section presents the Delphi Method, which is the research tool used as data collection and conceptualization of the $\mathrm{S}(\mathrm{CM})^{2}$.

\subsection{THE DELPHI METHOD AS A RESEARCH TOOL}

The Delphi Method was developed by the Rand Corporation in the 1950's with the objective to provide a technique to achieve the most reliable consensus of a group of experts (Okoli and Pawlowski, 2004). Delphi provides a method oriented to structuring a group communication process so that the process is effective in allowing individuals to deal, as a whole, with a complex problem (Linstone and Turoff, 1975). This technique is favorable to consider new and future trends in complex systems over an interdisciplinary environment (Akkermans et al. 2003). According to Kengpol and Touminen (2006), the 
Delphi Method is composed by three principal processes: Achieve the opinion of a group of experts, collate and statistically summarize these opinions, and provide feedback to the participants seeking for a revision in their judgments, if any.

1. Obtain the opinion of a group of experts. The Delphi Method usually involves sending a questionnaire to an expert panel in each of a number of rounds. The design of the questionnaire used in the first round must include a set of questions oriented to obtaining the opinion of a group of experts. Generally the questionnaire includes open, ranking or classification questions about the objective of the study. Some examples are questions to determine trends (Hayes, 2007); identify key constraints in a new process implementation (Akkermans et al. 2003); evaluate information technology proposals (Kengpol and Touminen, 2006), validate frameworks (Holsapple and Joshi, 2000), or forecast based on subjective judgment (Hong-Minh et al. 2001), among others.

The number of rounds should be sufficiently large to reach consensus in the experts' responses; at least, as many to reach marginal improvements or stability regarding previous rounds. However, too many rounds may fatigue the panelist, such that the quality on the responses and the number of responses decrease. In practice, most of the studies use only two or three rounds (Mullen, 2003).

2. Collate and statistically summarize these opinions. The analysis of the responses from the Delphi survey is generally quantitative and qualitative. The quantitative statistical analysis may include means and standard deviation, median, range, minima and maxima, quartiles, inter-quartile range, and frequency distribution, among others (Mullen, 2003). These are obtained from the numerical results of the questions, for 
example using a five-point Likert scale (from totally agree to totally disagree) or “yes/no/do not know" answer format (Verhagen et al. 1998).

The questionnaire may include statements divided on several questions, which are looking for consensus by question. The qualitative analysis is obtained from the collection, classification, and summary of all the comments or arguments provided by the experts. These comments or arguments may be generated through the inclusion of openend questions in the questionnaire (Holsapple and Joshi, 2000). All the information obtained from the analysis is used to modify the questionnaire for the next round in order to get consensus.

3. Provide necessary feedback to the participants. The information obtained from the analysis is included in a document and sent back to the panel of experts either in the questionnaire or in a separated document. Typically, the participants have the opportunity to modify their answers every new round, always keeping anonymity (Mullen, 2003).

Additionally, a very important decision on the application of the Delphi Method is the number of experts to be included in the study. In the literature, the size of the set of experts is reported in a wide range, depending on the purpose of the research. According to Turoff (1970) the most recommended values are between 10 and 50 (Holsapple and Joshi, 31; Akkermans et al. 23, Okoli and Pawlowski, 18; Haynes, 20).

Regarding the supply chain, there are several applications reported in the literature. For example, the evaluation of information technology in logistics firms (Kengpol and Touminen, 2006), the identification of supply chain solution in a building sector (Hong- 
Minh et al. 2001), or the impact of the ERP on supply chain management (Akkermans et al. 2003).

\subsection{Methodology USEd to Get The Meta-Model ConCePtualization}

Based on the information obtained from the literature review shown in Chapter 2, it was decided to design a sequential and progressive conceptualization method to generate the meta-model. Thus, the methodology used in this research includes three stages. Every stage adds more information to the model and validates the results achieved in the previous step. Finally, once the meta-model was validated, the final step was to design an assessment tool, which allowed passing from one maturity level to the next one.

The objective of stage one was to generate a draft characterization of the maturity levels in supply chain and obtain consensus of the key elements found in a supply chain definition. The objectives of the second stage were to improve and validate the supply chain definition, to improve the characterization of the maturity levels and to generate a definition for each one of them. Moreover, it was necessary to include tools, techniques and methodologies for each level in order to pass from one maturity level to the next one. At the end of this stage, a draft of the $\mathrm{S}(\mathrm{CM})^{2}$ was obtained. The objective of the final stage was to validate the $\mathrm{S}(\mathrm{CM})^{2}$ draft obtained in the second stage.

The first two stages of the methodology included a Delphi method as a research tool, running two rounds at each stage. The third stage included a comparison among the $\mathrm{S}(\mathrm{CM})^{2}$ and other models, a case study and a pilot improvement process. Figure 17, summarizes the methodology described. 


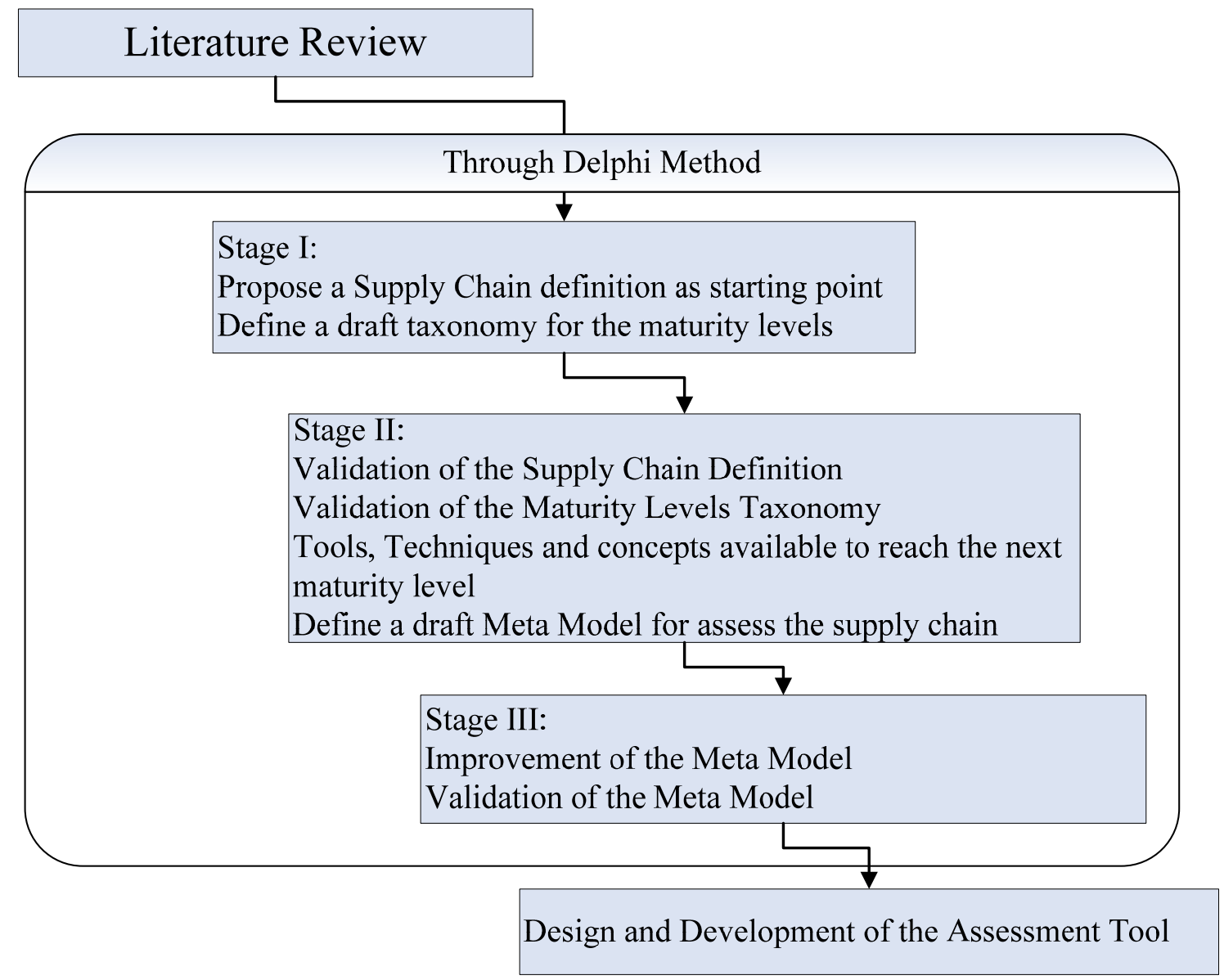

Figure 17: Research Methodology Diagram

The detailed methodology for each one of these stages is described in the next paragraphs.

\subsection{DETAILED DESCRIPTION OF STAGE I}

Figure 18 shows a detailed diagram flow for this stage. The next paragraphs describe steps one through fourteen. 


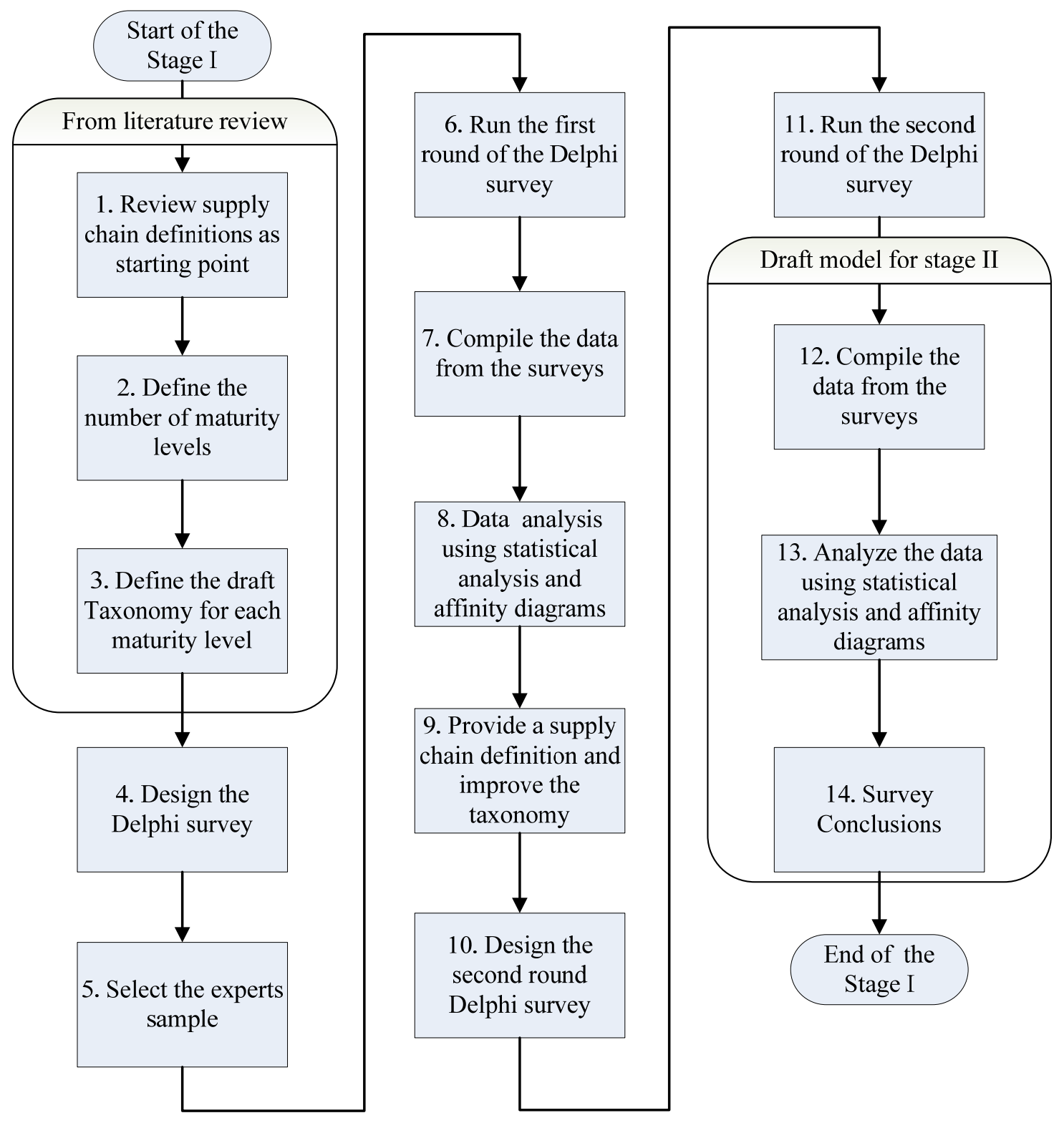

Figure 18: Diagram Flow for Stage I

1. Review supply chain definitions. There are many supply chain definitions in the literature. Selecting one of them as a starting point may bias the experts' answers about the supply chain related questions. Even though this research does not have the 
objective of finding a universal supply chain definition, this stage asked to a set of experts for a definition of supply chain in order to provide a common ground.

2. Define the number of maturity levels in the model. The literature shows that there are frameworks and models which use different numbers of maturity levels. The CMM uses five levels (Murugappan and Kenni, 2003). The CMM evolved into CMMI, which uses five levels in the representation of stages and six levels in the continuous representation (Yoo et al. 2004). Similarly, regarding the supply chain management, the business process orientation maturity model for supply chain uses five levels (Lockamy III and McCormack, 2004), whereas the Stevens' model uses 4 levels (Stevens, 1989). Considering these models, the $\mathrm{S}(\mathrm{CM})^{2}$ is integrated by 5 maturity levels named Initial, Defined, Integrated, Collaborative, and Leading. These maturity levels are considered as the model life-cycle.

3. Define the draft taxonomy for each maturity level. The CMM levels were derived from and analogous to the Crosby's Quality Maturity Grid (Gack and Robinson, 2003). Crosby, in his maturity grid, includes five successive stages of quality maturity as follows: uncertainty, awakening, enlightenment, wisdom, and certainty. The first stages imply a poor knowledge about quality. The intermediate stages are focused on transforming the attitude and understanding of quality as a management tool. The final stage implies the understanding and recognition of Total Quality Management (TQM) as an essential part of the company system (Calingo, 1996). The Lockamy III and McCormack model define five levels as: "ad hoc", defined, linked, integrated, and extended. At this point, and to avoid a possible bias in the answer of the experts, only the first and the last maturity levels were defined. The 
first level was defined as poor supply chain development and the last one was defined as leading in supply chain.

4. Design the Delphi questionnaire. In order to accomplish the objective of this stage, the initial questionnaire includes only two open ended questions.

1) What is your personal definition of supply chain?

2) What characteristics define each maturity level?

5. Select a set of experts. This first group of experts provided their judgments about the key elements what a definition of supply chain should include and the characterization of each maturity level. Taking into account that the exploratory nature of the first stage, a group size of between ten and twenty was set. A frequent assumption is that an expert should be professionally or scientifically qualified and/or own recognition on the study field (Mullen, 2003). For the purpose of this research, an expert is defined as anyone with five or more years of experience in supply chain or related fields as logistics, procurement, or sales.

6. Run the first round of the Delphi survey. Once the experts were selected, the next step was to send an invitation letter requesting their participation in the research. The letter included the objective of the research, a brief explanation of how participants were expected to answer, and the two open ended questions mentioned in step four. This Delphi study was run in Mexico; thus, most of the experts received the information personally or by e-mail in Spanish. A translation of the invitation letter used is shown in APPENDIX 1. 
7. Data compilation. Once surveys were answered, the data obtained were stored in a database for future analysis.

8. Data Analysis. The analysis was done using statistical tools and affinity diagrams. Results are shown and discussed in the next chapter.

9. Integrate a draft supply chain definition and improve the taxonomy. This step integrates a draft definition of supply chain. This definition summarizes the answers provided by the experts in the first round of this stage, regarding what they understood by Supply Chain. The supply chain definition generated is the following: "Supply chain is a network of enterprises, which integrates all processes from the supply and procurement of raw materials to delivering a finished good. The supply chain involves all processes oriented to improve logistics and productivity."

Even though providing a supply definition is not an objective of this research, this one was used to define a context for the experts. The definition was improved through stages I and II.

10. Design the second round of the Delphi survey. The second questionnaire included the draft definition shown in the last step and the list of key factors identified from the experts answers. The definition was improved and validated through two different types of questions. The first one ranks the definition agreement using the Likert scale and a second one was an open ended question about what elements were missing in the definition. A different section requests ranking the relevance of the key factors in each maturity level and an open ended question about the characterization of the level. A translation of this second survey is shown in Appendix 2. 
11. Run the second round of the Delphi survey. The surveys were sent personally or by email to the experts. The surveys were sent to the same set of experts of the first round even though some of them had not returned the first survey.

12. Data compilation: Once surveys were answered, the data obtained were stored in a database for future analysis.

13. Data Analysis. This analysis was done using statistical tools and affinity diagrams. The results from this round are shown and discussed in the next chapter.

14. Survey Conclusion. Once the analysis is done, it is possible to conclude about the findings reached in the stage. These are deeply discussed in the next chapter.

\subsection{DETAILED DESCRIPTION OF STAGE II}

This stage has several objectives. The first one is to validate the definition and characteristics of each maturity level. The second one is to identify the tools, techniques, and methodologies available to pass from one level to the next one. Finally, the last objective is to improve the supply chain definition, which is only a contextual reference in the model. Figure 19 shows a detailed diagram flow for stage II.

The numbering continues from the last step number in stage one, in a way that this stage includes steps fifteen to twenty eight. Notice that the darker boxes imply post analysis and improvement activities based on the Delphi results. The lighter boxes belong to the Delphi method such that they are the same as the used in the previous stage. 


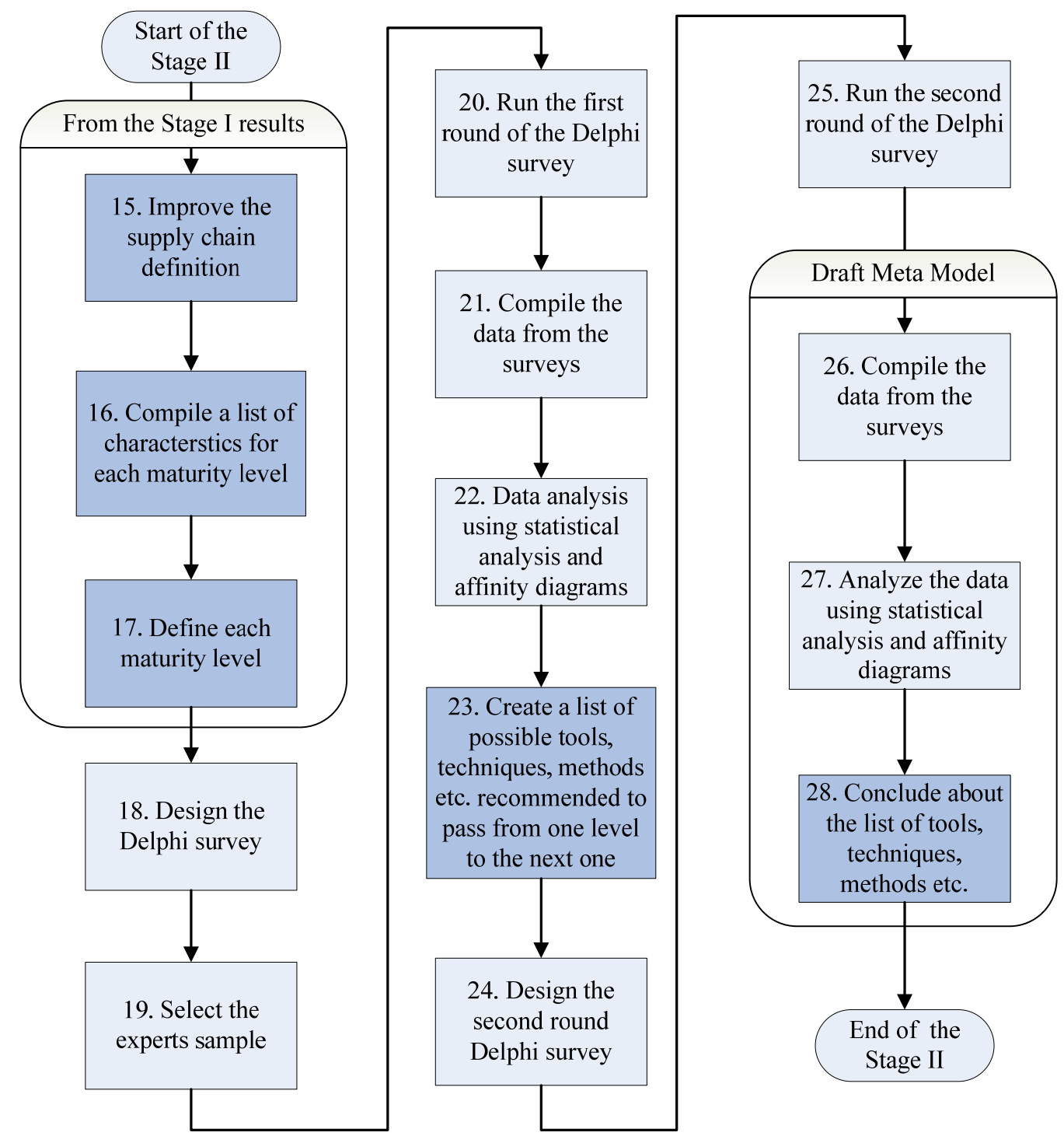

Figure 19: Diagram Flow for the Stage II

15. Improving the supply chain definition. Based on the answers provided by the experts in the first stage of the methodology, the supply chain definition shown in step 9 was improved. In the first stage the experts were asked about what was missing in the first supply chain definition. The following supply chain definition summarizes the feedback provided by the experts in the second round of the stage I. 
"Supply Chain is a system which manages and controls the use of facilities, processes, resources, and supplies in order to improve the logistic productivity in the enterprise. All the processes of the supply chain system have the objective of promoting products and/or services with value to their customers. This goal is achieved through the coordination among all the supply chain stakeholders. All supply chain processes are based on the knowledge and satisfaction of the customer requirements regarding quality, time response, cost, flexibility, and innovation".

16. Compilation of a list of characteristics for each level. These characteristics were obtained by summarizing the results from stage I regarding the elements which define each taxonomy level.

17. Define each maturity level. Based on the characteristics found in the last point, it generates a draft definition for each maturity level.

18. Design the first Delphi survey for the second stage. Considering the objectives of the stage, the survey should include open ended questions oriented to identify the tools, techniques and methodologies available to improve the supply chain, further validation of the questions using the Likert scale oriented to ask for acceptance of the maturity levels and a definition of supply chain. The final design includes three questions related to the supply chain definition, five questions related to the maturity levels, one for each level, and five open ended questions related to the possible improvement solutions, one for each level. The survey is shown in Appendix 3.

19. Select the set of experts. Since one of the objectives of this stage is to validate the maturity level taxonomy, it was convenient increased the set of experts, including a 
larger spectrum of scopes and interests, which implies considering a larger number of candidates to participate in the process. In this step a target of at least sixty invitations were sent, expecting a rate of answer of at least seventy percent.

20. Run the first round of the Delphi survey. Once the potential participants were selected, the next step was to sent an invitation letter requesting their participation in the research. The letter included the objective of the research, a brief explanation of how the participants were expected to answer, and the open ended questions mentioned in step eighteen. Appendix 3 shows a translation of this invitation letter.

21. Data compilation: Once surveys were answered, the data obtained were stored in a database for future analysis.

22. Data Analysis. This analysis was done using statistical tools and affinity diagrams. The results from this round are shown and discussed in Chapter 5.

23. Create a list of possible solutions to improve the supply chain. After analyzing the results from the first round in this stage, it is necessary to compile a list of all the possible solutions provided by the experts to improve the supply chain at each level. This list will be validated and improved in the second round by the same experts.

24. Design the second round Delphi survey. Considering the information obtained in the first round, the original questionnaire was modified including the additions to the draft definition of each maturity level, generated from the first round of answers. Once the modifications were made, the experts were consulted again using the second Delphi survey. The number of questions used in this round increased, due to the need of validating some discrepancies obtained from the affinity diagrams regarding the 
tools, techniques, methodologies etc. available to improve the supply chain processes. For example, some of them appeared on several levels; thus, it was necessary to define a single level or to consider them useful in more than one level.

25. Run the second round of the Delphi survey. The surveys were sent personally or by email to the experts. The surveys were sent to the same set of experts even though some of them had not returned the first survey.

26. Data Compilation: Once surveys were answered, the data obtained were stored in a database for future analysis.

27. Data Analysis. This analysis was done using statistical tools and affinity diagrams. The results from this round are shown and discussed in the next chapter.

28. Survey Conclusion. Once the analysis is done, it is possible to conclude about the findings reached in the stage. These are in depth discussed in Chapter 5.

\subsection{DetaILED DESCRIPTION OF STAGE III}

The objectives of this stage were to: 1) define the $\mathrm{S}(\mathrm{CM})^{2}$ model, 2) verify and validate the $\mathrm{S}(\mathrm{CM})^{2}$ model and 3) define an assessment tool based on the $\mathrm{S}(\mathrm{CM})^{2}$. Figure 20 shows a detailed diagram flow for this stage. The numbering continues from the last step number in stage two, such that this stage includes the steps from twenty nine to thirty nine.

29. Views and abstraction level definition. Similarly to the enterprise modeling frameworks reviewed in Chapter 2, the $\mathrm{S}(\mathrm{CM})^{2}$ requires to define views and abstraction levels. Based on these views and abstraction levels, it is possible to 
represent the model as a matrix of explicitly differentiable elements over the model life-cycle.

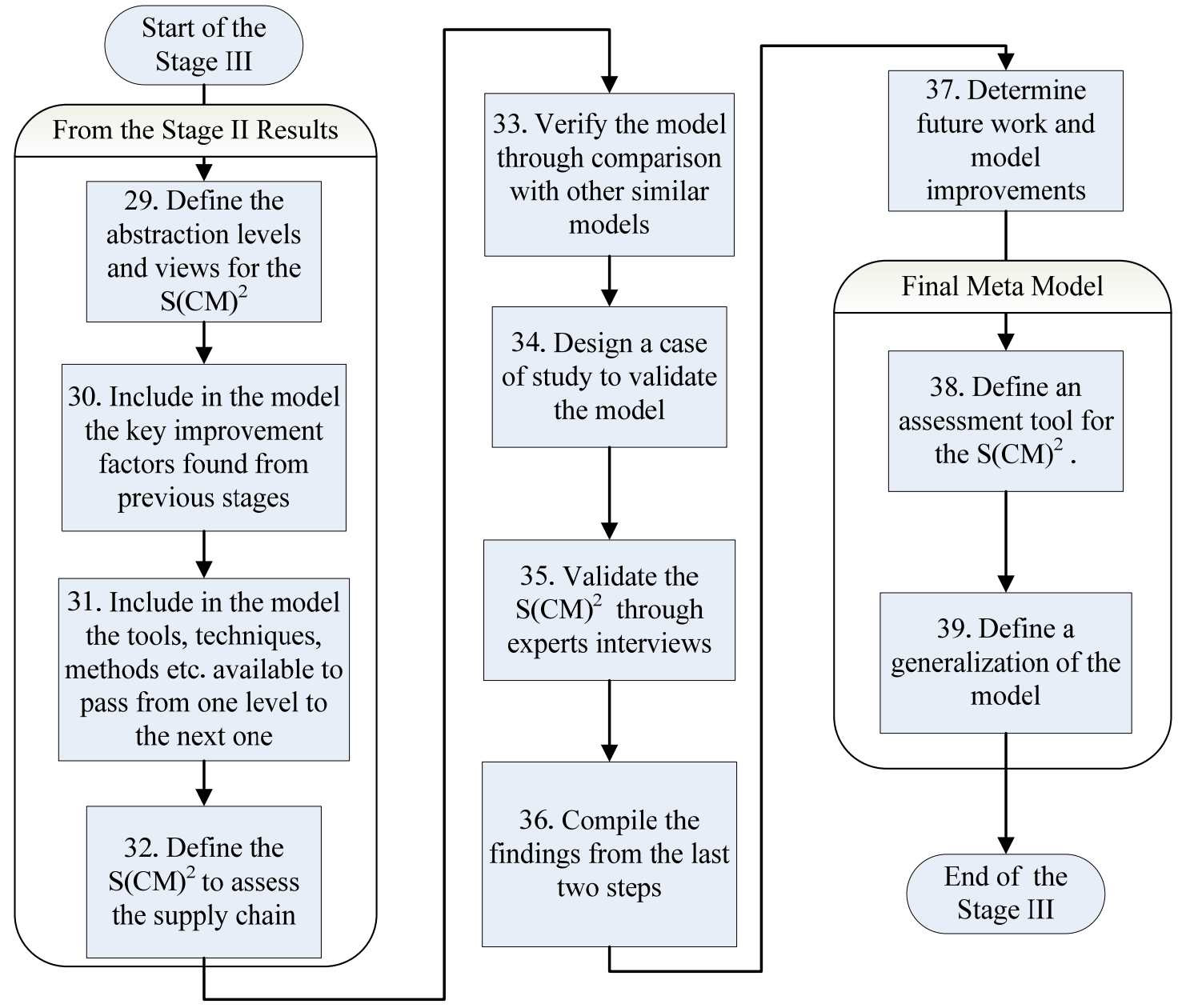

Figure 20: Diagram flow for stage III

30. Include the key improvement factors per level. Since the model has the objective to improve a supply chain, it requires a prioritized list of key improvement elements in each maturity level. This prioritized list came from the experts' responses obtained after applying the Delphi survey in the second stage. 
31. Include tools to pass through levels. Identifying key improvement elements is not good enough to achieve improvement. The model requires a set of tools, techniques, and methodologies useful to pass from one maturity level to the next one. These tools, techniques, and methodologies came from the experts' responses obtained after applying the Delphi survey.

32. Define the $\mathrm{S}(\mathrm{CM})^{2}$. Having completed the two previous steps, the model was built. The maturity levels as the model life-cycle, the views, the abstraction levels, the key improvement factor, and the tools compose the whole $\mathrm{S}(\mathrm{CM})^{2}$ meta-model.

33. Verify the Model. Once the model was built, the following step was to verify its conceptualization through a comparison with the models reviewed in Chapter 2.

34. Run a case study to validate the Model. After the verification, the model was validated as a diagnostic tool through the application of a case study. This case study describes a couple of enterprises, so that the participants in the study identify the maturity level of the enterprise.

35. Validate the model through interviews with experts. A different validation process was run in parallel to increasing the confidence in the model. This validation was done through interviews with experts in the supply chain field. Their comments, and responses were analyzed to define strengths, weaknesses, and future research related to the model.

36. Compile validation results. After running both validation processes the final documentation of the model was done. 
37. Future work and possible improvements. This step implies documenting the findings obtained from steps 34 and 35.

38. Define an assessment tool. Once the $\mathrm{S}(\mathrm{CM})^{2}$ was finished, this step defines and designs an assessment tool, which is useful to create an improvement path for the enterprise.

39. Model generalization. Finally, the model should have a universal way to be defined. The last step proposes a general supply chain performance classification, useful to provide a common language for future works related to this model. This classification is similar to the one used to classify waiting lines in the queue theory analysis.

The following chapters describe the results obtained after applying the methodology discussed in this chapter. 


\section{CHAPTER IV}

\section{STAGES RESULTS}

This chapter summarizes the findings obtained from the Delphi method during stages one and two of the research methodology. These results are the foundation of the $\mathrm{S}(\mathrm{CM})^{2}$ since they provide the taxonomy of the model, the key improvement factors in a supply chain, and a set of tools required to reach the next maturity level in the model. The results are presented in chronological order; thus, the information about the qualifications of the experts is shown before the main results for each stage are stated.

\subsection{QUALIFICATION OF THE EXPERTS FOR STAGE I}

Eighteen experts were invited to participate in the research process. The participants were selected from a list of personal contacts previously obtained. All the experts had at least five years of experience in supply chains or a related area such as logistics, sales, or procurement. Since a supply chain may be defined in several ways depending on the type of business, this set of experts represents different types of businesses. This assortment covers a wide kind of input about what a supply chain should be. The participants were in the industries listed in Table 2:

Regarding their academic qualifications, all the experts hold at least a BA or a BS degree, six of them hold a master's degree and one hold a PhD. The experts are related to the supply chain from different positions, such as logistics, processes engineering or production planning. Table 3 shows the position of the experts consulted. 
Table 2: Type of Business Represented in the Stage I

\begin{tabular}{|l|l|}
\hline Food packing (1) & Construction materials (1) \\
\hline Construction equipment (1) & Glass industry (1) \\
\hline Home improvements (1) & Air Conditioning products (1) \\
\hline Domestic motors (1) & Chemistry industry (1) \\
\hline Frozen food products (1) & Medical devices (2) \\
\hline Consultancy services (3) & Beauty supplies (1) \\
\hline Academy (3) & \\
\hline
\end{tabular}

Table 3: Positions Represented in the Stage I

\begin{tabular}{|l|l|}
\hline Logistics Manager (3) & Process Engineering (1) \\
\hline Project Manager (2) & Sales Manager (3) \\
\hline Professor (3) & Consultant (3) \\
\hline Planning Manager (1) & Operations Manager (1) \\
\hline Procurement Manager (1) & \\
\hline
\end{tabular}

\subsection{SUMMARY OF THE RESULTS FOR STAGE I}

After defining the sample of experts to be consulted in this stage, the experts received an invitation letter either by email or personally, which explained the research and the role they played. The eighteen participants answered the first and second rounds of the Delphi survey shown in Appendices 1 and 2. The first round allowed setting a basic supply chain definition and a list of characteristics which defined each maturity level. Additionally, the experts listed a set of key improvement factors related to the supply chain. The second round was focused on improving the supply chain reference definition, and to prioritizing the set of key improvement factors obtained in the first round. Also, the experts added any other key factors missing from the first round. Table 4 summarizes the main findings in this stage. 
Table 4. Principal Findings of the Stage I

\begin{tabular}{|l|l|}
\hline \multicolumn{1}{|c|}{ Round One } & \multicolumn{1}{|c|}{ Round Two } \\
\hline $\begin{array}{l}\text { Elements of a supply chain definition used as } \\
\text { a starting point during the research }\end{array}$ & $\begin{array}{l}\text { Consensus about the elements of a supply } \\
\text { chain definition. }\end{array}$ \\
$\begin{array}{l}\text { Main characteristics of each maturity level. } \\
\text { The taxonomy defines five maturity levels. }\end{array}$ & $\begin{array}{l}\text { A draft definition of each maturity level } \\
\text { based on the answers received in round one. } \\
\text { Level one describes an enterprise with poor } \\
\text { supply chain development and the level five } \\
\text { describes a leading enterprise in the market }\end{array}$ \\
$\begin{array}{l}\text { A list of Key Improvement Factors through } \\
\text { the maturity levels }\end{array}$ & $\begin{array}{l}\text { A prioritized list of Key Improvement Factor } \\
\text { through the maturity levels. }\end{array}$ \\
\hline
\end{tabular}

\subsubsection{Characterization of each Maturity Level}

The experts were asked about the characteristics a supply chain should have according to the following taxonomy. Level one: This is an enterprise with poor supply chain development, Level five: This is a leading enterprise in the market. The intermediate levels were set free to be defined by the answers of the experts. The characteristics collected were used to create a definition for each maturity level. This final result was used in the stage II as the starting definitions for each maturity level. Table 5 shows some of the results obtained for each maturity level.

Table 5: Characterization of each Maturity Level

\begin{tabular}{|c|l|}
\hline Maturity Level & \multicolumn{1}{|c|}{ Characteristics } \\
\hline One & $\begin{array}{l}\text { There is lack of performance indicators and communication between } \\
\text { departments. There is unpredictable process performance. There are no } \\
\text { procedures defined in the enterprise. Success is based on meeting the } \\
\text { customer requirements without concerns about cost. There are no information } \\
\text { systems. There is lack of inventory management and supplier selection } \\
\text { policies. Employees' training is deficient or non-existing. }\end{array}$ \\
\hline Two & $\begin{array}{l}\text { There are basic information systems, forecast methods, and performance } \\
\text { indicators. Beginning efforts to document and standardize processes, policies, } \\
\text { and procedures. There is weak coordination between departments and } \\
\text { processes. There is no certainty about inventory levels, how much and where } \\
\text { the products and raw materials are physically. The first attempts to increase } \\
\text { the quality in the products and services, to develop customers' loyalty appears. }\end{array}$ \\
\hline
\end{tabular}




\begin{tabular}{|c|c|}
\hline Maturity Level & Characteristics \\
\hline Three & $\begin{array}{l}\text { There is a formal project to integrate processes, information systems, } \\
\text { departments, activities, and other related procedures to organize the enterprise } \\
\text { internally. The first attempts to optimize processes appear, logistics is } \\
\text { recognized as a key competitive issue in the whole enterprise. The first cross- } \\
\text { disciplinary improvement tools such as ISO, Lean Manufacturing, or Six } \\
\text { Sigma start to be implemented. The KPIs are defined and its documentation is } \\
\text { in process. A customer service department emerges. A department oriented to } \\
\text { optimize the supply of raw materials and product distribution emerges. }\end{array}$ \\
\hline Four & $\begin{array}{l}\text { There is strict control of the supplier deliveries related to order completeness, } \\
\text { quality assurance, and delivery time. There is deep knowledge of the internal } \\
\text { enterprise processes. There are improvement processes oriented to the } \\
\text { implementation of technological solutions. Employees receive training } \\
\text { oriented to get better results in their positions. Customers trust the products } \\
\text { and services offered by the enterprise. The enterprise tries to have influence in } \\
\text { the customer's perception of value. The enterprise starts to explore the } \\
\text { possibility to make alliances or partnerships with other enterprises. }\end{array}$ \\
\hline Five & $\begin{array}{l}\text { Customers appreciate customer service. The work culture is well-defined and } \\
\text { established in the enterprise. The product distribution and supplies } \\
\text { procurement are constantly optimized. Relevant information is easily } \\
\text { reachable and shown with a high usability level. The enterprise invests on } \\
\text { research and product development. The enterprise has several certifications of } \\
\text { its products and processes. The enterprise has strong alliances and } \\
\text { partnerships with other enterprises. The enterprise is focused on its core } \\
\text { business tending to outsource the remaining processes. The enterprise has a } \\
\text { big influence over customers requirements and suppliers processes. The } \\
\text { enterprise is a benchmark for other enterprises. }\end{array}$ \\
\hline
\end{tabular}

These results highlight an enterprise's internal integration processes from levels one to three. Level four starts with the collaboration with other enterprises and the growth of partnerships and alliances. Finally, level five describes a leading enterprise in the market, with a strong focus on product development, innovation, research, customer satisfaction, integration of suppliers, and a very attractive working environment. Considering these descriptions, the maturity levels are labeled as: Undefined, Defined, Manageable, Collaborative, and Leading. 


\subsubsection{Prioritization of the Key Improvement Factor in a Supply Chain}

A very interesting result was the list of supply chain improvement factors. These were mentioned by the experts as key factors to attain the level proper of an outstanding supply chain. The first round of this stage collected twenty seven factors. These factors are shown in Table 6 .

Table 6: List of Key Improvement Factors

\begin{tabular}{|l|l|l|}
\hline $\begin{array}{l}\text { 1. Company Objectives, vision } \\
\text { and mission }\end{array}$ & 10. ISO & 19. Product \\
2. Cost & 11. KPI & 20. Product Distribution \\
3. Customer requirements & 12. Lead Time & 21. Production \\
4. Customer Service & 13. Logistics & 22. Quality \\
5. Defects/reworks/scrap & 14. Optimization processes & 23. Raw materials procurement \\
6. Demand Forecasting & 15. Organization structure & 24. Change Response Time \\
7. Demand Management & 16. Procedures & 25. Shipping \\
8. Enterprise Policies & 17. Process Capability & 26. Suppliers \\
9. Inventory Management & 18. Processes Synchronization & 27. Warehousing \\
\hline
\end{tabular}

Even though some of these factors could be similar, or overlap functions or processes, none were eliminated. The reason was to discriminate or specify as much as possible a prioritized list of improvement factors. In order to determine the relevance of each factor in each maturity level, the second round of the Delphi survey asked to select from the list shown in Table 6 the most important factors for each level. Table 7 shows the percentage times each factor was mentioned. The shaded cells are the three largest percentages for each level.

These percentages represent the number of times that a particular improvement factor was recognized as relevant in every maturity level. For example, the answers of the 
experts included at most eighteen mentions; fifteen of them remarked the product as key improvement factor for this maturity level. Thus, the final list was obtained considering those factors, which received at least the fifty percent of approval. Intending to provide a more clear description for these factors, some additional information was added to them.

Table 8 shows the key factor for each maturity level.

Table 7: Prioritization of Improvement Factors for Maturity Level

\begin{tabular}{|l|c|c|c|c|c|}
\hline \multicolumn{1}{|c|}{ Improvement Factor } & Level 1 & Level 2 & Level 3 & Level 4 & Level 5 \\
\hline Company Objectives, vision and mission & $17 \%$ & $22 \%$ & $50 \%$ & $17 \%$ & $11 \%$ \\
\hline Cost & $56 \%$ & $44 \%$ & $44 \%$ & $39 \%$ & $50 \%$ \\
\hline Customer requirements & $67 \%$ & $50 \%$ & $67 \%$ & $78 \%$ & $56 \%$ \\
\hline Customer Service & & $6 \%$ & $28 \%$ & $56 \%$ & $6 \%$ \\
\hline Defects/reworks/scrap & $50 \%$ & $67 \%$ & $44 \%$ & $6 \%$ & $6 \%$ \\
\hline Demand Forecasting & & & $11 \%$ & $11 \%$ & $6 \%$ \\
\hline Demand Management & & $33 \%$ & $28 \%$ & $6 \%$ & $17 \%$ \\
\hline Enterprise Policies & & $11 \%$ & $50 \%$ & $11 \%$ & $39 \%$ \\
\hline Inventory Management & $44 \%$ & $89 \%$ & $39 \%$ & $17 \%$ & $50 \%$ \\
\hline ISO & & & & & $44 \%$ \\
\hline KPI & $39 \%$ & $61 \%$ & $17 \%$ & $33 \%$ & $39 \%$ \\
\hline Lead Time & & $39 \%$ & $6 \%$ & $6 \%$ & \\
\hline Logistics & $39 \%$ & $22 \%$ & $56 \%$ & $67 \%$ & $67 \%$ \\
\hline Optimization processes & & & $33 \%$ & $6 \%$ & $6 \%$ \\
\hline Organization structure & & & $39 \%$ & $6 \%$ & \\
\hline Procedures & $33 \%$ & $44 \%$ & $78 \%$ & $33 \%$ & $33 \%$ \\
\hline Process Capability & & $50 \%$ & $17 \%$ & $39 \%$ & $61 \%$ \\
\hline Processes Synchronization & & & $6 \%$ & $22 \%$ & $67 \%$ \\
\hline Product & $78 \%$ & $39 \%$ & $17 \%$ & $11 \%$ & $22 \%$ \\
\hline Product Distribution & $11 \%$ & & & $50 \%$ & $6 \%$ \\
\hline Production & $83 \%$ & $44 \%$ & $33 \%$ & $61 \%$ & $28 \%$ \\
\hline Quality & $28 \%$ & $28 \%$ & & $39 \%$ & $17 \%$ \\
\hline Raw materials procurement & $28 \%$ & $56 \%$ & & $28 \%$ & $6 \%$ \\
\hline Response Time & $28 \%$ & $11 \%$ & $22 \%$ & $44 \%$ & $33 \%$ \\
\hline Shipping & & $72 \%$ & $78 \%$ & $67 \%$ \\
\hline Suppliers & & & & \\
\hline Warehousing & & & & \\
\hline
\end{tabular}


Table 8: Key Improvement Factor for each Maturity Level

\begin{tabular}{|l|l|}
\hline Maturity Level & \multicolumn{1}{|c|}{ Prioritized Key Improvement Factors } \\
\hline Undefined & $\begin{array}{l}\text { 1. Document Production processes; 2. Review the Catalog of Products; 3. Focus } \\
\text { on Customer requirements; 4. Focus on cost reduction; 5. Reduce defects / } \\
\text { reworks / scrap. }\end{array}$ \\
\hline Defined & $\begin{array}{l}\text { 1. Define Inventory management rules; 2. Reduce defects / reworks / scrap; 3. } \\
\text { Focus on Quality improvements; 4. Enterprise KPI's Definition; 5. Development } \\
\text { and Certification of suppliers; 6. Focus on Customer requirements; 7. Improve } \\
\text { process capability. }\end{array}$ \\
\hline Manageable & $\begin{array}{l}\text { 1. Development of procedures and control rules over all the enterprise processes; } \\
\text { 2. Focus on Quality improvements; 3. Focus on Customer requirements; 4. } \\
\text { Optimization of inbound and outbound logistics processes; 5. Evaluation and } \\
\text { actualization of the enterprise objectives, vision, mission; 6. Evaluation and } \\
\text { actualization of the enterprise policies. }\end{array}$ \\
\hline Collaborative & $\begin{array}{l}\text { 1. Focus on Customer requirements; 2. Focus on Quality improvements; 3. } \\
\text { Optimization of inbound and outbound logistics processes; 4. Analyze and } \\
\text { improve Production processes; 5. Focus on offering an outstanding customer } \\
\text { service; 6. Lead time and Response time reduction; 7. Product distribution } \\
\text { optimization. }\end{array}$ \\
\hline Leading & $\begin{array}{l}\text { 1. Optimization of inbound and outbound logistics processes; 2. Process } \\
\text { synchronization (production, sales, procurement etc); 3. Focus on Quality } \\
\text { improvements; 4. Improvement of the production process capability; 5. Focus on } \\
\text { Customer requirements; 6. Focus on cost reduction; 7. Review and Improve } \\
\text { Inventory management rules. }\end{array}$ \\
\hline
\end{tabular}

These findings were considered to design the second stage of the research. The main results obtained from this second stage are presented in the next two sections.

\subsection{QUALIFICATION OF THE EXPERTS FOR STAGE II}

Eighty experts were invited to participate in this research process. The sample size was increased in this stage due to the need to validate the maturity levels. Unfortunately, only seventy experts participated in the study. Similar to stage one, the seventy participants were selected from a list of personal contact information. All the experts had at least five years of experience on supply chain or a related area such as logistics, sales, 
or procurement. The average experience of the experts consulted was of twelve years. Table 9 shows the distribution of the years of experience of the participants in stage II.

Table 9: Experts' Years of Experience

\begin{tabular}{|c|c|c|}
\hline Years of Experience & Number of Experts & Percentage \\
\hline 5 to 9 & 29 & $41 \%$ \\
\hline 10 to 14 & 18 & $26 \%$ \\
\hline 15 to 20 & 10 & $14 \%$ \\
\hline 20 to 25 & 7 & $10 \%$ \\
\hline More than 25 & 6 & $9 \%$ \\
\hline Total & 70 & $100 \%$ \\
\hline
\end{tabular}

The increase in the size of the set of experts consulted allowed to include more types of businesses than in stage one. Since the $\mathrm{S}(\mathrm{CM})^{2}$ is a supply chain reference model, the more types of business represented, the more representative the sample was. Table 10 shows the type of businesses included in the Delphi study.

Table 10: Type of Business Represented in the Stage II

\begin{tabular}{|l|l|l|}
\hline Academy (4) & Construction (2) & Glass Industry (1) \\
\hline Air Condition Equipments (3) & Consultancy services (8) & Imports and Sales (1) \\
\hline Air Conditioning suppliers (2) & Customs (1) & Logistics Services (2) \\
\hline Automotive (3) & Electric Industry (2) & Newspapers (1) \\
\hline Beverages (9) & Electronic Equipments (1) & Pharmaceutical Research (1) \\
\hline Cement Industry (3) & Food Packing (1) & Plastic Products (2) \\
\hline Chemistry industry (1) & Food Products (6) & Purified Water (2) \\
\hline Clothes (1) & Footwear Industry (1) & Software Development (2) \\
\hline Computers (1) & Furniture (3) & Steel Industry (6) \\
\hline
\end{tabular}

Regarding their academic qualifications, all the experts hold at least a BA or a BS degree. The experts were related to the supply chain from different positions, such as 
logistics, processes engineering or production planning. Table 11 shows the position of the experts consulted.

Table 11: Positions Represented in Stage II

\begin{tabular}{|l|l|}
\hline CEO (13) & Production Manager (4) \\
\hline Consultant (7) & Professor (4) \\
\hline Distribution Manager (6) & Project Manager (2) \\
\hline Industrial Engineering Manager (1) & Quality Manager (1) \\
\hline Logistics Manager (9) & Regional Manager (3) \\
\hline Operations Manager (4) & Sales Manager (8) \\
\hline Planner Manager (1) & Service Manager (1) \\
\hline Procurement Manager (4) & Supply Chain Manager (1) \\
\hline Product Development (1) & \\
\hline
\end{tabular}

Observe that, the $64 \%$ of the positions represented $(45 / 70)$ are managers, who are the most probably users of this mete-model.

\subsection{SUMMARY OF THE RESULTS FOR STAGE II}

After defining the sample of experts to be consulted in the second stage, the experts received an invitation letter either by email or personally, which contained the explanation about the research and the role they played. The seventy participants answered the first and second rounds of the Delphi survey in this stage. The first round was focused on validating the definition of each maturity level and the supply chain definition used as a starting point for this second stage.

The supply chain maturity level definitions were built considering the characteristics described in Table 5, the improvement models proposed by Crosby in his Quality Maturity Grid, and Stevens in his Supply Chain Integration Model. Thus, the first maturity levels imply a poor knowledge about supply chain (undefined \& defined). The 
intermediate level is focused on transforming the attitude and understanding of the supply chain, such that the enterprise reaches an internal integration (Manageable). The final stages imply the understanding and recognition of management about the supply chain

processes as an essential part of the company's systems. Consequently, level four (Collaborative) represents the start of the external integration among suppliers, enterprise, and customers. Finally, level five (Leading) represents an enterprise, leader in the market, which is commonly used as benchmarking by its supply chain processes. Regarding the supply chain definition, it is not a main objective of this work, so only the relevant results regarding the maturity levels are reported in this document.

The second round of this stage was focused on collecting a set of tools, techniques, methodologies, or work philosophies useful to improve the supply chain processes from one level to the next one. The maturity level definitions, their respective validation results, and the set of tools collected for each level are shown together in the following subsections.

\subsubsection{Validation of the Maturity Level: Undefined}

The following definition for the Undefined level was sent to the experts:

Maturity Level: Undefined. This is an enterprise with no process documentation or standardization; there is lack of knowledge about the enterprise's processes, activities, and tasks; the enterprise primarily reacts to the environment instead of planning; the enterprise remains in the market by a small advantage on sale price, location, or customer relationship in comparison with the competition; there is no continuous improvement plan defined; all the improvements are reached by individual and isolated efforts; the 
productive processes are focused on completing the customer orders; however, they may experience frequent problems in meeting customers' expectations; the enterprise does not have a defined vision or mission.

The experts indicated their agreement level through a Likert scale, which was defined as: Strongly agree, moderately agree, neutral, moderately disagree, and strongly disagree. Due to the wide conceptualization of a supply chain discussed previously, the eighty percent of agreement is considered a minimum boundary for validation purposes. According to the Likert scale, the Strongly Agree and Moderately Agree options should accumulate at least $80 \%$ of the answers. Figure 21 shows the validation results for this level. Analyzing the results, the $47 \%$ of the answers were Strongly Agree and $40 \%$ of the answers were Moderately Agree, which implied an $87 \%$ of acceptance.

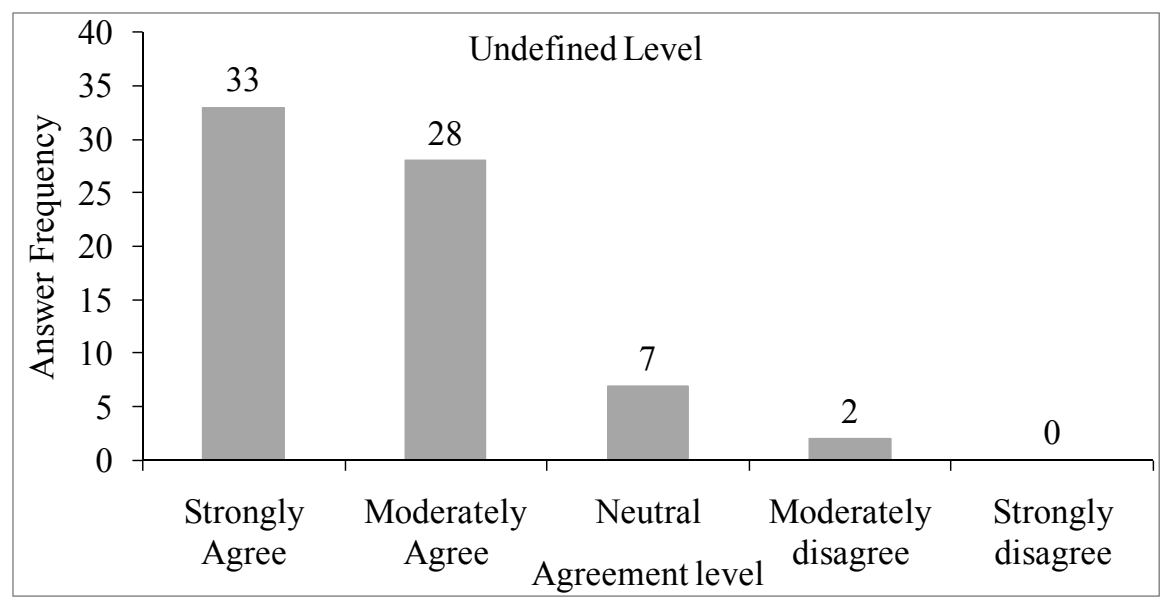

Figure 21: Acceptance of the Definition for the Undefined Level

\subsubsection{Set of Useful Improvement Tools for the Undefined Level}

Regarding the second round of results, the set of tools, methodologies, work philosophies, etc. recommended by the experts to improve processes from this maturity level to the Defined level were as follows: do Strategic Planning (mission, vision, 
company values...); do SWOT analysis; do flow, process, and operation diagrams; implement basic office tools (worksheets, text files etc...) useful to generate reports, store data, get information etc.; do customer interviews; deploy strategies to define KPI's: research in the literature and previous models, do Delphi benchmarking, focus groups etc.; document and standardize enterprise's models; apply 5's concepts; and use Internal logistics tools.

\subsubsection{Validation of the Maturity Level: Defined}

The following definition for the Defined level was sent to the experts:

Maturity Level: Defined. This is an enterprise which recognizes the value of defining its vision and mission; at this level the enterprise starts to consider the strategic market elements such as price fluctuations, new products, tendencies, etc; there is lack of documentation at all the enterprise levels; the enterprise has not defined a target market to which offer a wide catalog of products, even though many of the products imply losing money; the first attempts to develop customer loyalty and suppliers appear; the enterprise has basic and generic office software without specialized software for the industry or functions; the enterprise starts to collect data and use them to generate information useful to making decisions; there are no performance measurement systems; and the improvement efforts are still unorganized.

Figure 22 shows the validation results for this level. Analyzing the results, $39 \%$ of the answers were Strongly Agree and $46 \%$ of the answers were Moderately Agree, which implies an $84 \%$ of acceptance. 


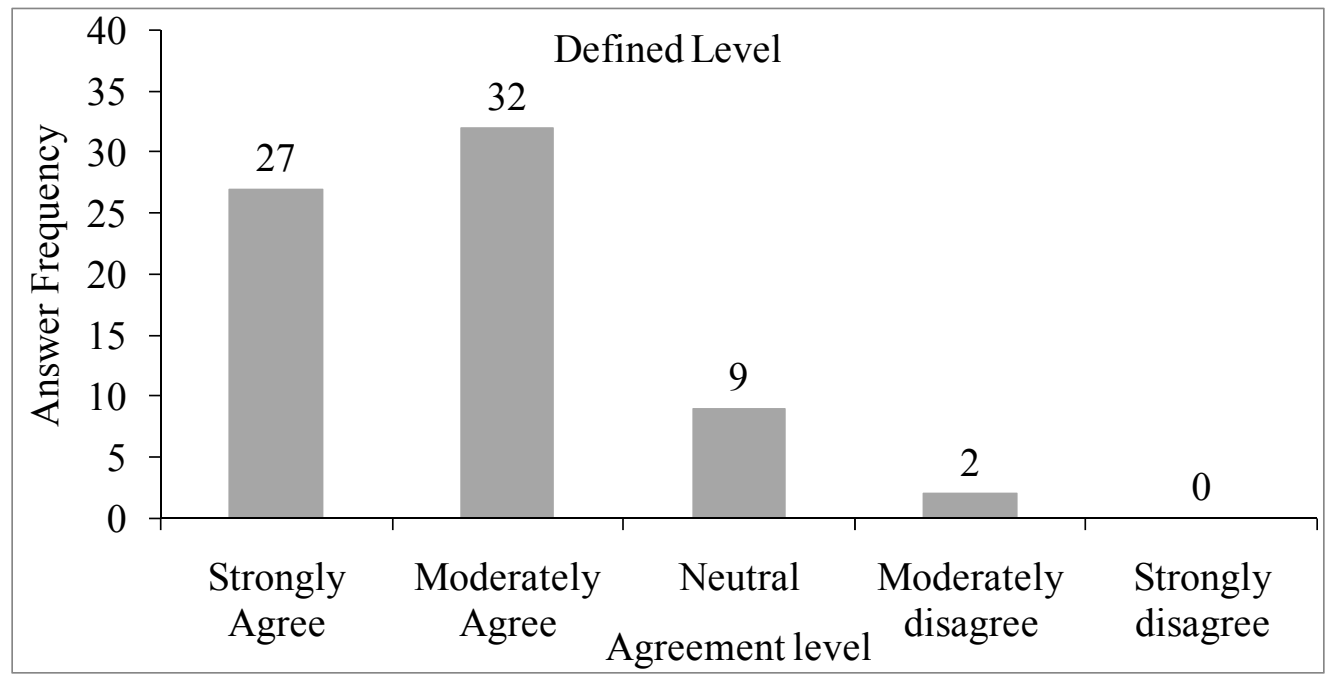

Figure 22: Acceptance of the Definition for the Defined Level

\subsubsection{Set of Useful Improvement Tools for the Defined Level}

Regarding the second round of results, the set of tools, methodologies, work philosophies, etc. recommended by the experts to improve processes form this maturity level to the Manageable level were as follows: define a target market; research on customer requirements; integrate internal processes; training personnel; do cost analysis; implement seven administrative tools; implement process control tools; optimize processes; improve the MRP technical support; improve basic technology systems; document the positions profile; implement warehouse management systems; and audit processes.

\subsubsection{Validation of the Maturity Level: Manageable}

The following definition for the Manageable level was sent to the experts:

Maturity Level: Manageable. The enterprise is searching a target market, the first attempt to integrate processes is made; the enterprise starts to deploy continuous 
improvement plans with special focus on process documentation and standardization; the personnel is induced to an organizational culture oriented to customer satisfaction and personal development; there are closer negotiations with suppliers regarding policies, times and costs; the improvement process applied a set of tools or techniques instead of a single one; there are isolated information systems useful to measure, control, and make decisions oriented to processes improvement.

Figure 23 shows the validation results for this level. Analyzing the results, $56 \%$ of the answers were Strongly Agree and $33 \%$ of the answers were Moderately Agree, which implies $89 \%$ of acceptance.

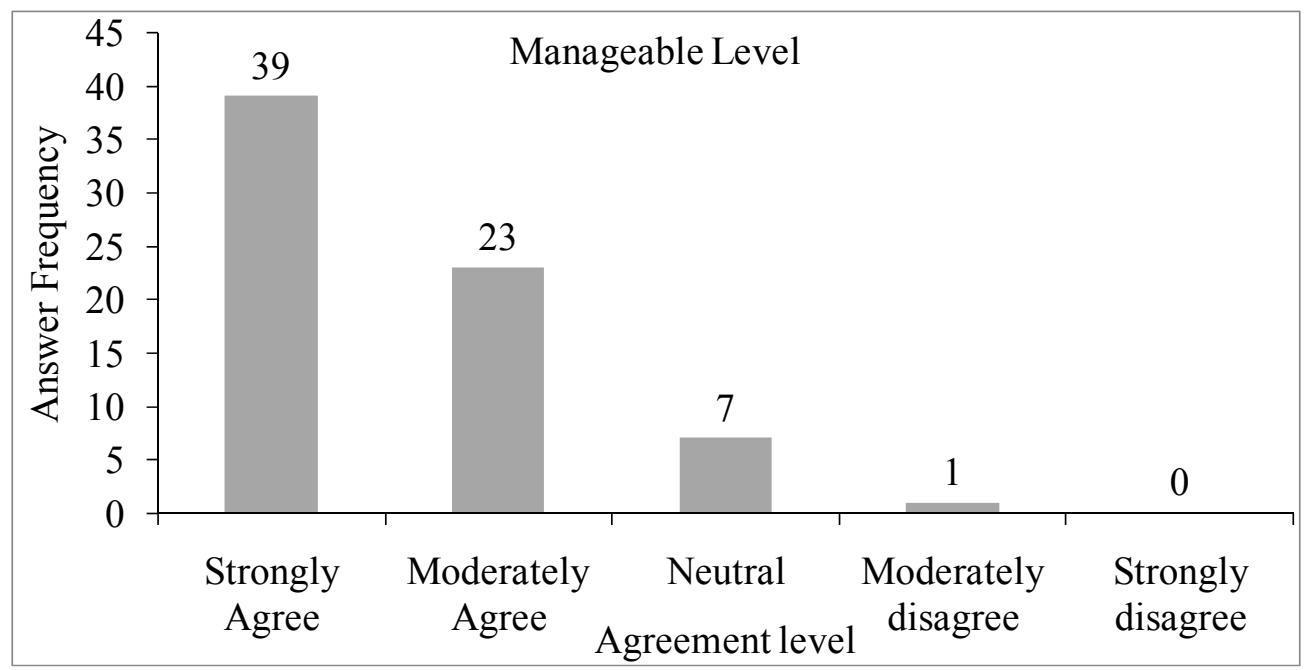

Figure 23: Acceptance of the Definition for the Manageable Level

\subsubsection{Set of Useful Improvement Tools for the Manageable Level}

Regarding the second round of results, the set of tools, methodologies, work philosophies, etc. recommended by the experts to improve processes form this maturity level to the Collaborative level were as follows: implement internal logistic tools such as 
Kanban, JIT concepts, Lean tools; Statistical Process Control, Statistical Analysis; classify source and outsource processes; use specialized software i.e. MRP, ERP, etc.; use process standardization tools such as flow diagrams, process documentation, auditing, etc.; obtain quality certifications and awards; make strategic alliances with suppliers and other enterprises; analyze customer satisfaction periodically; optimize tools such as Linear and Integer Programming; Analyze tools such as Simulation, Design of Experiments; deploy continuous improvement programs; implement Decision Support Systems; and provide training based on functions and skills required.

\subsubsection{Validation of the Maturity Level: Collaborative}

The following definition for the Collaborative level was sent to the experts:

Maturity Level: Collaborative. An enterprise at this level has defined collaboration strategies oriented to integrate customers and suppliers; there is clear orientation to satisfy the customer's expectations; there are several improvement processes related to the knowledge of customers' needs; there are integrated information systems, which provide a technological platform for data exchange among suppliers, company, and customers, generating key information about the market and the competence; there are several measurements and evaluation related to the supplier's performance; there is a better selection of suppliers; the enterprise uses more complex improvement processes due to the holistic project focus; there is in depth knowledge of all the enterprise's processes. Figure 24 shows the validation results for this level. Analyzing the results, $57 \%$ of the answers were Strongly Agree and $34 \%$ of the answers were Moderately Agree, which implies 91\% of acceptance. 


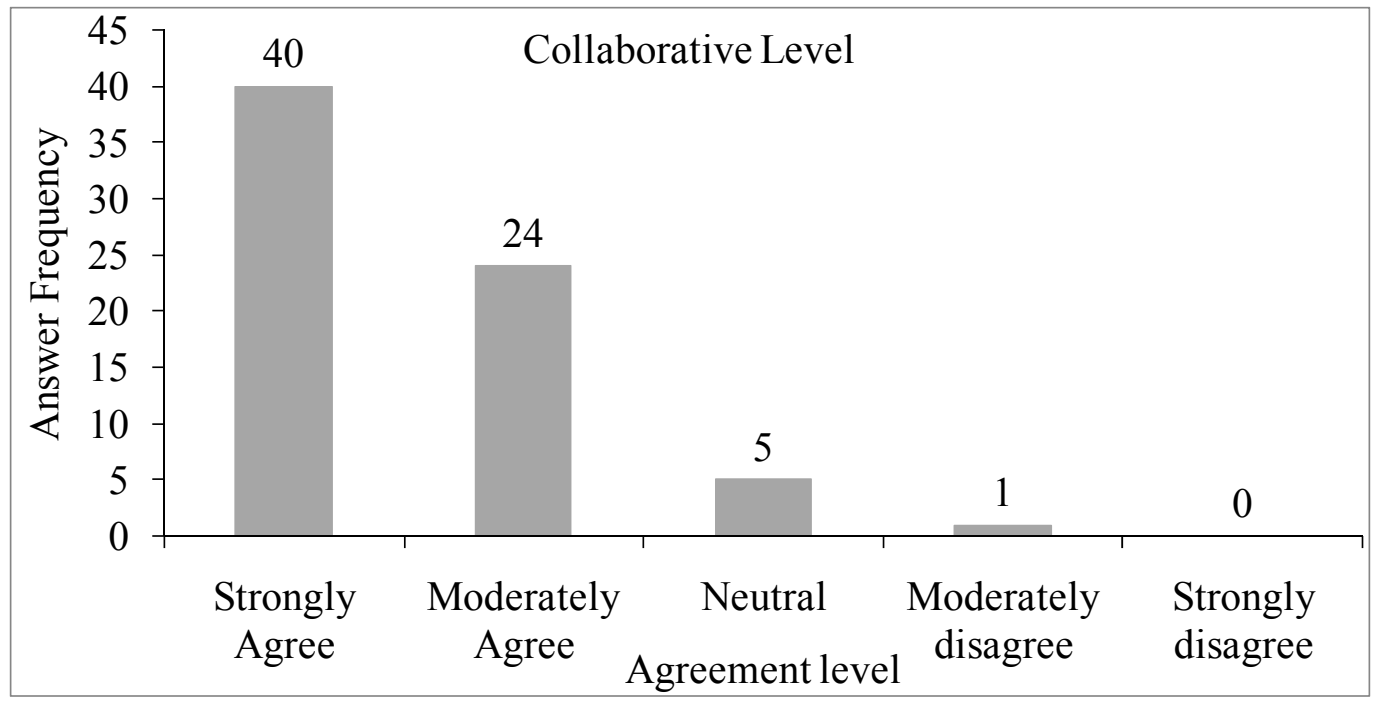

Figure 24: Acceptance of the Definition for the Collaborative Level

\subsubsection{Set of Useful Improvement Tools for the Collaborative Level}

Regarding the second round of results, the set of tools, methodologies, work philosophies, etc. recommended by the experts to improve processes form this maturity level to the Leading level were as follows: use Total Quality Management concepts; implement Supplier Relationship Management and Customer Relationship Management systems; integrate internal processes; provide personnel training and encourage commitment; optimize processes; Improve technological tools, automate processes; implement Warehousing Management Systems; obtain quality certifications and awards; manage daily work; use Hoshin Kanri method; implement lean thinking tools; implement decision support systems; use technology management strategies; use modeling tools such as systems thinking, relationship diagrams, dynamic modeling; implement concurrent engineering processes; optimize routing systems; and do value analysis. 


\subsubsection{Validation of the Maturity Level: Leading}

The following definition for the Leading level was sent to the experts:

Maturity Level: Leading: An enterprise in this maturity level will be able to innovate, develop, and transfer the best practices; this type of enterprises has a strong influence over suppliers and customers regarding their work culture and methods, information systems, continuous improvement processes etc; key processes and functions are aligned to the enterprise's mission and corporative strategy; the personnel is aware about the value that they add to the product with their activities, such that they are looking for more efficient and effective ways to do them. Information systems integrate suppliers, company, and customers' key information, which is available to everyone who needs it; there is a strong dependence of technological solutions.

Figure 25 shows the validation results for this level. Analyzing the results, $61 \%$ of the answers were Strongly Agree and $33 \%$ of the answers were Moderately Agree, which implies $94 \%$ of acceptance.

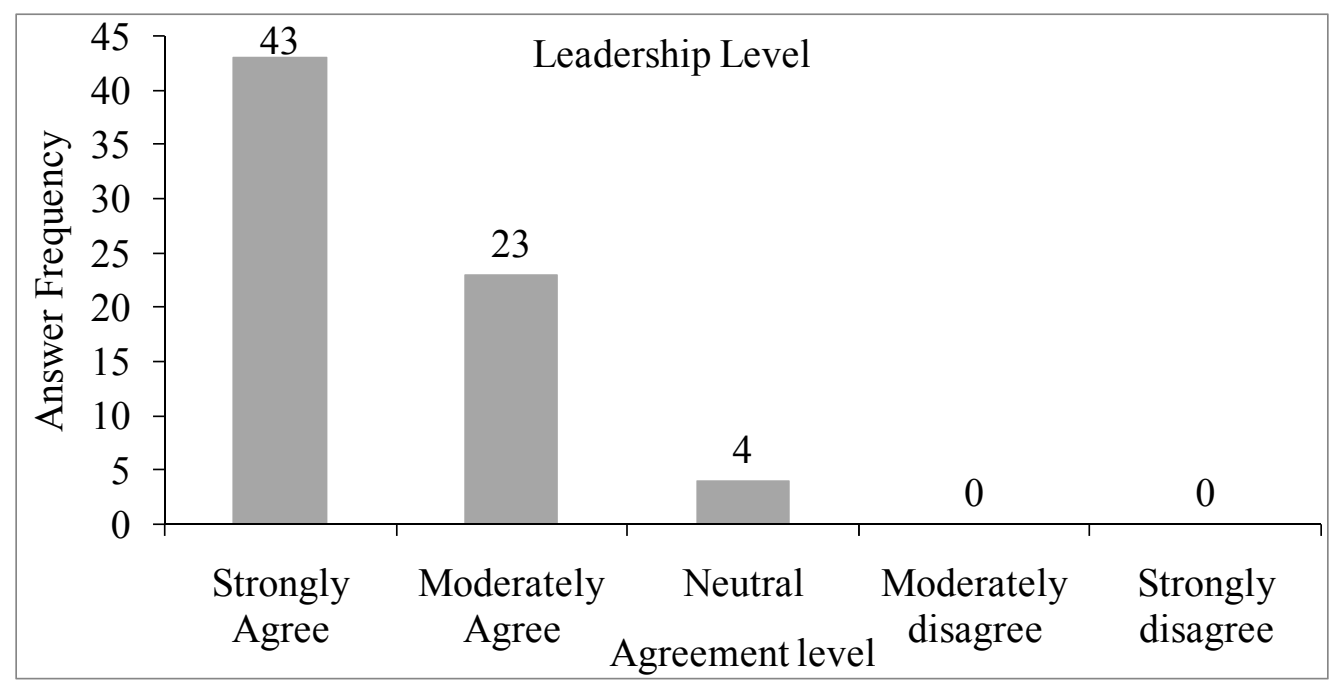

Figure 25: Acceptance of the Definition for the Leading Level 


\subsubsection{Set of Useful Improvement Tools for the Leading Level}

Regarding the second round of results, the set of tools, methodologies, work philosophies, etc. recommended by the experts to keep processes in this maturity level were as follows: share systems information in real time; optimize Processes; integrate internal processes; provide personnel training and encourage commitment; implement Warehousing Management Systems; integrate stakeholders; do focus groups with customers; implement TQM systems; apply innovation methodologies in the enterprise processes such as TRIZ, implement Design for Six Sigma, and QFD; use Hoshin Kanri method; implement Decision Support Systems; use rapid prototyping; implement computer integrated manufacturing and flexible manufacturing systems; and implement value engineering tools.

Summarizing the results the five maturity levels have at least $80 \%$ of acceptance to its definition. Thus it is possible to conclude that they have been are validated by the experts participating in the Delphi survey.

The following chapter describes how these results are used to integrate the final Supply Chain Capability Maturity Model. It also presents the verification and validation processes for this $\mathrm{S}(\mathrm{CM})^{2}$. 


\section{CHAPTER V}

\section{THE SUPPLY CHAIN CAPABILITY MATURITY MODEL}

The previous chapter described how the Delphi method was used to assess a supply chain from different perspectives in regards the maturity level taxonomy. Also, the answers obtained from the Delphi method allowed to collect a set of reference actions performed by enterprises to improve the supply chain, which described the characteristics of several supply chain elements from different points of view. The maturity level taxonomy and these reference actions are related among them, jointly represent a snapshot of a supply chain process through two different scopes. Additionally, a third element was the set of prioritized Key Improvement Factors for each maturity level, which provided information about key supply chain elements for each maturity level. Thus, this chapter describes how to integrate these three elements in a meta-model, the $\mathrm{S}(\mathrm{CM})^{2}$

\subsection{Definition OF THE VIEWS AND AbSTRACTION LEVELS IN THE S(CM) ${ }^{2}$}

Considering the findings obtained from the Delphi survey and based on the models described in Chapter 2, the information is integrated through a set of views and abstraction levels. The views collectively describe and clarify the complex activities of a supply chain system. The abstraction levels are the time perspectives for each view, which are used to determine the supply chain business activities through time, to meet the maturity level requirements. As a result of this arrangement, views and abstraction levels integrate a matrix of clearly differentiable supply chain elements. 
The views were defined through an analysis of the results obtained from the previous two stages. From the first stage, the whole set of characteristics provided by the experts to define a supply chain, and from the second stage, the maturity level definitions validated by the experts. After combining these two results in a database, the characteristic were grouped defining seven views.

1. Suppliers

2. Production Systems

3. Inventory

4. Customers

5. Human Resources

6. Information Systems \& Technology

7. Performance Measurement Systems

The definition of each view is the following:

1. Suppliers: This view contains functions, processes, activities, and tasks related to the integration, collaboration, and development of the suppliers. The reference actions include defining policies to select and develop suppliers; defining collaboration strategies with the suppliers; implementing quality assurance in the transportation and delivery of raw materials; making commercial agreements such as incoterms etc.

2. Production Systems: This view includes the functions, processes, activities, and tasks regarding the transformation of the product or service. In other words, the 
reference actions, which add value to the product or service, such as reduction of defects, scrap, and reworks; documentation and standardization of functions and processes; internal logistics issues; deployment of projects to reduce the lead time; implementation of production planning strategies etc.

3. Inventory: This view encloses all the reference actions related to the inventory management and control. Therefore, reference actions related the management and control of all kinds of inventories such as raw materials, finished goods, work in process, scrap, spare parts, etc. are included in this view.

4. Customers: The customers view includes all the reference actions in regards to meeting the customer's expectations. Consequently, some of the actions enclosed in this view are identifying the customer needs; attending the customers' complains; developing customers' loyalty to the company products and services; following up the sale after delivery; implementing projects to increase the perception of value in the products and services provided by the enterprise etc.

5. Human Resources: The Human Resources view contains the reference actions related to the enterprise's employees, their integration in the company and the work environment. Therefore, in this view are reference actions such as training; development of a work culture; implementing actions to reduce the employees' turnover; implementing projects to improve the enterprise's work conditions; development of rewarding strategies etc.

6. Information Systems \& Technology: This view encloses the reference actions directly linked to the development and implementation of information systems, 
and the technology management processes. Some of the actions included in the view are evaluating and implementing technological solutions such as ERP systems, RFID solutions, Warehousing Management Systems; automated equipments and so on; documenting and standardization of the data collection process; implementing projects to reduce the down times in the information systems and equipments of the enterprise etc.

7. Performance Measurement Systems: This view comprises the reference actions oriented to measure the enterprise's performance regarding processes, functions, and employees. Thus, some of the reference actions enclosed in this view are defining the enterprise KPI's; defining the periodicity of the information analysis concerning the performance of a process, function or employee; communicating to the employees the meaning of each performance indicator, and how to calculate it; standardize the use and presentation of the performance indicators and so on.

Regarding the abstraction levels, there are three common perspectives used to plan and analyze the supply chain business activities, these perspectives are namely operational, tactical, and strategic. According to several supply chain experts, these perspectives are required to develop the integration of a marketing channel, which is one of the main goals of this model (Svensson, 2002). The operational perspective considers those activities that should be done in a long time period, generally during more than one year. The tactical perspective considers an intermediate time horizon; generally less than one year. Finally, the operational perspective considers short-range activities, which should be done in hours or days (Ballou, 2004). The resulting matrix of integrated views and abstraction levels is shown in Figure 26. 


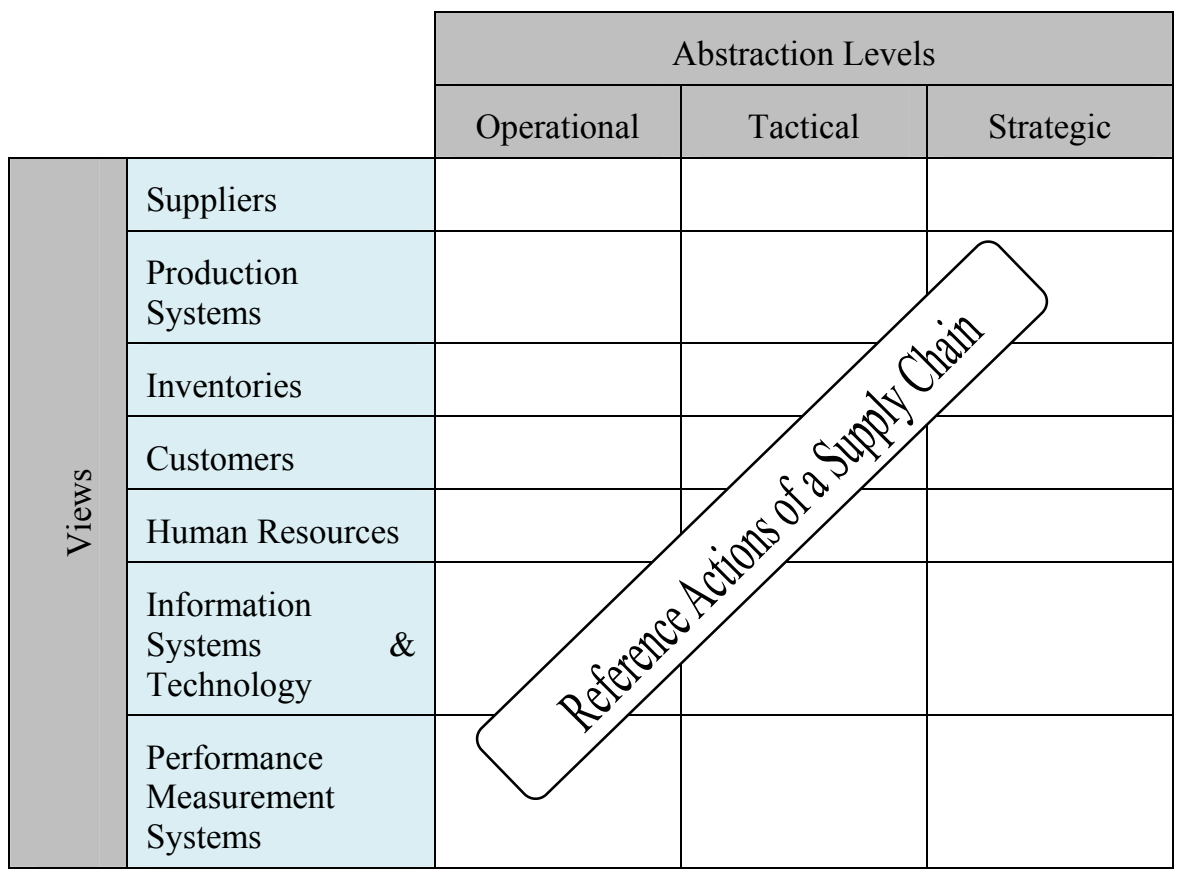

Figure 26: Views and Abstraction Levels for the $\mathrm{S}(\mathrm{CM})^{2}$

The next section describes how this matrix is integrated in the other supply chain models obtained in this research.

\subsection{THE INTEGRATION OF THE $\mathrm{S}(\mathrm{CM})^{2}$}

The matrix shown in Figure 26 encloses a set of reference actions in a supply chain. This set is grouped regarding seven views and three abstraction levels. These views and abstraction levels are independent of the maturity level description obtained in the research. However, each maturity level may include a matrix of supply chain reference actions. Thus, the $\mathrm{S}(\mathrm{CM})^{2}$ includes five supply chain reference action matrixes, one for each maturity level. Moreover, there are a set of improvement factors and a set of useful tools for each maturity level. Therefore, the models previously developed may be integrated in the meta-model. Figure 27 shows the final $\mathrm{S}(\mathrm{CM})^{2}$ framework. This framework includes the definition of the maturity level, the key improvement factors 
sorted by priority, the matrix of supply chain reference actions, and a set of useful tools to improve the supply chain, for the next maturity level to be reached.

\begin{tabular}{|c|c|c|c|c|c|c|c|}
\hline \multirow{2}{*}{\multicolumn{2}{|c|}{$\begin{array}{c}\text { Maturity } \\
\text { Level }\end{array}$}} & \multirow{2}{*}{$\begin{array}{c}\text { Key Improvement } \\
\text { Factor }\end{array}$} & \multirow{2}{*}{ View } & \multicolumn{3}{|c|}{ Abstraction Level } & \multirow{2}{*}{$\begin{array}{l}\text { Useful } \\
\text { Tools }\end{array}$} \\
\hline & & & & Operational & Tactical & Strategic & \\
\hline \multirow{5}{*}{$\begin{array}{c}\mathrm{L} \\
\mathrm{e} \\
\mathrm{v} \\
\mathrm{e} \\
1\end{array}$} & \multirow{5}{*}{ f } & & Suppliers & & & & \\
\hline & & & $\begin{array}{c}\text { Production } \\
\text { Systems }\end{array}$ & & & & \\
\hline & & & Inventory & & & & \\
\hline & & & Customers & & & & \\
\hline & & & $\begin{array}{c}\text { Human } \\
\text { Resources }\end{array}$ & & & & \\
\hline \multirow{2}{*}{$\begin{array}{c}\mathrm{n} \\
\mathrm{a} \\
\mathrm{m} \\
\mathrm{e}\end{array}$} & $\begin{array}{l}\mathrm{t} \\
\mathrm{i} \\
\mathrm{o}\end{array}$ & & $\begin{array}{l}\text { Information } \\
\text { Systems / } \\
\text { Technology }\end{array}$ & & & & \\
\hline & $\mathrm{n}$ & & $\begin{array}{l}\text { Performance } \\
\text { Measurement } \\
\text { System }\end{array}$ & & & & \\
\hline
\end{tabular}

Figure 27: The Supply Chain Capability Maturity Model Framework

\subsubsection{The $\mathrm{S}(\mathrm{CM})^{2}$ in a Tableau Form}

Populating this framework with the supply chain reference actions implies considering all the comments, answers, and feedback provided by the experts involved in the first and second stages. Even though this information is useful, it is not enough to fill out the whole meta-model. Therefore, some of the matrix cells should be completed with supply chain reference actions, according to the view, abstraction level, and maturity level which define the unfilled cells. An example of one maturity level of the $S(C M)^{2}$ is shown in Figure 28, which shows the operative and tactical abstraction levels and Figure 29 , which shows the strategic abstraction level and the useful tools. The complete metamodel is shown in Appendix 5. 


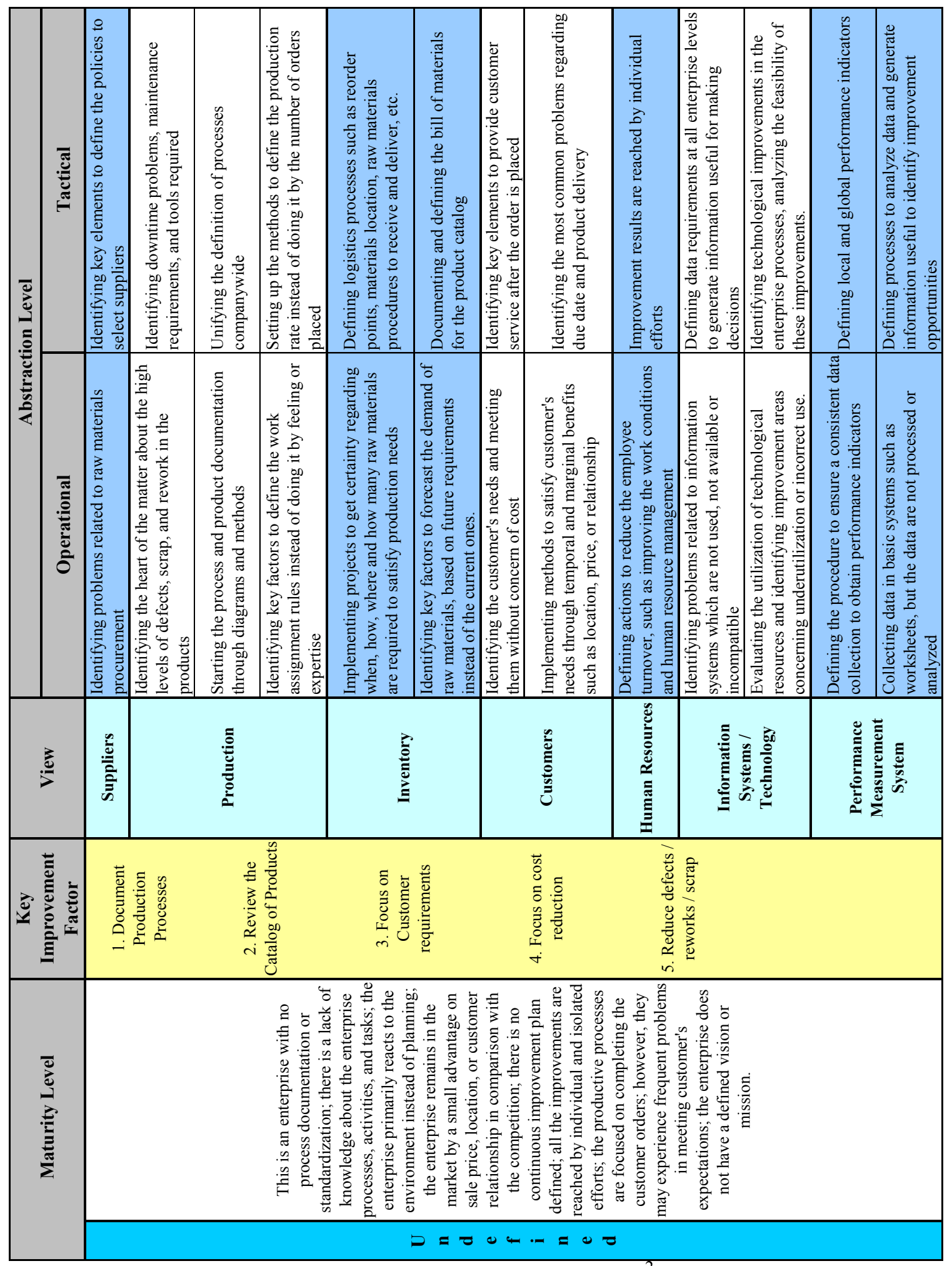

Figure 28: Example of a Maturity Level of $\mathrm{S}(\mathrm{CM})^{2}$ in Tabular Form 


\begin{tabular}{|c|c|c|c|c|c|c|c|c|c|c|}
\hline 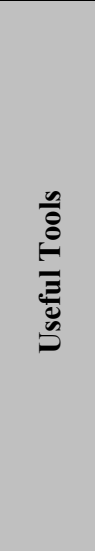 & 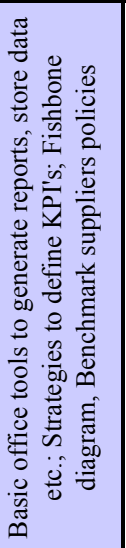 & \multicolumn{2}{|c|}{ 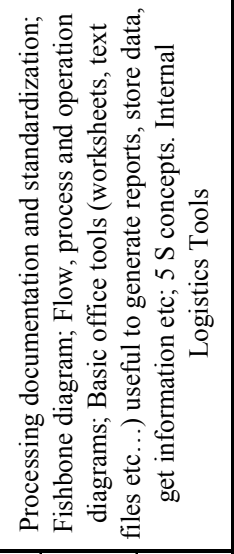 } & \multicolumn{2}{|c|}{ 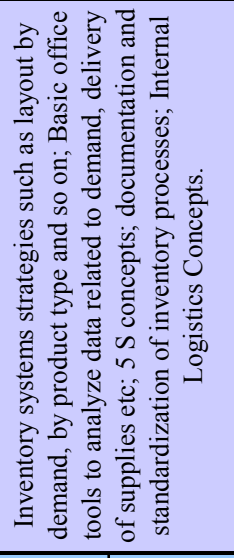 } & \multicolumn{2}{|c|}{ 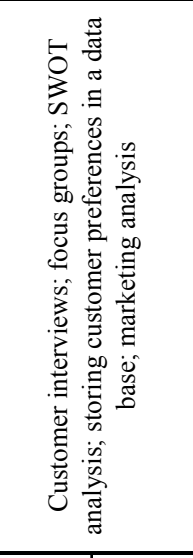 } & 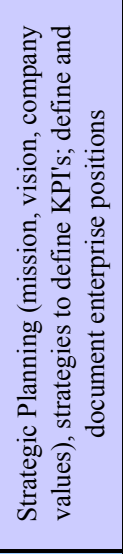 & 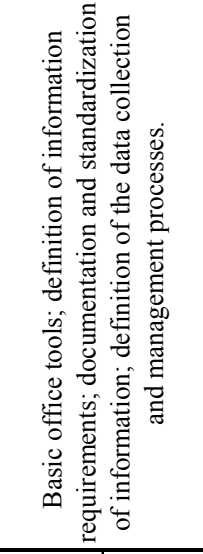 & 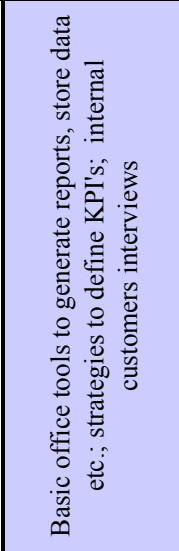 \\
\hline 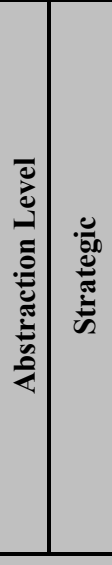 & 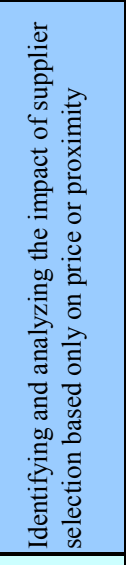 & 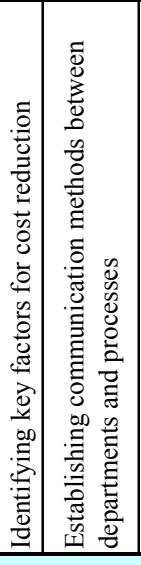 & 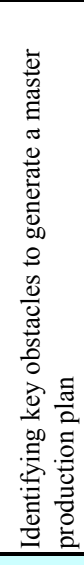 & 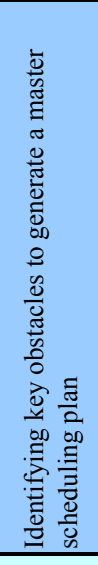 & 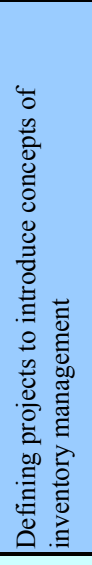 & 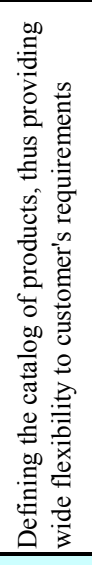 & 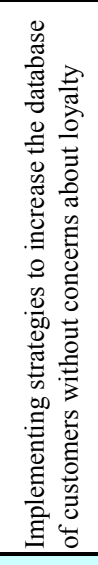 & 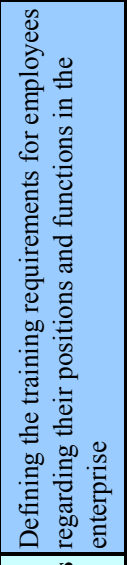 & 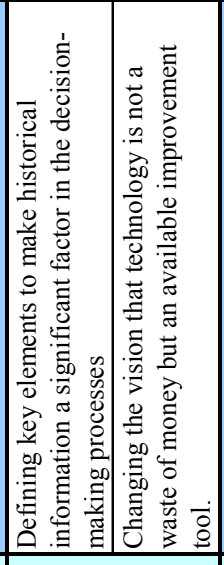 & 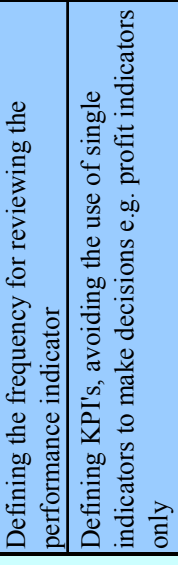 \\
\hline$\stackrel{0}{\frac{3}{2}}$ & 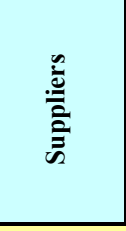 & \multicolumn{2}{|c|}{ 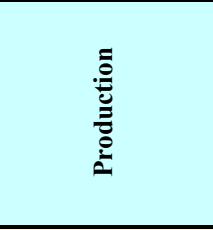 } & \multicolumn{2}{|c|}{ لِّ } & \multicolumn{2}{|c|}{ 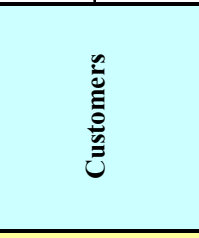 } & 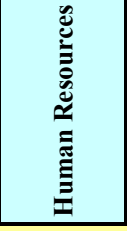 & 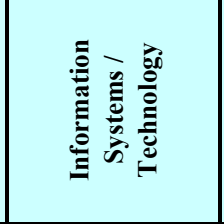 & 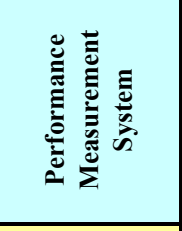 \\
\hline 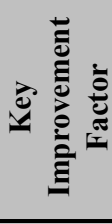 & 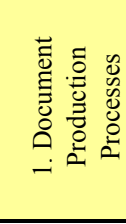 & & & \multicolumn{2}{|c|}{ 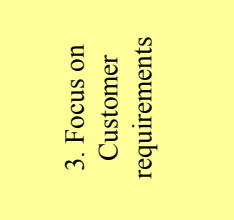 } & \multicolumn{4}{|c|}{ 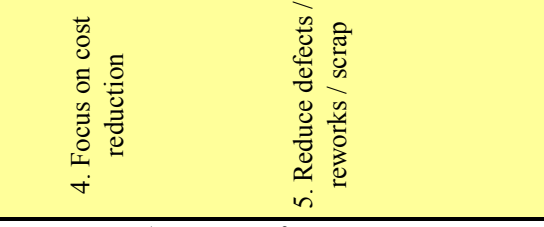 } & \\
\hline \multirow[t]{2}{*}{ 离 } & \multirow{2}{*}{\multicolumn{9}{|c|}{ 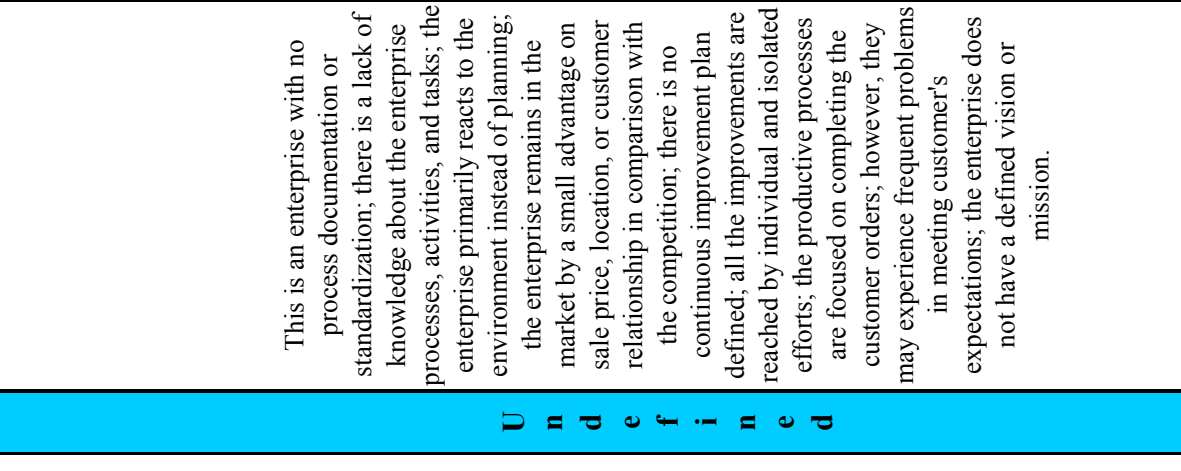 }} & \\
\hline & & & & & & & & & & \\
\hline
\end{tabular}

Figure 29: Example of a Maturity Level of $\mathrm{S}(\mathrm{CM})^{2}$ in Tabular Form (b) 


\subsubsection{The $\mathrm{S}(\mathrm{CM})^{2}$ in a graphical Form}

Similar to the reference architectures described in chapter 2 , the $\mathrm{S}(\mathrm{CM})^{2}$ may be represented in a $3 \mathrm{D}$ graphical way. The final $\mathrm{S}(\mathrm{CM})^{2}$ model is integrated by the maturity levels, representing the model life-cycle; the views of the model, identifying a particular point of view to analyze the supply chain; and the abstraction levels, representing a time frame into each maturity level. These complete a cube similar to the one presented by CIMOSA or GERAM. Additionally, a set of key elements to be improved in the supply chain, which are cross-disciplinary elements overlapping several views in the model; and finally a set of tools useful to reach the required improvement to advance to the next maturity level. Figure 30 shows the graphical representation of the $\mathrm{S}(\mathrm{CM})^{2}$.

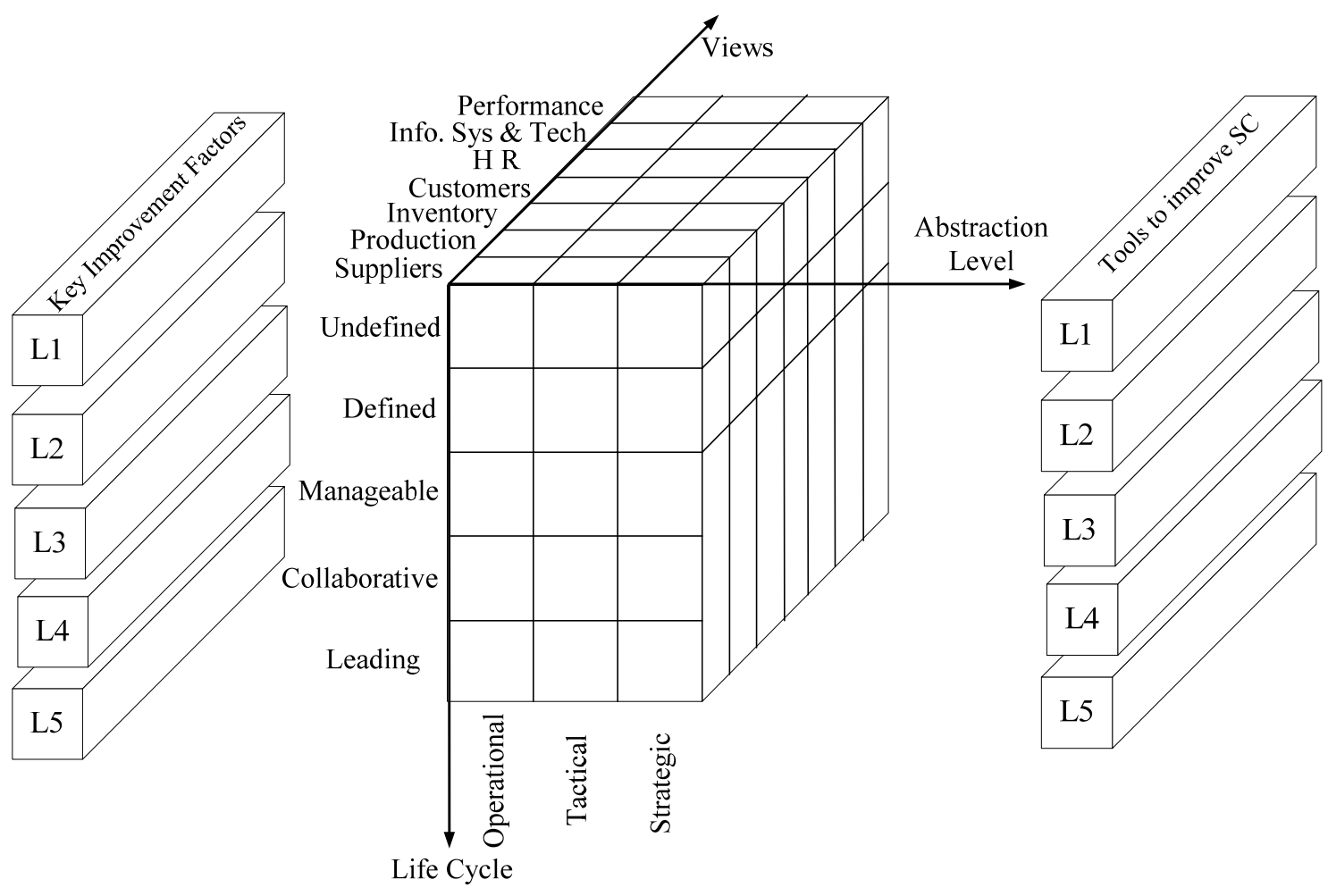

Figure 30: The Graphical Representation of the $\mathrm{S}(\mathrm{CM})^{2}$ 


\subsection{VERIFICATION OF THE S(CM) ${ }^{2}$}

The information shown in the last two sections presents the final meta-model, which mainly contains the results verified and validated by experts through the Delphi Method. Some of the reference actions were not verified or validated since the information collected from the experts was not enough to fill out all the cells in the model. Thus, it is necessary to verify and validate the final model. This section shows the verification process made by comparison with other reference models. The next section describes the final validation process.

Since the $\mathrm{S}(\mathrm{CM})^{2}$ intends to be a supply chain reference model, it is necessary to make a comparison with other reference models. In order to verify the final model, it has been compared with the GIM, CIMOSA and PERA models, which were previously discussed in Chapter 2. These three reference models have similar characteristics, which define the enterprise architecture such as objective, focus, views, abstraction levels or perspectives, and life-cycle. Table 12 shows a comparison among GIM, CIMOSA, PERA and $\mathrm{S}(\mathrm{CM})^{2}$.

Table 12: Comparison of Reference Models

\begin{tabular}{|c|c|c|c|c|}
\hline Element & GIM & CIMOSA & PERA & $\mathrm{S}(\mathrm{CM})^{2}$ \\
\hline Objective & $\begin{array}{l}\text { Analyzes the } \\
\text { current production } \\
\text { systems. This } \\
\text { diagnosis allows to } \\
\text { design alternative } \\
\text { system conceptions } \\
\text { and to support their } \\
\text { understanding }\end{array}$ & $\begin{array}{l}\text { Represents an } \\
\text { enterprise system } \\
\text { from a general to a } \\
\text { particular model } \\
\text { passing through } \\
\text { partial models for } \\
\text { every view }\end{array}$ & $\begin{array}{c}\text { Defines a } \\
\text { hierarchical } \\
\text { arrangement, such } \\
\text { that the } \\
\text { dependency on the } \\
\text { human } \\
\text { understanding, } \\
\text { judgment, and } \\
\text { decision making } \\
\text { required for a } \\
\text { success } \\
\text { implementation is } \\
\text { minimized }\end{array}$ & $\begin{array}{l}\text { Provides a cross- } \\
\text { disciplinary } \\
\text { perspective of an } \\
\text { enterprise's supply } \\
\text { chain performance }\end{array}$ \\
\hline
\end{tabular}




\begin{tabular}{|c|c|c|c|c|}
\hline Element & GIM & CIMOSA & PERA & $\mathrm{S}(\mathrm{CM})^{2}$ \\
\hline Focus & $\begin{array}{l}\text { Emphasizes the } \\
\text { organizational } \\
\text { structure of an } \\
\text { enterprise and the } \\
\text { associated } \\
\text { decisional system } \\
\text { of production } \\
\text { systems }\end{array}$ & $\begin{array}{c}\text { Facilitates the } \\
\text { description } \\
\text { modeling of an } \\
\text { enterprise operation } \\
\text { based on a process- } \\
\text { oriented modeling } \\
\text { approach }\end{array}$ & $\begin{array}{l}\text { Recognizes the } \\
\text { relevance of the } \\
\text { human judgment } \\
\text { and decision } \\
\text { making to merge } \\
\text { special } \\
\text { management } \\
\text { requirements, such } \\
\text { as innovation and } \\
\text { creativity into } \\
\text { design } \\
\end{array}$ & $\begin{array}{l}\text { Identifies } \\
\text { assessment } \\
\text { opportunities in } \\
\text { supply chain } \\
\text { processes, and } \\
\text { provides the tools } \\
\text { required to define } \\
\text { an enterprise's } \\
\text { improvement road } \\
\text { map }\end{array}$ \\
\hline Views & $\begin{array}{l}\text { Informational, } \\
\text { decisional, } \\
\text { physical, and } \\
\text { functional }\end{array}$ & $\begin{array}{l}\text { Function, } \\
\text { Information, } \\
\text { Resource, and } \\
\text { Organization }\end{array}$ & $\begin{array}{l}\text { Manufacturing, } \\
\text { Human and } \\
\text { Organizational, and } \\
\text { Information }\end{array}$ & $\begin{array}{c}\text { Suppliers, } \\
\text { Production } \\
\text { Systems, Inventory, } \\
\text { Customers, Human } \\
\text { Resources, } \\
\text { Information } \\
\text { Systems and } \\
\text { Technology, and } \\
\text { Performance } \\
\text { Measurement } \\
\text { Systems } \\
\end{array}$ \\
\hline $\begin{array}{l}\text { Abstraction } \\
\text { Levels }\end{array}$ & $\begin{array}{c}\text { Conceptual, } \\
\text { Structural, and } \\
\text { Realizational }\end{array}$ & $\begin{array}{l}\text { General Model, } \\
\text { Partial Model, and } \\
\text { Particular Model }\end{array}$ & Not Specified & $\begin{array}{l}\text { Operational, } \\
\text { Tactical, and } \\
\text { Strategic }\end{array}$ \\
\hline Life-cycle & $\begin{array}{l}\text { Analysis, Design, } \\
\text { and } \\
\text { Implementation }\end{array}$ & $\begin{array}{l}\text { Analysis, Design, } \\
\text { and } \\
\text { Implementation }\end{array}$ & $\begin{array}{l}\text { Identification, } \\
\text { Concept, } \\
\text { Definition, } \\
\text { Functional Design, } \\
\text { Detailed Design, } \\
\text { Construction, } \\
\text { Operation and } \\
\text { Maintenance, } \\
\text { Renovation or } \\
\text { Disposal, and Legal } \\
\text { Dissolution }\end{array}$ & $\begin{array}{c}\text { Undefined, } \\
\text { Defined, } \\
\text { Manageable, } \\
\text { Collaborative, and } \\
\text { Leading }\end{array}$ \\
\hline
\end{tabular}

Considering this table, the $\mathrm{S}(\mathrm{CM})^{2}$ meets the characteristics used for these reference models to describe an enterprise system or process. Even though GIM, CIMOSA, and PERA are reference models for other study fields, it is possible to conclude by similarity that the verification of the $\mathrm{S}(\mathrm{CM})^{2}$ is done regarding a reference model framework.

On the other hand, due to the particular application of the $\mathrm{S}(\mathrm{CM})^{2}$, it is necessary to make a comparison with some supply chain models or other models from a supply chain 
related field. Considering the supply chain models reviewed in Chapter 2, only the SCOR model is useful to make the comparison, since it is the only one defined as supply chain reference model.

However, SCOR does not offer a step-by-step procedure to improve the supply chain as the one presented in the $\mathrm{S}(\mathrm{CM})^{2}$ model. Also, according to the Supply Chain Council, SCOR does not include: Sales administration processes, technology development processes, product and process design and development processes, and some postdelivery technical support processes. Besides, SCOR assumes but does not explicitly address: training, quality, and information technology (IT) administration (non-SCM).

These elements are explicitly included in the $\mathrm{S}(\mathrm{CM})^{2}$ model. Moreover, the $\mathrm{S}(\mathrm{CM})^{2}$ includes the human resource element as a view, which is not considered as a key element in the SCOR model. Regarding similarities, SCOR defines five decision areas named Plan, Source, Make, Deliver, and Return, while the $\mathrm{S}(\mathrm{CM})^{2}$ represents these decision areas through the key improvement factors, views and the supply chain reference actions. The $\mathrm{S}(\mathrm{CM})^{2}$ explicitly includes reference actions concerning planning elements through the model (Plan); procurement and supplier collaboration (Source); production actions (Make); and inbound and outbound logistics optimization (Delivery and Return).

Searching for a model from a related supply chain field, there is a model from the value chain field. The value chain is defined as the enterprise's value system, which means the value system that creates the product's value to the customer (White and Pearson, 2001). Thus, the value chain definition overlaps with the supply chain of a company. A classic model from this field was developed by Porter (1985); he defined 
two kinds of activities in the value chain, primary activities (Inbound Logistics, Operations, Outbound Logistics, Marketing and Sales, and Service) and support activities (Procurement, Technology Development, Human Resource Management, and Firm Infrastructure). Figure 31 shows the model graphically.

\section{Procurement}

\section{Technology Development}

Human Resources Management

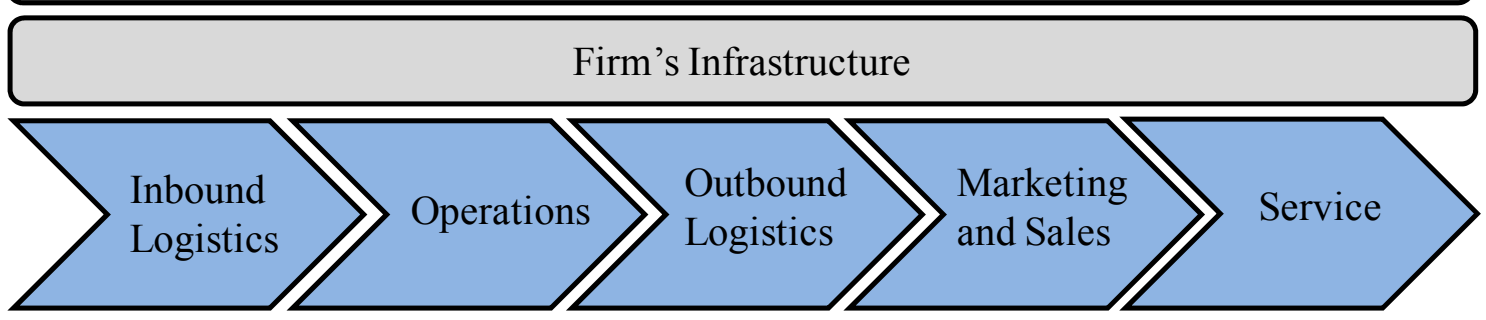

Figure 31: The Porter's Chain Value

Considering this model, Table 13 shows a comparison between Porter's chain value model and the $\mathrm{S}(\mathrm{CM})^{2}$. Considering this comparison, it is possible to argue that the verification process is complete, since the meta-model has the same elements than the reference models, and the activities defined by the SCOR and Porter's value chain models enclosed, at least partially or implicitly.

Table 13: Comparison Between Porter's Model and the S(CM) ${ }^{2}$

\begin{tabular}{|c|c|c|}
\hline Activity & Porter's Model & $\mathrm{S}(\mathrm{CM})^{2}$ \\
\hline $\begin{array}{l}\text { Inbound } \\
\text { Logistics }\end{array}$ & $\begin{array}{l}\text { Includes receiving, storing, inventory } \\
\text { control, and transportation scheduling. }\end{array}$ & $\begin{array}{l}\text { Covered in the views of suppliers and } \\
\text { Inventory. Implicitly included in the key } \\
\text { improvement factors Optimization of } \\
\text { Inbound and Outbound Logistics } \\
\text { Processes }\end{array}$ \\
\hline
\end{tabular}




\begin{tabular}{|c|c|c|}
\hline Activity & Porter's Model & $\mathrm{S}(\mathrm{CM})^{2}$ \\
\hline Operations & $\begin{array}{l}\text { Includes machining, packaging, } \\
\text { assembly, equipment maintenance, } \\
\text { testing and all other value-creating } \\
\text { activities that transform the inputs into } \\
\text { the final product. }\end{array}$ & Contained in the view Production \\
\hline $\begin{array}{l}\text { Outbound } \\
\text { Logistics }\end{array}$ & $\begin{array}{l}\text { The activities required to get the finished } \\
\text { product to the customers: warehousing, } \\
\text { order fulfillment, transportation, } \\
\text { distribution management. }\end{array}$ & $\begin{array}{l}\text { Covered in the view inventory, and the } \\
\text { key improvement factors of } \\
\text { Optimization of Inbound and Outbound } \\
\text { Logistics Processes }\end{array}$ \\
\hline $\begin{array}{l}\text { Marketing and } \\
\text { Sales }\end{array}$ & $\begin{array}{l}\text { The activities associated with getting } \\
\text { buyers to purchase the product including } \\
\text { channel selection, advertising, } \\
\text { promotion, selling, pricing, retailing, etc. }\end{array}$ & Covered in the view Customers \\
\hline Service & $\begin{array}{c}\text { The activities that maintain and enhance } \\
\text { the product's value, including customer's } \\
\text { support, repair services, installation, } \\
\text { training, spare parts management, } \\
\text { upgrading, etc. }\end{array}$ & Contained in the view Customers \\
\hline $\begin{array}{l}\text { Firm } \\
\text { Infrastructure }\end{array}$ & $\begin{array}{l}\text { Includes general management, planning } \\
\text { management, legal, finance, accounting, } \\
\text { public affairs, quality management, etc. }\end{array}$ & $\begin{array}{l}\text { Implicitly enclosed in the view } \\
\text { Performance Measurement Systems }\end{array}$ \\
\hline $\begin{array}{l}\text { Human } \\
\text { Resources } \\
\text { Management }\end{array}$ & $\begin{array}{c}\text { The activities associated with recruiting, } \\
\text { development (education), retention and } \\
\text { compensation of employees and } \\
\text { managers. }\end{array}$ & Enclosed in the view Human Resources \\
\hline $\begin{array}{l}\text { Technology } \\
\text { Development }\end{array}$ & $\begin{array}{l}\text { Includes technology development to } \\
\text { support the value chain activities, such } \\
\text { as Research and Development, Process } \\
\text { automation, design, redesign. }\end{array}$ & $\begin{array}{c}\text { Contained in the view Information } \\
\text { Systems \& Technology }\end{array}$ \\
\hline Procurement & $\begin{array}{l}\text { Procurement of raw materials, servicing, } \\
\text { spare parts, buildings, machines, etc. }\end{array}$ & Contained in the view Suppliers \\
\hline
\end{tabular}




\subsection{VALIDATION OF THE $\mathrm{S}(\mathrm{CM})^{2}$}

Concerning the validation of the $\mathrm{S}(\mathrm{CM})^{2}$, it is necessary to document that the $\mathrm{S}(\mathrm{CM})^{2}$ is suited for its intended use. Therefore, the validation process should to document that the $\mathrm{S}(\mathrm{CM})^{2}$ is useful to assess the enterprise's supply chain processes and to help the development process by to provide an improvement road map. This goal was meeting through two different validation processes. The first one includes a survey and a case study. The second one was a pilot test of the model in a real enterprise.

The survey had the objectives to validate the usefulness of the meta-model to assess the supply chain processes and to define an improvement road map. The case study has the objective to demonstrate the ability of the meta-model to help managers assess the supply chain processes of an enterprise by identifying the maturity level for each view. Finally, the pilot test provides a real try out for the $\mathrm{S}(\mathrm{CM})^{2}$, documenting the assess of the enterprise's supply chain and the road map obtained from the meta-model. The next two sections describe each one of these validations and show the results obtained.

\subsubsection{Experts' Validation of the $\mathrm{S}(\mathrm{CM})^{2}$}

The main objective of the meta-model proposed in this research is to provide a crossdisciplinary perspective of an enterprise's supply chain performance. Consequently, an enterprise may identify the assessment opportunities in supply chain processes, and may define an enterprise improvement road map. In order to validate this objective, a small group of experts was invited to validate the model. These experts were selected by their experience in the supply chain. For this case, the experts had at least ten years of experience in supply chain or a related field. 
The invitation was made to ten experts; each of them received an email containing three files. The first file was a Powerpoint presentation containing the invitation and the explanation of the model, the second file was the model itself, and the third file was a survey shown as a verification sheet, which included three questions to validate the model. Appendix 6 shows the validation sheet sent to the experts. Until the publishing time of this research four of them had answered the validation sheet. Table 14 shows the information related to the credentials of these four participants.

Table 14: Information of the Experts consulted to Validate the $\mathrm{S}(\mathrm{CM})^{2}$

\begin{tabular}{|c|c|c|c|c|}
\hline Participant & $\begin{array}{c}\text { Years of } \\
\text { Experience }\end{array}$ & Position & Business Type & $\begin{array}{c}\text { Academic } \\
\text { Credentials }\end{array}$ \\
\hline 1 & 15 & $\begin{array}{c}\text { President and CEO of a } \\
\text { consultancy group in } \\
\text { International Trade and } \\
\text { Transportation }\end{array}$ & Consultancy & $\begin{array}{c}\text { Master in } \\
\text { International } \\
\text { Law }\end{array}$ \\
\hline 2 & 14 & $\begin{array}{c}\text { Director of a Consultancy group } \\
\text { in Supply Chain and Logistics }\end{array}$ & Consultancy & $\begin{array}{c}\text { PhD in } \\
\text { Industrial } \\
\text { Engineering }\end{array}$ \\
\hline 3 & 11 & $\begin{array}{c}\text { Associate Professor and } \\
\text { Researcher in Supply Chain and } \\
\text { Logistics }\end{array}$ & Academic & $\begin{array}{c}\text { PhD in } \\
\text { Industrial } \\
\text { Engineering }\end{array}$ \\
\hline 4 & 10 & Planning Manager in an \\
automotive enterprise & Automotive & $\begin{array}{c}\text { BSc in } \\
\text { Industrial } \\
\text { Engineering }\end{array}$ \\
\hline
\end{tabular}

Concerning the questions included in the verification sheet, these were as follows:

Q.1 What advantages can you identify in the model?

Q.2 What improvement opportunities can you identify in the model? 
Q.3 This model was developed to assess the processes in a supply chain and to define an improvement road map. Do you consider this model meet the goals? Yes/No/Why?

Table 15 summarizes the results for each question

Table 15: Answers Obtained Through the Validation Sheet

\begin{tabular}{|c|c|}
\hline Question & Answers \\
\hline Advantages & $\begin{array}{l}\text { Provides a step by step improvement process } \\
\text { May be used by any size of company } \\
\text { Takes control of the improvement process since the beginning } \\
\text { Considers the customer needs even though the model is not based on the } \\
\text { customers } \\
\text { Provides a set of references to improve the supply chain processes, key } \\
\text { improvement factors, and useful tools } \\
\text { Helps to identify relevant projects associated to each maturity level } \\
\text { May be used by consultants and enterprises } \\
\text { Provides a straightforward model to improve the supply chain, since it is easy to } \\
\text { understand }\end{array}$ \\
\hline $\begin{array}{l}\text { Improvement } \\
\text { Opportunities }\end{array}$ & $\begin{array}{l}\text { The point of view of Finances is not clear enough } \\
\text { The Outbound Logistics should be more explicit in the model, maybe as a view } \\
\text { The model needs to increase its references to strategic concepts such as the } \\
\text { development of a distribution net, the use of transportation modes, Less than } \\
\text { Truckload (LTL), Truckload (TL), intermodal, and so on. } \\
\text { Consider including international trade constraints such as customs duties } \\
\text { Prioritize the useful tools or linked to each view and abstraction level } \\
\text { Increase the information about the tools and how to deploy them in the enterprise }\end{array}$ \\
\hline Meet the goals & $\begin{array}{l}\text { Yes, The model provides a clear set of reference actions, which are useful to } \\
\text { assess the supply chain processes. Moreover, the model is oriented to motivate } \\
\text { the human resources to excel themselves through creativity and innovation, first } \\
\text { of all internally in the enterprise and then externally as leaders in the market } \\
\text { Yes, because the model provides a reference, which helps to assess and improve } \\
\text { the supply chain processes } \\
\text { Yes, the model is useful to assess and improve the supply chain processes. } \\
\text { Yes, the model helps to assess the supply chain processes and define an } \\
\text { improvement path to reach the next maturity level. }\end{array}$ \\
\hline
\end{tabular}


Even though the model shows some improvement opportunities, the four experts agree that the $\mathrm{S}(\mathrm{CM})^{2}$ meets both goals, to assess the enterprise's supply chain processes and to define an improvement road map. Moreover, some of the advantages mentioned by the experts are key design objectives for the $\mathrm{S}(\mathrm{CM})^{2}$. For instance, provides a step by step improvement process and a model easy to understand, both characteristics allows to conclude the $\mathrm{S}(\mathrm{CM})^{2}$ contributes to the state of the art of supply chain modeling since other models do not offer a step by step improvement process or the models do not use an appropriate language for the supply chain. Regarding to the improvement opportunities, it was actually expected being this is the first version of the $\mathrm{S}(\mathrm{CM})^{2}$, these improvement can be explored with greater detail in future work.

\subsubsection{Case Study Results}

The case study was done to demonstrate the easiness of the $\mathrm{S}(\mathrm{CM})^{2}$ used as an assessment tool. To accomplish this goal, the validation instrument selected was a case study. The case study contains a brief explanation about the views and maturity levels of the model, the definition of the maturity levels, a set of instructions to answer the case study, the descriptions of the "as-is" states of two different fictitious enterprises named X and $\mathrm{Y}$, and a table of results.

The "as-is" state of each enterprise was built using randomly the reference actions defined in the $\mathrm{S}(\mathrm{CM})^{2}$ for each view. For example the description of the "as-is" state of enterprise $\mathrm{X}$ includes the following paragraph:

"The management has remarked the need to improve the customer service activities; thus, some improvements have been made to reach this objective, such that, it has 
established a customer service department to document the processes of the department, and to assign responsibilities to all the employees of the department"

Thus, it is possible to define an expected answer of the maturity level at each view, based on the maturity model. For instance Figure 32 shows the reference actions shown in the maturity level manageable at the customer view. The case study description is based on these reference actions, such that the expected answer in the customer view is manageable.

\begin{tabular}{|c|c|c|c|}
\hline \multirow{3}{*}{ Customers } & $\begin{array}{l}\text { Identifying the functions of a customer service } \\
\text { department or, at least, someone responsible } \\
\text { for customer relationships }\end{array}$ & $\begin{array}{l}\text { Defining the functions of a customer service } \\
\text { department or, at least, someone responsible } \\
\text { for customer relationships }\end{array}$ & $\begin{array}{l}\text { Establishing a customer service department or, } \\
\text { at least, making someone responsible for } \\
\text { customer relationships }\end{array}$ \\
\hline & $\begin{array}{l}\text { Deploying cross departmental efforts to reduce } \\
\text { costs and to assure quality }\end{array}$ & $\begin{array}{l}\text { Deploying actions to integrate the enterprise's } \\
\text { internal processes and to share information } \\
\text { about customer's behavior within the } \\
\text { enterprise's functions }\end{array}$ & $\begin{array}{l}\text { Collaborating in the implementation of } \\
\text { technological solutions to integrate } \\
\text { information, mainly in CRM solutions. }\end{array}$ \\
\hline & $\begin{array}{l}\text { Applying basic tools to improve the customer's } \\
\text { perception of value such as the fishbone } \\
\text { diagram, histograms, Pareto charts etc. }\end{array}$ & $\begin{array}{l}\text { Applying tools to improve customer product } \\
\text { and service satisfaction such as FMEA, } \\
\text { Kaizen, focus groups, etc }\end{array}$ & $\begin{array}{l}\text { Defining project to implement holistic } \\
\text { methodologies to increase the customers' } \\
\text { perception of value such as QFD, TQM, etc. }\end{array}$ \\
\hline
\end{tabular}

Figure 32: View Customer, Level Manageable

The tables of results collected from the participants have the classification they provided for each view, according to the maturity level description. Appendix 7 shows the format used in the case study and Table 16 shows the expected answer for each view for both, Enterprise X and Enterprise Y.

Table 16: Expected Answers for the Case Study

\begin{tabular}{|c|c|c|}
\hline View & Enterprise X & Enterprise Y \\
\hline Suppliers & Defined & Collaborative \\
\hline Production & Manageable & Defined \\
\hline Inventories & Undefined & Manageable \\
\hline Customers & Manageable & Defined \\
\hline Human Resources & Undefined & Collaborative \\
\hline Information Systems and Technology & Defined & Collaborative \\
\hline Performance Measurement Systems & Defined & Manageable \\
\hline
\end{tabular}


The participants did not require having experience in supply chain or to know the model, since the meta-model may be used by anyone interested in assess and improve the processes in a supply chain. Thus, the case study was sent by email to twenty-five possible participants. Regarding their activities, they are professors, master degree students, PhD students, bachelor in science students, and alumni. The number of responses received was fourteen.

In order to analyze the resulting data easily, each level was assigned a number as follows: Undefined-1, Defined-2, Manageable-3, Collaborative-4, and Leading-5. This arrangement allowed running statistical analysis such as mean hypothesis test. The hypotheses were defined as follows

Ho: The mean of the answers is equal to the expected answer value

Ha: The mean of the answers is different to the expected answer value

Assuming the answers come from a normal distribution with a mean equal to the reference number, the sample size equals $n$, and because there are less than thirty answers, the statistical estimator is a t-test for the mean as is shown in equation [1].

$$
\mathrm{t}=\frac{x-E(x)}{\frac{s}{\sqrt{\mathrm{n}}}}
$$

Regarding the statistical significance of the test $(\alpha)$, it was set to $5 \%$ such that Ho cannot be rejected if

$$
\mathrm{t}_{0.025,13} \leq \frac{x-E(x)}{\frac{s}{\sqrt{\mathrm{n}}}} \leq \mathrm{t}_{0.975,13}
$$


Thus, Table 17 shows the results obtained from the fourteen participants

Table 17: Results of the Case Study

\begin{tabular}{|c|c|c|c|c|c|c|c|c|c|c|c|c|c|c|}
\hline & \multicolumn{7}{|c|}{ Enterprise $\mathrm{X}$} & \multicolumn{7}{|c|}{ Enterprise $\mathrm{Y}$} \\
\hline Participant & $\mathrm{S}$ & $\bar{P}$ & $\bar{I}$ & $\mathrm{C}$ & HR & IS\&T & MS & $\mathrm{S}$ & $\mathrm{P}$ & I & $\mathrm{C}$ & HR & IS\&T & MS \\
\hline 1 & 2 & 3 & 1 & 3 & 1 & 2 & 1 & 5 & 2 & 4 & 1 & 5 & 5 & 3 \\
\hline 2 & 2 & 3 & 1 & 2 & 1 & 3 & 2 & 5 & 1 & 4 & 1 & 5 & 3 & 4 \\
\hline 3 & 4 & 4 & 2 & 2 & 2 & 2 & 2 & 4 & 3 & 3 & 3 & 5 & 4 & 3 \\
\hline 4 & 2 & 3 & 1 & 4 & 1 & 1 & 2 & 5 & 1 & 5 & 1 & 4 & 5 & 2 \\
\hline 5 & 2 & 3 & 1 & 2 & 1 & 2 & 2 & 3 & 2 & 3 & 2 & 4 & 3 & 2 \\
\hline 6 & 2 & 3 & 1 & 2 & 1 & 2 & 1 & 4 & 1 & 2 & 1 & 5 & 4 & 2 \\
\hline 7 & 2 & 3 & 1 & 2 & 1 & 2 & 2 & 4 & 2 & 4 & 2 & 4 & 4 & 2 \\
\hline 8 & 2 & 4 & 1 & 3 & 1 & 3 & 2 & 4 & 2 & 3 & 2 & 5 & 5 & 2 \\
\hline 9 & 2 & 2 & 1 & 3 & 1 & 2 & 1 & 4 & 2 & 3 & 1 & 3 & 4 & 3 \\
\hline 10 & 2 & 3 & 1 & 2 & 1 & 2 & 2 & 3 & 2 & 3 & 1 & 4 & 3 & 2 \\
\hline 11 & 2 & 4 & 1 & 2 & 1 & 2 & 2 & 5 & 2 & 3 & 2 & 4 & 4 & 3 \\
\hline 12 & 2 & 3 & 1 & 3 & 1 & 3 & 2 & 3 & 2 & 3 & 2 & 4 & 4 & 2 \\
\hline 13 & 3 & 4 & 1 & 2 & 1 & 3 & 2 & 4 & 1 & 4 & 2 & 4 & 5 & 4 \\
\hline 14 & 2 & 4 & 1 & 4 & 1 & 2 & 2 & 5 & 2 & 3 & 2 & 4 & 5 & 4 \\
\hline
\end{tabular}

\begin{tabular}{|c|c|c|c|c|c|c|c|c|c|c|c|c|c|c|}
\hline Avg & 2.21 & 3.29 & 1.07 & 2.57 & 1.07 & 2.21 & 1.79 & 4.14 & 1.79 & 3.36 & 1.64 & 4.29 & 4.14 & 2.71 \\
\hline std dev & 0.58 & 0.61 & 0.27 & 0.76 & 0.27 & 0.58 & 0.43 & 0.77 & 0.58 & 0.74 & 0.63 & 0.61 & 0.77 & 0.83 \\
\hline$\mu_{0}$ & 2 & 3 & 1 & 3 & 1 & 2 & 2 & 4 & 2 & 3 & 2 & 4 & 4 & 3 \\
\hline $\mathrm{t}=$ & 1.38 & 1.75 & 1.00 & -2.12 & 1.00 & 1.38 & -1.88 & 0.69 & -1.38 & 1.79 & -2.11 & 1.75 & 0.69 & -1.30 \\
\hline $\mathrm{t}_{0.025,13}=$ & 2.16 & 2.16 & 2.16 & 2.16 & 2.16 & 2.16 & 2.16 & 2.16 & 2.16 & 2.16 & 2.16 & 2.16 & 2.16 & 2.16 \\
\hline Result & OK & OK & OK & OK & OK & OK & OK & OK & OK & OK & OK & OK & OK & OK \\
\hline
\end{tabular}

Considering the results, it is possible to argue that the easiness of classifying the model views and reference actions was validated, since the average of the answers obtained is statistically equal to the expected average value $\mu_{0}$. Moreover, there is a key finding from this validation process related to the relevance of providing an assessment methodology, which shows step by step how to use the $\mathrm{S}(\mathrm{CM})^{2}$ to assess and improve the supply chain processes in the enterprise. This argument comes from the distribution of answers obtained from the case study, which showed how many answers were the same as the reference values. Table 18 shows these distributions. 
Table 18: Distribution of the Case Study Answers

\begin{tabular}{|c|c|c|c|c|c|c|c|c|c|c|c|c|c|c|}
\cline { 2 - 16 } \multicolumn{1}{c|}{} & \multicolumn{9}{c|}{ Enterprise X } & \multicolumn{8}{c|}{ Enterprise Y } \\
\hline Level & S & P & \multicolumn{1}{c|}{ I } & HR & IS\&T & MS & S & P & I & \multicolumn{1}{c|}{ HR IS\&T MS } \\
\hline 1 & & & $93 \%$ & & $93 \%$ & $7 \%$ & $21 \%$ & & $29 \%$ & & $43 \%$ & & & \\
\hline 2 & $86 \%$ & $7 \%$ & $7 \%$ & $57 \%$ & $7 \%$ & $64 \%$ & $79 \%$ & & $64 \%$ & $7 \%$ & $50 \%$ & & & $50 \%$ \\
\hline 3 & $7 \%$ & $57 \%$ & & $29 \%$ & & $29 \%$ & & $21 \%$ & $7 \%$ & $57 \%$ & $7 \%$ & $7 \%$ & $21 \%$ & $29 \%$ \\
\hline 4 & $7 \%$ & $36 \%$ & & $14 \%$ & & & & $43 \%$ & & $29 \%$ & & $57 \%$ & $43 \%$ & $21 \%$ \\
\hline 5 & & & & & & & & $36 \%$ & & $7 \%$ & & $36 \%$ & $36 \%$ & \\
\hline Ref & 2 & 3 & 1 & 3 & 1 & 2 & 2 & 4 & 2 & 3 & 2 & 4 & 4 & 3 \\
\hline
\end{tabular}

Analyzing Table 18, it is possible to see that only the view customer of Enterprise X has a mode different from the reference value. This fact is minimized since the mode of the customers view is the immediate lower level, implying an improvement road map starting from a lower point, and eventually, enclosing improvement processes until the third maturity level.

On the other hand, for the Production and the Information Systems \& Technology views in the Enterprise $\mathrm{X}$ description, and for the all the views, except Customers, in the Enterprise Y description, at least four participants classified the view in a higher maturity level. A possible explanation for these results was lack of information and training received by the participants before answering the case study. The case study only considered the definitions of the maturity levels, and some of the reference actions instead of the whole set of reference actions, which helped to classify the views more accurately.

\subsection{The Pilot Test of The S(CM) ${ }^{2}$}

The final validation process was assessing a real enterprise's supply chain. The assessment process requires completing a questionnaire shown from Table 19 to 25 . This questionnaire helps managers to obtain the maturity level classification for each view in 
the $\mathrm{S}(\mathrm{CM})^{2}$, since the questions was developed based in the reference actions of the model. Thus, the questionnaire has seven sets of questions; one set by view, this arrangement was based on the assessment tool used by the CMMI. Also, each question was numbered according to the maturity level for each view. The possible answers for each question are "yes" or "no". In case the answer will be yes the enterprise should document the evidence which support the affirmative answer. A negative answer in one of the level questions implies an improvement opportunity such that the expected level characteristics are not meet. Thus, the enterprise receives a maturity classification of the last level completed. This classification allows to define an improvement road map based in the reference actions and the tools recommended in the model. Once the level is complete the enterprise may continue improving its processes from this maturity level to the next level up to reach the leading maturity level.

In order to perform the assessment, an enterprise's manager was selected from a contact list. Regarding the enterprise's information, it is as follows.

Business type: Metallic Stamping and Sheet Metal

Contact position: Operations Manager

Number of years in the current position: 5 years

Number of years in the enterprise: 9 years

The following set of questions shown in Table 19 was used to assess the enterprise's supply chain processes according to the suppliers view. By confidential purposes, the name of the enterprise and the evidences documented were omitted. 
Table 19: Assessment Questionnaire for the view Suppliers

\begin{tabular}{|c|c|c|c|c|}
\hline Level & & Questions & $\begin{array}{l}\text { Answer } \\
\text { (Yes/No) }\end{array}$ & Evidence \\
\hline Undefined & $\begin{array}{l}\text { S.1 } \\
\text { S.2 }\end{array}$ & $\begin{array}{l}\text { The main problems related to the supply of raw } \\
\text { materials and consumables are identified and } \\
\text { documented. } \\
\text { There are improvement projects oriented to solve the } \\
\text { problems identified in the last question. }\end{array}$ & Yes & \\
\hline Defined & $\begin{array}{l}\text { S.3 } \\
\text { S.4 } \\
\text { S.5 }\end{array}$ & $\begin{array}{l}\text { There are processes documented and implemented to } \\
\text { assess the quality of the raw materials and } \\
\text { consumables. } \\
\text { There are policies documented and implemented to add } \\
\text { a new supplier to the enterprise's suppliers catalog. } \\
\text { There are meetings periodically with the suppliers to } \\
\text { evaluate and to provide feedback related to their } \\
\text { service level. }\end{array}$ & $\begin{array}{l}\text { Yes } \\
\text { Yes }\end{array}$ & \\
\hline Manageable & $\begin{array}{l}\text { S.6 } \\
\text { S.7 } \\
\text { S.8 } \\
\text { S.9 }\end{array}$ & $\begin{array}{l}\text { There are processes documented and implemented to } \\
\text { assess the suppliers' service level. } \\
\text { There are processes which collect data and provide } \\
\text { statistical information related to the delivery time and } \\
\text { order completion of every supplier. } \\
\text { There are projects jointly with the supplier to develop } \\
\text { and to integrate them in the enterprise's supply chain } \\
\text { processes. } \\
\text { There are policies documented and implemented to } \\
\text { select and to hire outsource services (3rd Party } \\
\text { Logistics, 4th Party Logistics). }\end{array}$ & $\begin{array}{l}\text { Yes } \\
\text { Yes }\end{array}$ & \\
\hline Collaborative & $\begin{array}{l}\text { S.10 } \\
\text { S.11 } \\
\text { S.12 } \\
\text { S.13 }\end{array}$ & $\begin{array}{l}\text { There are procedures documented and implemented to } \\
\text { determine the level of collaboration and integration } \\
\text { among the suppliers and the enterprise's processes. } \\
\text { There are procedures documented and implemented to } \\
\text { determine if it is worth to invest in developing a } \\
\text { supplier. } \\
\text { There are procedures documented and implemented to } \\
\text { develop the suppliers' service level and the } \\
\text { collaboration. } \\
\text { There are procedures documented and implemented to } \\
\text { certify new suppliers and to renew the certification to } \\
\text { current suppliers. }\end{array}$ & Yes & \\
\hline Leading & $\begin{array}{l}\text { S.14 } \\
\text { S.15 } \\
\text { S.16 } \\
\text { S.17 }\end{array}$ & $\begin{array}{l}\text { There are procedures documented and implemented to } \\
\text { deploy projects jointly with the suppliers to develop } \\
\text { new products. } \\
\text { There are procedures documented and implemented to } \\
\text { aware the suppliers in advance about any change in the } \\
\text { raw materials and consumables for the new or current } \\
\text { products. } \\
\text { There are documented and implemented best practices } \\
\text { related to collaboration and selection of suppliers. } \\
\text { There had been Benchmarks studies about the } \\
\text { collaboration and supplier selection processes } \\
\text { developed by the enterprise. }\end{array}$ & Yes & \\
\hline
\end{tabular}


Based in the results obtained, the maturity level of this enterprise for the view supplier is Defined. Thus, this enterprise should take the reference actions described for the view suppliers in the level manageable as starting point to define its improvement path. The improvement projects should be focus in those questions with negative answers. In this case, this enterprise should work jointly with the supplier to develop and to integrate their processes to the enterprise's supply chain processes, also to develop, document and implement policies to select and to hire outsource services. Considering the useful tools suggested by the $\mathrm{S}(\mathrm{CM})^{2}$, some possible solutions implies integrates the suppliers processes through a MRP system and to define collaboration agreements with other enterprises, in this case outsourcing enterprises.

Even though the maturity level classification obtained was defined, there is evidence, according to the answers obtained from the questionnaire that the enterprise shows advance in the next maturity levels. This advance may be represented by a color convention implying the improvement urgency, due to an enterprise process which has not complete at least the defined level represent a poor development levels one and two are identified by a red color. Similarly the intermediate levels Manageable and Collaborative by a yellow color and the Leading maturity level by a green color. Thus, the negative answers are identified using these color convention. For instance, the questions S.8, S.9, S.10, S.11, and S.12 will be marked using the color yellow because they assess the levels manageable and collaborative, while the questions S.14 and S.17 will be marked using the color green because they assess the maturity level leading. 
Thus, Figure 33 shows the resulting graph for the suppliers view. Each axis represents the result of the assessment using the following abbreviation.
S: Suppliers
P: Production
I: Inventories
C: Customer
H: Human Resources
T: Info. Systems \& Technology

M: Performance Measurement Systems

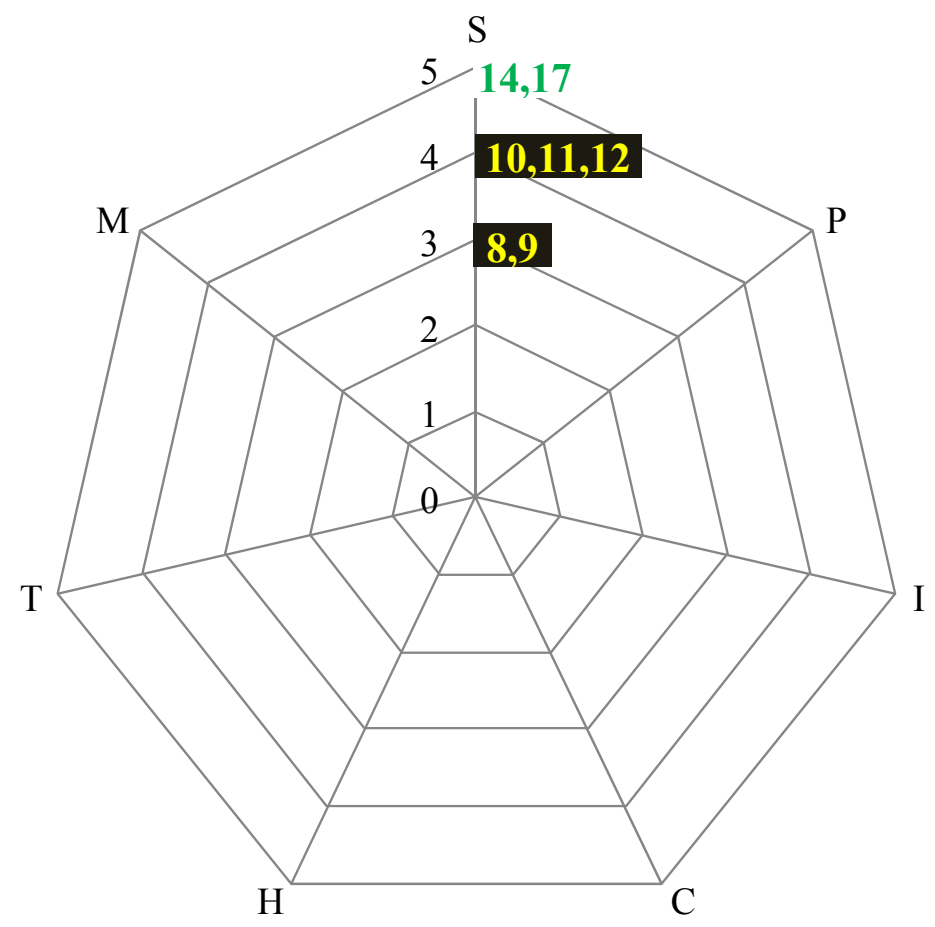

Figure 33: Radar Graph for the View Suppliers

Tables 20 to 25 show the results for the other views assessment. Also after each table there is an example of improvement roadmap for each view. 
Table 20: Assessment Questionnaire for the view Production

\begin{tabular}{|c|c|c|c|c|}
\hline Level & & Questions & $\begin{array}{l}\text { Answer } \\
\text { (Yes/No) }\end{array}$ & Evidence \\
\hline Undefined & $\begin{array}{l}\text { P.1 } \\
\text { P.2 } \\
\text { P.3 } \\
\text { P. } 4 \\
\text { P.6 }\end{array}$ & $\begin{array}{l}\text { The main problems related to scrap, defect and } \\
\text { reworks are documented and identified. } \\
\text { There are documents and diagrams which describe in } \\
\text { detail the enterprise's productive processes such as } \\
\text { flow diagrams, product flow diagram, operation } \\
\text { diagram, assembly diagrams and so on. } \\
\text { The documents and diagrams provided as evidence in } \\
\text { the last question are known and used by anyone who } \\
\text { needs them. } \\
\text { The main problems related to the processes downtimes } \\
\text { and failures due to the lack of maintenance are } \\
\text { identified and documented. } \\
\text { There are documented and implemented joint projects } \\
\text { with other departments inside the enterprise. } \\
\text { The productive operations and the procedure to assign } \\
\text { tasks are standardized. }\end{array}$ & $\begin{array}{l}\text { Yes } \\
\text { Yes } \\
\text { Yes } \\
\text { Yes } \\
\text { Yes } \\
\text { Yes }\end{array}$ & \\
\hline Defined & $\begin{array}{l}\text { P.7 } \\
\text { P.8 } \\
\text { P.9 } \\
\text { P.10 } \\
\text { P.11 }\end{array}$ & $\begin{array}{l}\text { There are documented and implemented improvement } \\
\text { programs focusing on the reduction of scrap, defects } \\
\text { and reworks in the enterprise's productive processes. } \\
\text { There are documented and implemented processes to } \\
\text { determine the delivery time for the products and } \\
\text { services offered by the enterprise. } \\
\text { There are cross-disciplinary improvement programs } \\
\text { oriented to reduce the delivery time of the product and } \\
\text { services offered by the enterprise. } \\
\text { There is a documented and implemented procedure to } \\
\text { make a master production plan. } \\
\text { There are documented and implemented procedures to } \\
\text { assign tasks to the employees. } \\
\text { There is a defined maintenance program in the } \\
\text { enterprise. }\end{array}$ & $\begin{array}{l}\text { Yes } \\
\text { Yes } \\
\text { Yes } \\
\text { Yes } \\
\text { Yes } \\
\text { Yes }\end{array}$ & \\
\hline Manageable & $\begin{array}{l}\text { P.14 } \\
\text { P.15 } \\
\text { P.16 } \\
\text { P.17 } \\
\text { P.18 }\end{array}$ & $\begin{array}{l}\text { There are documented and implemented quality } \\
\text { assurance processes for all the products and services } \\
\text { offered by the enterprise. } \\
\text { There are periodical meetings with other departments } \\
\text { to work jointly in the improvement of the enterprise's } \\
\text { production processes. } \\
\text { There are taskforces oriented to the implementation of } \\
\text { modern production techniques and methodologies, } \\
\text { such as MRPII, JIT, manufacturing flex systems, lean } \\
\text { manufacturing, etc. } \\
\text { The quality standards for the products and services } \\
\text { offered by the enterprise are constantly documented } \\
\text { and updated. } \\
\text { The productive processes are optimized by the use of } \\
\text { tools and methodologies. } \\
\text { The enterprise's key logistics processes are identified } \\
\text { and documented. }\end{array}$ & Yes & \\
\hline
\end{tabular}




\begin{tabular}{|c|c|c|c|c|}
\hline Level & & Questions & $\begin{array}{c}\text { Answer } \\
\text { (Yes/No) }\end{array}$ & Evidence \\
\hline Collaborative & $\begin{array}{l}\text { P.21 } \\
\text { P.22 } \\
\text { P.23 }\end{array}$ & $\begin{array}{l}\text { The enterprise has received certifications related to its } \\
\text { process standardization and quality, such as ISO, } \\
\text { QS14000, Six Sigma, etc. } \\
\text { There have been improvement efforts based on } \\
\text { contemporary improvement models, methodologies, } \\
\text { and tools such as lean manufacturing, just-in-time, } \\
\text { SCOR, concurring engineering, etc. } \\
\text { There is documentation in regards to operation and } \\
\text { results required to submit for the application in a } \\
\text { quality, production or standardization process award. } \\
\text { There are defined strategies to make alliances with } \\
\text { other enterprises to have more productive systems } \\
\text { within the enterprise. } \\
\text { There are strategies oriented to the innovation in } \\
\text { process improvement and to the development of new } \\
\text { products. } \\
\text { The life-cycle of the enterprises' products and/or } \\
\text { services is clearly defined. }\end{array}$ & $\begin{array}{l}\text { No } \\
\text { No } \\
\text { No } \\
\text { No }\end{array}$ & \\
\hline Leading & $\begin{array}{l}\text { P. } 25 \\
\text { P.26 } \\
\text { P. } 27 \\
\text { P.28 } \\
\text { P.29 }\end{array}$ & $\begin{array}{l}\text { The continuous improvement processes in the } \\
\text { product's logistics, quality, productivity and value for } \\
\text { the client are documented and implemented. } \\
\text { There are development and research programs to } \\
\text { improve the enterprises' key processes. } \\
\text { There is a defined procedure to determine if a process } \\
\text { or an activity can be outsourced. } \\
\text { There are alliances and agreements with other } \\
\text { enterprises that allow the enterprise to make its } \\
\text { processes more productive. } \\
\text { There are integral production strategies such as } \\
\text { computer-integrated manufacturing, process } \\
\text { automation, quality function deployment, etc which } \\
\text { are giving positive results. } \\
\text { There are follow-up and traceability processes for the } \\
\text { products and raw materials, which in the event of } \\
\text { quality problems in the products would allow to } \\
\text { identify and recover at a minimum cost. }\end{array}$ & $\begin{array}{l}\text { No } \\
\text { No }\end{array}$ & \\
\hline
\end{tabular}

Based in the results obtained, the maturity level of this enterprise for the view Production is Manageable. Thus, this enterprise should improve its supply chain processes starting by the opportunities detected by the questions P.20 through P.24. Some recommended actions and tool are the integration of internal production processes through technological solutions such as RFID, Lean Thinking tools such as value stream 
mapping, concurrent engineering, strengthening of value engineering projects such as

QFD, ISO, and TQM etc.

Table 21: Assessment Questionnaire for the view Inventory Systems

\begin{tabular}{|c|c|c|c|c|}
\hline Level & & Questions & $\begin{array}{c}\text { Answer } \\
\text { (Yes/No) }\end{array}$ & Evidence \\
\hline Undefined & $\begin{array}{l}\text { I.1 } \\
\text { I. } 2 \\
\text { I.3 } \\
\text { I. } 4 \\
\text { I. } 5\end{array}$ & $\begin{array}{l}\text { The areas for inventories in process, and material and } \\
\text { finished product warehouses are clearly identified. } \\
\text { There is a visual organization system in the material } \\
\text { and finished product warehouses. } \\
\text { There is a defined and implemented procedure for } \\
\text { incoming and outgoing raw material or product to and } \\
\text { from the warehouse. } \\
\text { There is a defined and implemented procedure to } \\
\text { manage the inventory levels and the inventory } \\
\text { physical location in the warehouses. } \\
\text { There is a documented catalog of materials and } \\
\text { finished products in stock in the warehouses. }\end{array}$ & $\begin{array}{l}\text { Yes } \\
\text { No } \\
\text { Yes } \\
\text { No } \\
\text { Yes }\end{array}$ & \\
\hline Defined & $\begin{array}{l}\text { I. } 6 \\
\text { I. } 7 \\
\text { I. } 8\end{array}$ & $\begin{array}{l}\text { There are replenishing methods and strategies, such as } \\
\text { forecasting, future demand, reordering levels, master } \\
\text { production plan, etc. } \\
\text { There are clearly defined, documented and } \\
\text { implemented policies for all inventory management } \\
\text { and control (parts, consumables, finished products, } \\
\text { material in process, etc.) } \\
\text { There are projects to integrate technological solutions } \\
\text { in the inventory control processes and management, } \\
\text { such as MRP, bar codes, product identification, etc. } \\
\text { There are clearly defined, documented and } \\
\text { implemented work procedures done jointly with other } \\
\text { departments in regards to delivery time, raw material } \\
\text { availability, finished products and required materials. }\end{array}$ & $\begin{array}{l}\text { Yes } \\
\text { Yes }\end{array}$ & \\
\hline Manageable & $\begin{array}{l}\text { I.10 } \\
\text { I. } 11 \\
\text { I. } 12 \\
\text { I. } 13 \\
\text { I. } 14\end{array}$ & $\begin{array}{l}\text { There are projects to automate inventory control with } \\
\text { ERP systems, warehouses management or similar } \\
\text { systems. } \\
\text { There are support systems for management and } \\
\text { inventory control decision making. } \\
\text { There is project deployment to optimize the levels of } \\
\text { inventories in process, materials and finished products. } \\
\text { There is project deployment to integrate inventory } \\
\text { management and control with the rest of the } \\
\text { enterprise's inventories. } \\
\text { The inventory information is reliable. It adds value to } \\
\text { the enterprise by generating more reliable master } \\
\text { production programs. }\end{array}$ & $\begin{array}{l}\text { No } \\
\text { Yes }\end{array}$ & \\
\hline
\end{tabular}




\begin{tabular}{|c|c|c|c|c|}
\hline Level & & Questions & $\begin{array}{c}\text { Answer } \\
\text { (Yes/No) }\end{array}$ & Evidence \\
\hline Collaborative & $\begin{array}{l}\text { I.15 } \\
\text { I. } 16\end{array}$ & $\begin{array}{l}\text { There are documented and implemented processes that } \\
\text { speed up inventory management and control such as } \\
\text { kanban, cross docking and inventory consolidation, } \\
\text { etc. } \\
\text { There are documented and implemented technological } \\
\text { solutions for inventory management and control such } \\
\text { as RFID, vendor management systems, inventory } \\
\text { automation, distribution centers, etc. } \\
\text { There is a catalog of reliable enterprises to sublet the } \\
\text { transportation of raw material and finished products. } \\
\text { There are documented and implemented policies about } \\
\text { the level of compliance of the enterprises supplying } \\
\text { raw material, service and distributing product in terms } \\
\text { of compliance, service level, delivery time, etc. } \\
\text { There is participation with other departments in the } \\
\text { enterprise to develop suppliers certification and } \\
\text { certification renewal policies. }\end{array}$ & $\begin{array}{l}\text { No } \\
\text { Yes } \\
\text { Yes }\end{array}$ & \\
\hline Leading & $\begin{array}{l}\text { I. } 20 \\
\text { I. } 21\end{array}$ & $\begin{array}{l}\text { The warehouses are orderly, clean, clearly identified; } \\
\text { and the information of inventory levels is highly } \\
\text { reliable. } \\
\text { Comparative studies about how the enterprise's } \\
\text { inventories are managed and controlled are frequently } \\
\text { done. } \\
\text { Concurrent engineering teams participate in providing } \\
\text { information about the replenishing of the raw material } \\
\text { required for the enterprise's new products and/or } \\
\text { services. } \\
\text { There are documented and implemented processes to } \\
\text { assure the quality of the raw material, starting from the } \\
\text { suppliers' plants. }\end{array}$ & $\begin{array}{l}\text { No } \\
\text { No }\end{array}$ & \\
\hline
\end{tabular}

Based in the results obtained, the maturity level of this enterprise for the view Inventory Systems is Level 0, which means the enterprise has not complete at least the level Undefined. Thus, this enterprise should improve its supply chain processes starting by the opportunities detected by the questions I.2 and I.4. Some recommended actions and tool are Inventory systems strategies such as layout by demand, by product type and so on, basic office tools to analyze data related to demand, delivery of supplies, $5 \mathrm{~S}$ concepts, documentation and standardization of inventory processes etc. 
Table 22: Assessment Questionnaire for the view Customers

\begin{tabular}{|c|c|c|c|c|}
\hline Level & & Questions & $\begin{array}{l}\text { Answer } \\
\text { (Yes/No) }\end{array}$ & Evidence \\
\hline Undefined & $\begin{array}{l}\text { C. } 1 \\
\text { C. } 2 \\
\text { C. } 3 \\
\text { C. } 4\end{array}$ & $\begin{array}{l}\text { There is information about the customer market and } \\
\text { the needs the enterprise's products and or services } \\
\text { meet. } \\
\text { There is a documented and implemented process to } \\
\text { follow up customer's complaints. } \\
\text { There is a documented and implemented procedure to } \\
\text { follow up customers' orders in regards to delivery } \\
\text { time, timely delivery, satisfaction, etc. } \\
\text { There are periodical meetings with clients for need } \\
\text { detection and for adaptation of products and services } \\
\text { offered to the market. } \\
\text { There is a basic database about customers' } \\
\text { information: address, contact, phone numbers, etc. }\end{array}$ & $\begin{array}{l}\text { Yes } \\
\text { Yes } \\
\text { Yes } \\
\text { Yes } \\
\text { Yes }\end{array}$ & \\
\hline Defined & $\begin{array}{l}\text { C. } 6 \\
\text { C. } 7 \\
\text { C. } 8 \\
\text { C. } 9 \\
\text { C. } 10 \\
\text { C. } 11\end{array}$ & $\begin{array}{l}\text { There is a documented and implemented vision about } \\
\text { the meaning the enterprise gives to providing service } \\
\text { and customer service. } \\
\text { There are reliable updating processes about the order } \\
\text { status as required by the customers; that is to know in } \\
\text { what part of the process they are. } \\
\text { There are defined, documented and defined policies } \\
\text { about customer service such as product change, } \\
\text { product substitution, product maintenance, etc. } \\
\text { There are documented and implemented procedures to } \\
\text { determine the customer's level of satisfaction with the } \\
\text { products and / or services provided by the enterprise. } \\
\text { There is deployment of improvement projects based } \\
\text { on customers' feedback to improve products and/ or } \\
\text { services offered by the enterprise. } \\
\text { There are teams evaluating the introduction of a } \\
\text { support system to manage customers' information. }\end{array}$ & $\begin{array}{l}\text { Yes } \\
\text { Yes } \\
\text { Yes } \\
\text { Yes } \\
\text { Yes }\end{array}$ & \\
\hline Manageable & $\begin{array}{l}\text { C. } 12 \\
\text { C. } 13 \\
\text { C. } 14 \\
\text { C. } 15 \\
\text { C. } 16\end{array}$ & $\begin{array}{l}\text { There is a documented and implemented system to } \\
\text { generate customers' loyalty to the brand. } \\
\text { There are teams participating interdepartmentally for } \\
\text { the implementation of information systems to provide } \\
\text { better service to customers. } \\
\text { There is a customer service department which has } \\
\text { clearly defined functions to guarantee the fulfillment } \\
\text { of customer's expectations in regards to product and / } \\
\text { or service. } \\
\text { There is deployment of continuous improvement } \\
\text { interdisciplinary projects oriented to improve the } \\
\text { customer's level of satisfaction with the enterprise. } \\
\text { Integral tools are used to analyze the quality level of } \\
\text { products and services such as the quality function } \\
\text { deployment (QFD). }\end{array}$ & $\begin{array}{l}\text { No } \\
\text { Yes }\end{array}$ & \\
\hline
\end{tabular}




\begin{tabular}{|c|c|c|c|c|}
\hline Level & & Questions & $\begin{array}{c}\text { Answer } \\
\text { (Yes/No) }\end{array}$ & Evidence \\
\hline Collaborative & $\begin{array}{l}\text { C. } 17 \\
\text { C. } 18 \\
\text { C. } 19 \\
\text { C. } 20 \\
\text { C. } 21\end{array}$ & $\begin{array}{l}\text { There are training programs for the staff attending } \\
\text { clients. } \\
\text { The customer service staff is empowered to make } \\
\text { decisions which imply increasing the customer's level } \\
\text { of satisfaction such as changing product, returning } \\
\text { products, offering compensations, etc. } \\
\text { There are documented and implemented procedures to } \\
\text { determine the key characteristics that make products } \\
\text { and services offer advantages over the competition's } \\
\text { products or substitutes. } \\
\text { Strategies are deployed to assure customers' loyalty } \\
\text { toward the enterprise's products by means of } \\
\text { marketing, focus groups, rewards, interviews, etc. } \\
\text { There are procedures to rank the importance of } \\
\text { customers to the enterprise, such as the documentation } \\
\text { of the benefits this classification offers like discounts, } \\
\text { priority in product delivery, etc. }\end{array}$ & $\begin{array}{l}\text { Yes } \\
\text { Yes }\end{array}$ & \\
\hline Leading & $\begin{array}{l}\text { C. } 22 \\
\text { C. } 23 \\
\text { C. } 24 \\
\text { C. } 25 \\
\text { C. } 26\end{array}$ & $\begin{array}{l}\text { There are documented and implemented procedures to } \\
\text { determine the characteristics that add value to products } \\
\text { and / or services the enterprise offers considered from } \\
\text { the customer's view. } \\
\text { Sets of projects are deployed in combination with } \\
\text { other processes in the enterprise to develop innovative } \\
\text { products and / or services to meet the customers' } \\
\text { unfulfilled needs. } \\
\text { The best practices on service and customer service are } \\
\text { documented. } \\
\text { The enterprise has been granted awards for customer } \\
\text { service and / or community programs. } \\
\text { The enterprise has a culture of its own in regards to } \\
\text { customer service reflecting a low level of complaints. }\end{array}$ & $\begin{array}{l}\text { No } \\
\text { Yes }\end{array}$ & \\
\hline
\end{tabular}

Based in the results obtained, the maturity level of this enterprise for the view Customers is Undefined. Therefore, this enterprise should improve its supply chain processes starting by the opportunities detected by the question C.11. Some recommended actions and tool are the definition of a target market, doing research of customers' requirements, defining the customer service mission and vision, implementing focus groups, assessing of customer relationship management solutions, defining the customer service policies; etc. 
Table 23: Assessment Questionnaire for the view Human Resources

\begin{tabular}{|c|c|c|c|c|}
\hline Level & & Questions & $\begin{array}{l}\text { Answer } \\
\text { (Yes/No) }\end{array}$ & Evidence \\
\hline Undefined & $\begin{array}{l}\text { H.1 } \\
\text { H.2 }\end{array}$ & $\begin{array}{l}\text { Strategies to avoid personnel absenteeism and turn } \\
\text { over are deployed. } \\
\text { The basic required training for each position in the } \\
\text { enterprise is defined. }\end{array}$ & $\begin{array}{l}\text { Yes } \\
\text { Yes }\end{array}$ & \\
\hline Defined & $\begin{array}{l}\text { H.3 } \\
\text { H.4 } \\
\text { H.5 } \\
\text { H.6 }\end{array}$ & $\begin{array}{l}\text { There is a corporate identity enterprise wide. } \\
\text { There is a definition of the profile and functions for } \\
\text { every position in the enterprise. } \\
\text { Strategies are deployed to identify, preserve and } \\
\text { develop the outstanding human capital. } \\
\text { There are reward systems for employees' performance. }\end{array}$ & $\begin{array}{l}\text { Yes } \\
\text { Yes } \\
\text { No } \\
\text { No }\end{array}$ & \\
\hline Manageable & $\begin{array}{l}\text { H.7 } \\
\text { H.8 } \\
\text { H.9 } \\
\text { H.10 } \\
\text { H.11 }\end{array}$ & $\begin{array}{l}\text { Strategies are deployed to guarantee that employees } \\
\text { make the enterprise's mission, vision and objectives } \\
\text { their own. } \\
\text { There is a personal development program for } \\
\text { employees. } \\
\text { There is a continuous training program for employees. } \\
\text { There are established programs to acknowledge and } \\
\text { reward outstanding employees. } \\
\text { There are continuous improvement programs for the } \\
\text { work area and climate in the enterprise. }\end{array}$ & $\begin{array}{l}\text { Yes } \\
\text { No } \\
\text { Yes } \\
\text { No } \\
\text { Yes }\end{array}$ & \\
\hline Collaborative & $\begin{array}{l}\text { H.12 } \\
\text { H.13 } \\
\text { H.14 } \\
\text { H.15 } \\
\text { H.16 }\end{array}$ & $\begin{array}{l}\text { There are employee development and promotion } \\
\text { programs which offer a career plan appropriate for } \\
\text { each post in the enterprise. } \\
\text { Strategies are deployed to generate a collaborative and } \\
\text { teamwork environment among employees. } \\
\text { There are clear mechanisms to listen to employees' } \\
\text { requests and proposals. } \\
\text { The Human Resources staff is trained to attend the rest } \\
\text { of its coworkers in the enterprise. } \\
\text { There are commercial agreements that provide } \\
\text { employees advantages, discounts in the purchase of } \\
\text { goods and services. }\end{array}$ & $\begin{array}{l}\text { No } \\
\text { Yes } \\
\text { Yes } \\
\text { Yes } \\
\text { Yes }\end{array}$ & \\
\hline Leading & $\begin{array}{l}\text { H.17 } \\
\text { H.18 } \\
\text { H.19 } \\
\text { H.20 }\end{array}$ & $\begin{array}{l}\text { There are yearly evaluations of the enterprise's climate } \\
\text { and the results indicate that employees perceive a good } \\
\text { climate. } \\
\text { Strategies are deployed to develop in employees a } \\
\text { culture of leadership, creativity and innovation. } \\
\text { There are personal development programs for } \\
\text { employees and their families. } \\
\text { There are integral development programs for } \\
\text { employees (health care, education, training, culture, } \\
\text { etc.) }\end{array}$ & $\begin{array}{l}\text { Yes } \\
\text { No } \\
\text { No } \\
\text { No }\end{array}$ & \\
\hline
\end{tabular}


Based in the results obtained, the maturity level of this enterprise for the view Human Resources is Undefined. Therefore, this enterprise should improve its supply chain processes starting by the opportunities detected by the questions H.5 and H.6. Some recommended actions and tool are the definition of training requirements, deployment of strategies to create an enterprise work culture, definition of reward policies and communication of reward program, definition of career plans for employees and enterprise's position etc.

Table 24: Assessment Questionnaire for the view Info. Sys. \& Technology

\begin{tabular}{|c|c|c|c|c|}
\hline Level & & Questions & $\begin{array}{c}\text { Answer } \\
\text { (Yes/No) }\end{array}$ & Evidence \\
\hline Undefined & $\begin{array}{l}\text { T.1 } \\
\text { Т.2 } \\
\text { Т.3 } \\
\text { Т.4 }\end{array}$ & $\begin{array}{l}\text { The information is documented without using a } \\
\text { computing system. } \\
\text { There are basic information systems like spreadsheets } \\
\text { or basic databases. } \\
\text { There are compatibility problems with the enterprise's } \\
\text { information systems. } \\
\text { The enterprise's processes depend greatly on the } \\
\text { employees' experience and have little or no } \\
\text { technological support. }\end{array}$ & $\begin{array}{l}\text { Yes } \\
\text { Yes }\end{array}$ & \\
\hline Defined & $\begin{array}{l}\text { T.5 } \\
\text { T.6 } \\
\text { T.7 } \\
\text { T.8 } \\
\text { T.9 }\end{array}$ & $\begin{array}{l}\text { Data collection systems and information management } \\
\text { in word processors, spreadsheets and databases have } \\
\text { been developed, but the systems have little or no } \\
\text { interface between them } \\
\text { There are evaluation programs to determine possible } \\
\text { improvements in processes based on technological } \\
\text { support. } \\
\text { Projects are deployed to assure compatibility between } \\
\text { technology and information systems used in the } \\
\text { enterprise. } \\
\text { There is a trained staff to give maintenance and make } \\
\text { the enterprise's technology and information systems } \\
\text { more efficient. } \\
\text { There is a staff in charge of evaluating possible } \\
\text { technological solutions and information systems for } \\
\text { the enterprise. }\end{array}$ & $\begin{array}{l}\text { Yes } \\
\text { No } \\
\text { No } \\
\text { Yes }\end{array}$ & \\
\hline
\end{tabular}




\begin{tabular}{|c|c|c|c|c|}
\hline Level & & Questions & $\begin{array}{l}\text { Answer } \\
\text { (Yes/No) }\end{array}$ & Evidence \\
\hline Manageable & $\begin{array}{l}\text { T.10 } \\
\text { T.11 } \\
\text { T.12 } \\
\text { T.13 } \\
\text { T.14 }\end{array}$ & $\begin{array}{l}\text { There are improvement teams in charge of training } \\
\text { personnel when new technology or information } \\
\text { systems such as ERO; CRM, SRM, etc., are } \\
\text { introduced. } \\
\text { There is a documented and implemented standardized } \\
\text { process to manage and generate data. } \\
\text { There are defined and documented strategies to update } \\
\text { and replace technology. } \\
\text { Projects are deployed to define strategies to integrate } \\
\text { suppliers and customers in the enterprise's information } \\
\text { systems. } \\
\text { There are improvement processes for ease of access to } \\
\text { information and way in which it is presented to users. }\end{array}$ & $\begin{array}{l}\text { Yes } \\
\text { Yes } \\
\text { No } \\
\text { No }\end{array}$ & \\
\hline Collaborative & $\begin{array}{r}\text { T.15 } \\
\text { T.16 } \\
\text { T.17 } \\
\text { T.18 } \\
\text { T.19 }\end{array}$ & $\begin{array}{l}\text { There are interdisciplinary teams to optimize use and } \\
\text { management of technology. } \\
\text { Projects are deployed to integrate suppliers and } \\
\text { customers in the enterprise's information systems. } \\
\text { Stabilization in the implementation of information } \\
\text { systems in the enterprise has been fulfilled. } \\
\text { There are defined policies to manage technology and } \\
\text { to make technological alliances. } \\
\text { There are technology development projects oriented to } \\
\text { improve the enterprise's processes. }\end{array}$ & $\begin{array}{l}\text { Yes } \\
\text { No } \\
\text { No } \\
\text { No } \\
\text { Yes }\end{array}$ & \\
\hline Leading & $\begin{array}{l}\text { T.20 } \\
\text { T.21 } \\
\text { T.22 } \\
\text { T.23 }\end{array}$ & $\begin{array}{l}\text { There is high dependence on technology and } \\
\text { information systems to achieve good performance in } \\
\text { the enterprise's processes. } \\
\text { There are defined policies to share developed } \\
\text { technology with other enterprises. } \\
\text { There are technological alliances with other } \\
\text { enterprises. } \\
\text { The enterprise's best practices are documented and } \\
\text { shared with technological partners. }\end{array}$ & $\begin{array}{l}\text { No } \\
\text { No }\end{array}$ & \\
\hline
\end{tabular}

Based in the results obtained, the maturity level of this enterprise for the view Information Systems and Technology is Undefined. Therefore, this enterprise should improve its supply chain processes starting by the opportunities detected by the questions T.7 and T.8. Some recommended actions and tool are the definition of technology requirements to ensure the product flow and the availability of information, the 
development of policies to justify technology acquisitions and the definition of training

requirements to keep information systems and technology tuned on.

Table 25: Assessment Questionnaire for the view Performance Measurement

\begin{tabular}{|c|c|c|c|c|}
\hline Level & & Questions & $\begin{array}{c}\text { Answer } \\
\text { (Yes/No) }\end{array}$ & Evidence \\
\hline Undefined & $\begin{array}{l}\text { M.1 } \\
\text { M.2 } \\
\text { M. } 3\end{array}$ & $\begin{array}{l}\text { There are documented and implemented procedures to } \\
\text { assure the integrity of the collected data about process } \\
\text { performance. } \\
\text { Key performance indicators are defined and } \\
\text { documented } \\
\text { The behavior of indicators is analyzed to define } \\
\text { improvement projects in the enterprise. }\end{array}$ & $\begin{array}{l}\text { Yes } \\
\text { Yes }\end{array}$ & \\
\hline Defined & $\begin{array}{l}\text { M.4 } \\
\text { M.5 } \\
\text { M. } 6\end{array}$ & $\begin{array}{l}\text { There are documented procedures to store the } \\
\text { enterprise's historic information. } \\
\text { There are defined and implemented information report } \\
\text { formats appropriate for each position. } \\
\text { There are projects to use the information in the design } \\
\text { and implementation of support systems for decision } \\
\text { making processes. } \\
\text { Employee performance and key processes in the } \\
\text { enterprise are evaluated periodically }\end{array}$ & $\begin{array}{l}\text { Yes } \\
\text { Yes } \\
\text { Yes } \\
\text { Yes }\end{array}$ & \\
\hline Manageable & $\begin{array}{l}\text { M. } 8 \\
\text { M. } 9 \\
\text { M.10 } \\
\text { M.11 }\end{array}$ & $\begin{array}{l}\text { There is a documented and implemented procedure to } \\
\text { calculate the key performance indicators in the } \\
\text { enterprise. } \\
\text { The performance indicators are constantly updated and } \\
\text { are accessible to all decision makers who require } \\
\text { them. } \\
\text { There are defined processes to generate indicators and } \\
\text { information useful to undertake the enterprise's } \\
\text { strategic planning. } \\
\text { It is defined what indicators should be presented to } \\
\text { each level within the enterprise. }\end{array}$ & $\begin{array}{l}\text { Yes } \\
\text { Yes } \\
\text { No } \\
\text { No }\end{array}$ & \\
\hline Collaborative & $\begin{array}{l}\text { M.14 } \\
\text { M.15 } \\
\text { M.16 }\end{array}$ & $\begin{array}{l}\text { Projects to improve the enterprise's accessibility to and } \\
\text { presentation of key indicators are done. } \\
\text { There are processes to periodically compare the } \\
\text { enterprise's key indicators with those of the } \\
\text { competition or another leading enterprise in the } \\
\text { market. } \\
\text { There is access to the database of performance } \\
\text { indicators of the leading enterprises in the market. } \\
\text { There is deployment of improvement projects about } \\
\text { the forecasting accuracy of the enterprise's key } \\
\text { indicators } \\
\text { There is a documented and implemented system of } \\
\text { performance measurement for outsourced activities } \\
\text { and processes. }\end{array}$ & $\begin{array}{l}\text { No } \\
\text { No } \\
\text { No } \\
\text { No } \\
\text { Yes }\end{array}$ & \\
\hline
\end{tabular}




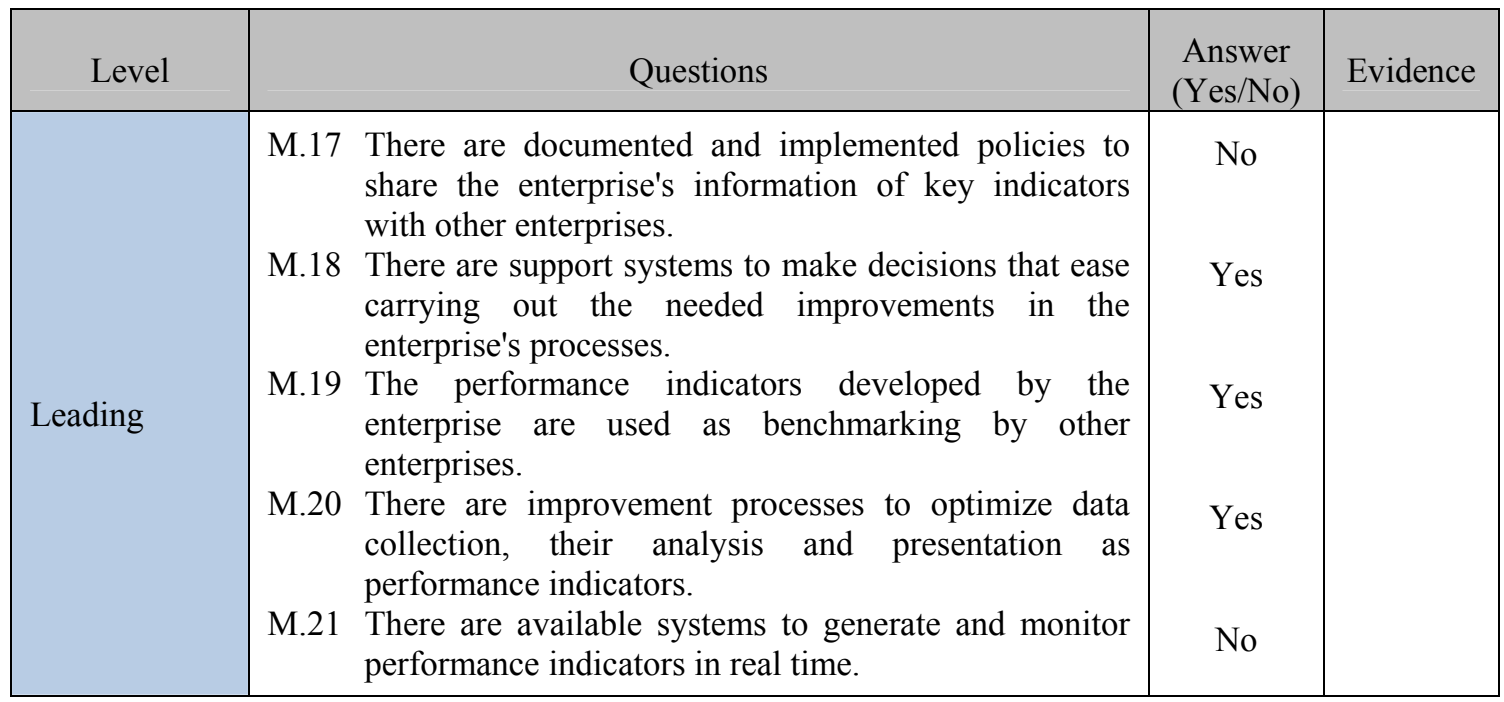

Based in the results obtained, the maturity level of this enterprise for the view Performance Measurement Systems is Defined. Therefore, this enterprise should improve its supply chain processes starting by the opportunities detected by the questions M.10 and M.11. Some recommended actions and tool are the definition of requirements for the decision making processes at all management levels, assessment of KPIs accuracy, benchmarking of the KPIs generation process, information systems working together to ensure accessibility to performance indicators.

Integrating the results obtained from the assessment of all the views, the complete radar graph of the enterprise's supply chain system may be represented graphically as is shown in Figure 34. According to the results obtained from the assessment of the enterprise's supply chain processes, this enterprise should to improve inventories as priority one; human resources, information systems and technology, and customers as priority two; and suppliers, production, and performance measurement systems as priority 
three. In order to standardize the assessment process the following chapter describes the assessment methodology, which comes together with the $\mathrm{S}(\mathrm{CM})^{2}$.

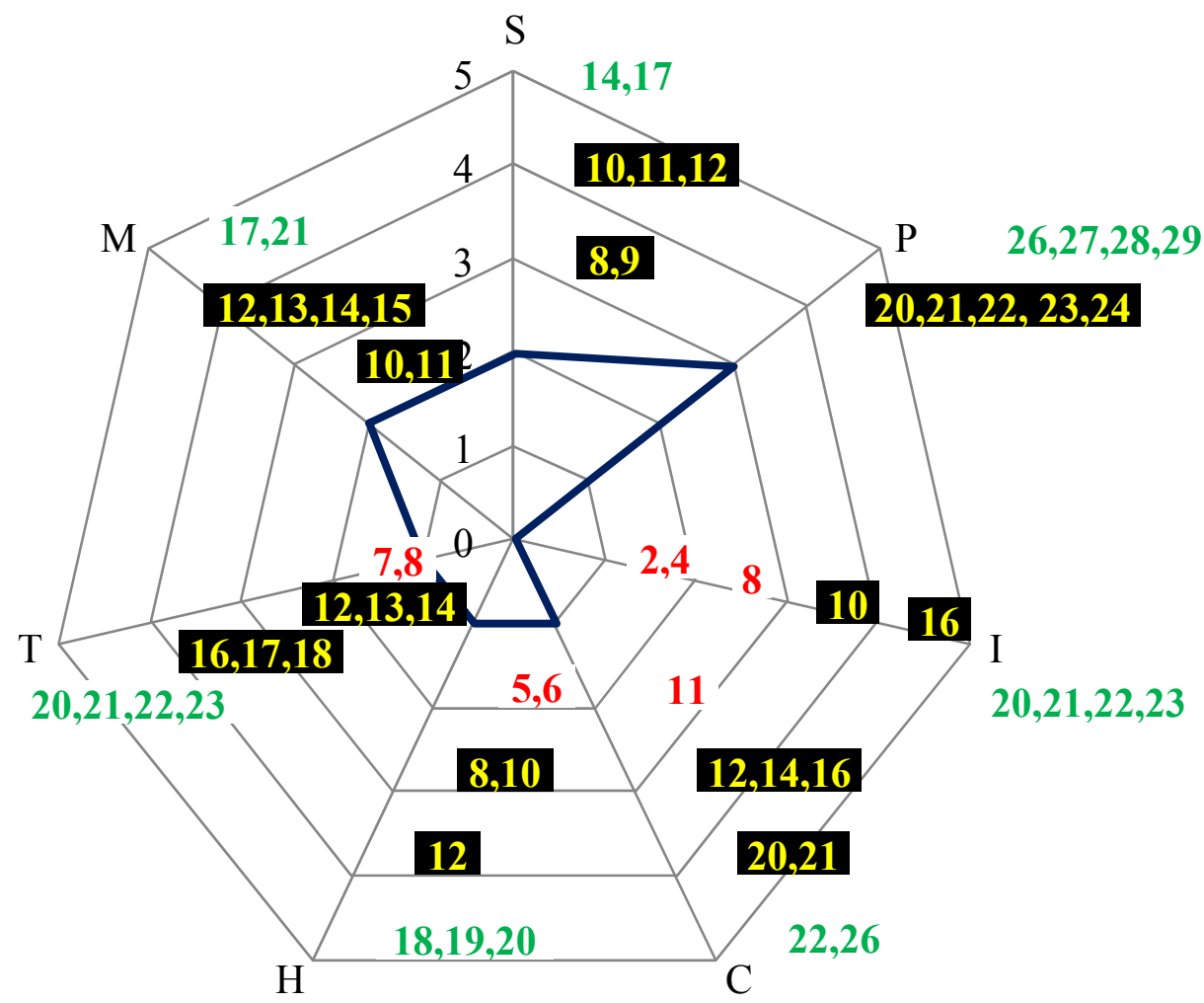

Figure 34: Maturity Levels for each view Assessed 


\section{CHAPTER VI}

\section{THE ASSESSMENT METHODOLOGY OF THE S(CM) ${ }^{2}$}

An important component of the $\mathrm{S}(\mathrm{CM})^{2}$ is the assessment methodology, which provides a standardized way to implement the meta-model to assess and improve the supply chain processes in the enterprise. This chapter describes the assessment methodology of the $\mathrm{S}(\mathrm{CM})^{2}$. Also, this chapter shows how to generalize the classification of the "as-is" state of the supply chain processes in the enterprise.

\subsection{The Generalization OF The Supply Chain Classification}

Concerning the assessment methodology, this includes the use of several forms and documentation. In order to provide a standardized classification format for each process assessment, the model uses a general classification similar to the Kendall \& Lee classification used in queuing theory. Thus, the generalization of the model is defined through the following format $(A / B / C / D)(E / F / G)$ in which each letter represents the maturity level of one view after the assessment, such that each variable has a range from one to five. Regarding the relationship among the letters and the views, this is as follows:
A: Suppliers
B: Production
$\mathrm{C}$ : Inventories
D: Customers
E: Human Resources 
F: Information Systems \& Technology

\section{G: Performance Measurement Systems}

This classification has two subsets. The first one represents the maturity level of the views related to the product flow from the downstream to the upstream of the supply chain; the second one represents the maturity level of the views related to controlling and speeding up the product flow.

Therefore, a process assessment report may be as is shown in Figure 35.

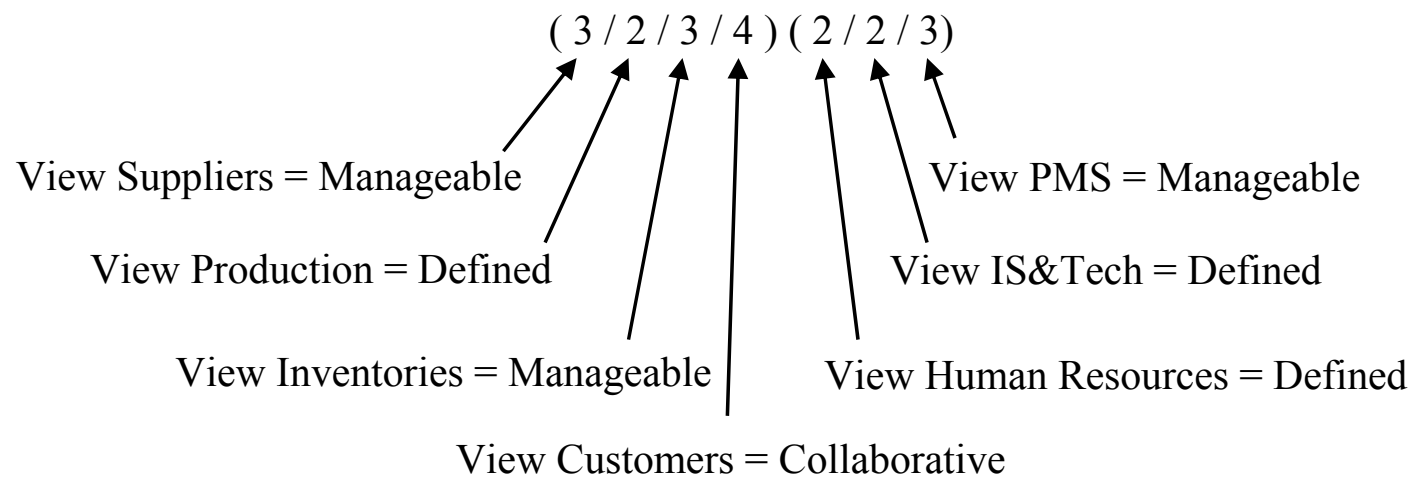

Figure 35: Supply Chain Assessment Report

To remember this general classification, the following acronym is suggested, SUPPLYS (SUpplier, Production, PLanning of inventory, and Shopper(customer)) HSYSTEMS (Human SYStems, TEchnology, Measurement Systems (Metrics)). After classifying an enterprise process according to this format, the next step is define an improvement road map based on the supply chain reference actions, Key improvement factors, and Useful tools provided by the meta-model. The next section describes the suggested methodology to assess and improve the supply chain processes in the enterprise, such that an analyst may obtain the general classification shown. 


\subsection{The Supply Chain Assessment Process}

The $\mathrm{S}(\mathrm{CM})^{2}$ is a reference model useful to assess and improve the processes in a supply chain. However, this meta-model requires a step-by-step methodology to standardize the assessment process. Figure 36 shows the methodology graphically.

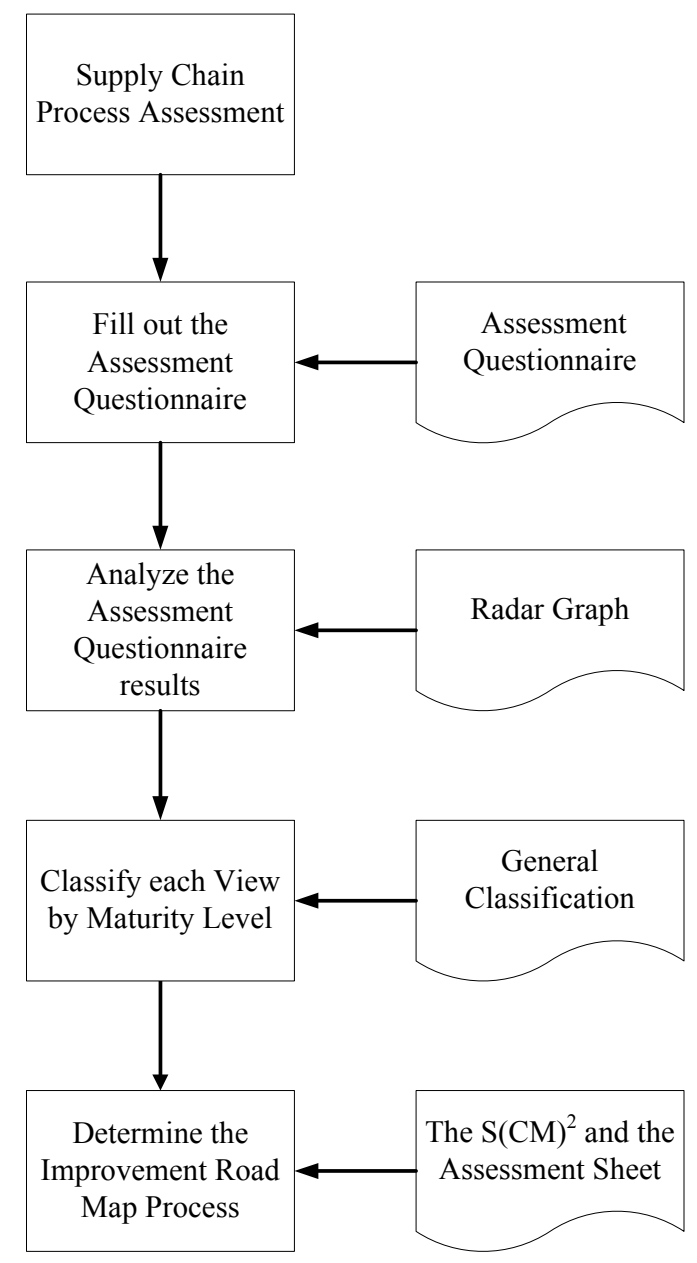

Figure 36: The $\mathrm{S}(\mathrm{CM})^{2}$ Assessment Methodology

The methodology starts with a general assessment of the supply chain process. This general assessment is obtained from the results of the assessment questionnaire shown in Appendix 8. The questionnaire results describe the "as is" state of the enterprise's supply 
chain under analysis. The result of this general assessment tool is analyzed and reported in a radar graph. This radar graph, allows prioritizing the supply chain views according to the maturity level obtained. Also this shows a gap analysis by comparison among the "as-is" system and the "to-be" system defined by the maturity level leading.

Once this step is done, the last assessing step is to obtain the general classification of the supply chain analyzed as was shown in Figure 35. Based on the general classification, it is possible to define an improvement road map prioritizing the improvement projects according the maturity level obtained, such that the lower maturity classification has the biggest improvement priority. However, other possible rules to prioritize the views may be also applied, for instance including strategic or economic considerations.

In order to provide a tool in which all the improvement projects can be shown, it is possible to define a matrix of views and improvement projects. This matrix will include all the observations, comments, constraints and improvement strategies used to improve the supply chain. The useful tools provided by the $\mathrm{S}(\mathrm{CM})^{2}$ help to select an appropriated best improvement practice for each view in each maturity level. The final result, is an assessment sheet, Figure 37 shows the assessment sheet provided by the meta-model.

Once the assessment information is organized in this matrix, the analyst may be able to define an improvement road map based on the general classification as a starting point, the maturity level definition, the supply chain reference actions for each view and maturity level, and the sets of key improvement factors and useful tools provided for each level. 


\begin{tabular}{|c|c|c|c|c|c|}
\hline \multicolumn{6}{|c|}{ Assesment Sheet } \\
\hline \multirow[t]{2}{*}{ Analyst name: } & & & \multicolumn{3}{|c|}{ Report Date: } \\
\hline & & & Observations & & \\
\hline Views & Undefined & Defined & Manageable & \begin{tabular}{|l|} 
Collaborative \\
\end{tabular} & Leadership \\
\hline Suppliers & & & & & \\
\hline Production & & & & & \\
\hline Inventories & & & & & \\
\hline Customers & & & & & \\
\hline $\begin{array}{l}\text { Human } \\
\text { Resources }\end{array}$ & & & & & \\
\hline $\begin{array}{c}\text { Information } \\
\text { Systems \& } \\
\text { Technology }\end{array}$ & & & & & \\
\hline $\begin{array}{c}\text { Performance } \\
\text { Measurement } \\
\text { Systems }\end{array}$ & & & & & \\
\hline
\end{tabular}

Figure 37: Assessment Sheet for the $\mathrm{S}(\mathrm{CM})^{2}$ 


\section{CHAPTER VII}

\section{CONCLUSIONS AND FUTURE WORK}

Enterprises seek to have tools, models, or methodologies to help them improve their supply chain processes. There are many tools, models and methodologies which might be implemented to obtain the desired improvements. However, how can an enterprise select from all of them? Can the expected results be obtained using a particular tool, or a combination of tools? Does an enterprise have the require maturity and knowledge for implementing some tool or methodology? Considering these questions, this research presents a model to provide a Supply Chain Capability Maturity Model S(CM $)^{2}$, such that

an enterprise may use the $\mathrm{S}(\mathrm{CM})^{2}$ to assess its supply chain and define a road map for its supply chain improvement process based on the maturity level of each model view.

The $\mathrm{S}(\mathrm{CM})^{2}$ provides a supply chain model including a cross-disciplinary and dynamic point of view through the model life-cycle and the abstraction levels, which implicitly consider the time variable. Besides, the meta-model provides a supply chain representation, which is different from previous models.

The problem related with the selection of a system improvement strategy is addressed by the set of tools recommended by maturity level, such that an enterprise may select from these set the improvement tool or select similar tools not included in the list. Additionally, the supply chain reference actions may be used to select a tool or define an improvement road map such that the reference action is reached. 
The final problem discussed was the vertical and horizontal integration. The $\mathrm{S}(\mathrm{CM})^{2}$ addressed this problem integrating the enterprise's processes vertically in the maturity levels one, two and three; after that, the meta-model integrates the enterprise's processes horizontally through collaboration and innovation.

\subsection{RESEARCH CONTRIBUTION}

This meta-model contributes to the state of the art of enterprise modeling and supply chain improvement process by defining a method of how companies may improve their supply chain performance. The meta-model contributions are as follows:

1. The research defines a Capability Maturity Model to assess the processes and performance of enterprises in the supply chain. This model helps to determine which processes and variables must be improved or controlled in order to improve the overall enterprise supply chain performance.

2. The $\mathrm{S}(\mathrm{CM})^{2}$ integrates several best practices, methodologies, concepts, and tools from different knowledge areas in a cross-disciplinary meta-model.

3. The $\mathrm{S}(\mathrm{CM})^{2}$ provides a set of supply chain reference actions in each maturity level. These reference actions are used as building blocks for each view and abstraction level, such that an enterprise may identify its maturity level for each view by comparing it with the model.

4. The $\mathrm{S}(\mathrm{CM})^{2}$ provides a set of supply chain key improvement factors, which are prioritized by maturity level, and a set of useful tools to improve the supply chain processes until reaching the next maturity level 
5. This research provides a diagnostic tool for the enterprise supply chain operations processes, oriented to help the company to identify its improvement opportunities and offer guidance on how to reach the next maturity level. Moreover, this initial diagnosis enables a plan for improving its current business processes through different tools and best practices.

6. The $\mathrm{S}(\mathrm{CM})^{2}$ selects a set of tools and best practices to fit the requirements for each maturity level defined in the $\mathrm{S}(\mathrm{CM})^{2}$. This set of tools and best practices is a menu of possible solutions, such that an enterprise may customize the sub set required to improve the opportunities identified by the diagnostic tool.

7. The research contributes to the current state of the art related to merging the use and implementation of several best practices making them work together in an improvement process.

8. It provides conclusion and future research about the constraints, advantages and, disadvantages of the use of a CMM which integrated the successful concepts of contemporary best practices.

9. The $\mathrm{S}(\mathrm{CM})^{2}$ has advantages over other general reference models because of the languages used to build the model and the fact that it was developed specifically to assess and improve the enterprise's supply chain processes. Additionally, the language is easily recognized and common in the supply chain field. 


\subsection{EXTENSION TO THIS WORK}

The $\mathrm{S}(\mathrm{CM})^{2}$ presented in this research is the first version; thus, the meta-model may be improved and increased in the following years. Moreover, the present work includes a detailed methodology, which describes how the model was built; thus, this research may be replicated to other fields different from supply chain such as food, automotive, electronics, and so on.

The final meta-model was built considering only Mexican experts. In order to increase the confidence in the $\mathrm{S}(\mathrm{CM})^{2}$; it is recommended to consider the opinion of international experts, such that the model may be considered useful to any supply chain in the world.

The $\mathrm{S}(\mathrm{CM})^{2}$ is a first level of detailed meta-model. In order to complete the whole documentation of the model, it is needed to decompose, describe and document each reference into several detail levels, such that the model describes the activities and tasks, included in each supply chain reference action.

Finally, the $\mathrm{S}(\mathrm{CM})^{2}$ may be extended and improved through more real implementation in several enterprises. The results obtained from this implementation will be helpful to increase the useful tools list and document the real benefits provided by the improvement projects originated by the enterprises' supply chain assessment. 


\section{REFERENCES}

Akkermans, H. A, P. Bogerd, E. Yücesan, and L. N. Van Wassenhove (2003), "The Impact of ERP on Supply Chain Management: Exploratory Findings from a European Delphi Study," European Journal of Operation Research, Volume 146, pp. 284-301.

Angerhofer, B. J., and M. C. Angelides (2000), "System Dynamic Modeling in Supply Chain Management: Research Review," Proceedings of the 2000 Winter Simulation Conference, J. A. Joines, R. R. Barton, K. Kang, and P. A. Fishwick, eds., pp. 342351.

Appelquist, P., J. Lehtonen, and J. Kokkonen (2004), "Modeling in Product and Supply Chain Design: Literature Survey and Case Study," Journal of Manufacturing Technology Management, Volume 15, Number 7, pp. 675-686.

Argyres, Nicholas (1996), "Evidence on the Role of Firm Capabilities in Vertical Integration Decision," Strategic Management Journal, Volume 17, Number 2, pp. 129-150.

Ballou R. H. (2004), Business Logistics Management, $5^{\text {th }}$ Edition, Phoenix, Arizona, Prentice Hall Inc.

Barber K. D., F. W. Dewhurst, R. L. D. H. Burns, and J. B. B. Rogers (2003), "BusinessProcess Modeling and Simulation for Manufacturing Management: A Practical Way Forward," Business Process Management Journal, Volume 9, Number 4, pp. 527542.

Bernus, P., and L. Nemes (1997), "Requirements of the Generic Enterprise Reference Architecture and Methodology," A Rev. Control, Volume 21, pp. 125-136.

Braganza, A. (2002), "Enterprise Integration: Creating Competitive Capabilities," Integrated Manufacturing Systems, Volume 13, Number 8, pp. 562-572.

Brewer, P. C. and T. W. Shep (2000), "Using the Balance Scorecard to Measure Supply Chain Performance," Journal of Business Logistics, Volume 21, Number 1, pp. 7593.

Bunting, R., F. Coallier, and G. Lewis (2002), "Interdisciplinary Influences in Software Engineering Practices" Proceedings of the $10^{\text {th }}$ International Workshop on Software Technology and Engineering Practice, pp. 62-69.

Calingo, L. M. R. (1996), "The Evolution of Strategic Quality Management," International Journal of Quality and Reliability Management, Volume 13, Number 9, pp. 19-37. 
Caputo, A. C., P. M. Pelagagge, and F. Scacchia (2003), "Integrating Transport Systems in Supply Chain Management Software Tools," Industrial Management \& Data Systems, Volume 103, Number 7, pp. 503-515.

Chalmeta, R., C. Campos, and R. Grangel (2001), "Reference Architectures for Enterprise Integration," The Journal of Systems and Software, Volume 57, pp. 175191.

Chan, F. T. S., N. K. H. Tang, H. C. W. Lau, and R. W. L. Ip (2002), "A Simulation Approach in Supply Chain Management," Integrated Manufacturing Systems, Volume 13, Number 2, pp. 117-122.

Chandra, C. and S. Kumar (2001), "Enterprise Architecture Framework for Supply Chain Integration," Industrial Management \& Data Systems, Volume 101, Number 6, pp. 290-303.

Chatfield, D. C., J. G. Kim, T. P. Harrison, and J. C. Hayya (2004), "The Bullwhip Effect-Impact of Stochastic Lead Time, Information Quality, and Information Sharing: A Simulation Study," Production and Operation Management, Volume 13, Number 4, pp. 340-353.

Chen, F., Z. Drezner, J. K. Ryan, and D. Simchi-Levi (2000), "Quantifying the Bullwhip Effect in a Simple Supply Chain: The Impact of Forecasting, Lead Times, and Information," Management Science, Volume 46, Number 3, pp. 436-443.

Chin, K., V. M. R. Tummala, J. P. F. Leung, and X. Tang (2004), “A Study on Supply Chain Management Practices: The Hong Kong Manufacturing Perspective," International Journal of Physical Distribution \& Logistics Management, Volume 34, Number 6, pp. 505-524.

Cooper M. C., D. M. Lambert, and J. D. Pagh (1997), "Supply Chain Management: More Than a New Name for Logistics," The International Journal of Logistics Management, Volume 8, Number 1, pp. 1-13.

Dangle, K. C., P. Larsen, M. Shaw, and M. V. Zelkowitz (2005), "Software Process Improvement in Small Organizations: A Case Study," IEEE Software, Volume 22, Number 6, pp. 68-75.

Davenport, T. H., and J. D. Brooks (2004), "Enterprise Systems and the Supply Chain," Journal of Enterprise Information Management, Volume 17, Number 1, pp. 8-19.

Davies, A. J., and A. K. Kochhar (2002), "Manufacturing Best Practice and Performance Studies: A Critique," International Journal of Operation and Production Management, Volume 22, Number 3, pp. 289-305. 
Dewhurst, F. W., K. D. Barber, and M. C. Pritchard (2002), "In Search of a General Enterprise Model," Management Decision, Volume 40, Number 5, pp. 418-427.

ESPIRIT Consortium AMICE (Eds) (1993), "CIMOSA: Open System Architecture for $C I M, " 2^{\text {nd }}$ revised and extended edition, Research Report, ESPIRIT Project 688/5288, Sringer-Verlang.

Ferrin, D. M., M. J. Miller, and D. Muthler (2005), "Lean Sigma and Simulation, so What's the Correlation? V2," Proceedings of the 2005 Winter Simulation Conference, M. E. Kuhl, N. M. Steiger, F. B. Armstrong, and J. A. Joines, eds., pp. 2011-2015.

Gack, G. A. and K. Robison (2003), "Integrating Improvement Initiatives: Connecting Six Sigma for Software, CMMI, Personal Software Process (PSP), and Team Software Process (TSP)," Software Quality Professional, Volume 5, Number 4, pp. 513.

Garg, D., Y. Narahari, and N. Viswanadham (2004), "Design of Six Sigma Supply Chains," IEEE Transactions on Automation Science and Engineering, Volume 1, Number 1, pp. 38-57.

Grover, V., M. J. Cheon, and J. T. C. Teng (1996), "The Effect of Service Quality and Partnership on the Outsourcing Information Systems Function," Journal of Management Information Systems, Volume 12, Number 4, pp. 89-116.

Gunasekaran, A., C. Patel, and E. Tirtiroglu, "Performance Measures and Metrics in a Supply Chain Environment," International Journal of Operations and Production Management, Volume 21, Number 1/2, pp.71-87.

Hakim, S., and J. Weinblatt (1993), "The Delphi Process as a Tool for Decision Making: The Case of Vocational Training of People with Handicaps," Evaluation and Program Planning, Volume 16, pp. 25-38.

Hammer, M. (2002), “Forward to basics," Fast Company, Volume 64, pp. 37-38.

Hammer, M. (2002b), "Process Management and the Future of Six Sigma," MIT Sloan Management Review, Volume 43, Number 2, pp. 26-32.

Harland, C., L. Knight, R. Lamming, and H. Walker (2005), "Outsourcing: Assessing the Risks and Benefits for Organizations, Sectors and Nations," International Journal of Operation and Production Management, Volume 25, Number 9, pp. 831-850.

Harrigan, K. R. (1986), "Matching Vertical Integration Strategies to Competitive Conditions," Strategic Management Journal, Volume 7, Number 6, pp. 535-555.

Hayes, T. (2007), "Delphi Study of the Future of Marketing of Higher Education," Journal of Business Research, Volume 60, pp. 927-931. 
Hicks, D. A. (1999), “A Four Step Methodology for Using Simulation and Optimization Technologies in Strategic Supply Chain Management," Proceedings of the 1999 Winter Simulation Conference, P. A. Farrington, H. B. Nembhard, D. T. Sturrock, G. W. Evans eds., pp. 1215-1220.

Holmberg, S. (2000). "A Systems Perspective on Supply Chain Measurements," International Journal of Physical Distribution \& Logistic Management, Volume 30, Number 10, pp. 847-868.

Holsapple, C. W. and K. D. Joshi (2000), "An Investigation of Factors that Influence the Management of Knowledge in Organization," Journal of Strategic Information Systems, Volume 9, pp. 235-261.

Hong-Minh, S. M., R. Barker, and M . M. Naim (2001), "Identifying Supply Chain Solutions in the UK House Building Sector," European Journal of Purchasing \& Supply Management, Volume 7, pp 49-59.

Huang, S. H., S. K. Sheoran, and G. Wang (2004), "A Review and Analysis of Supply Chain Operations Reference (SCOR) Model," Supply Chain Management: An International Journal, Volume 9, Number 1, pp. 23-29.

Huang, S. H., S. K. Sheoran, and H. Keskar (2005), "Computer-Assisted Supply Chain Configuration Based on Supply Chain Operations Reference (SCOR) Model," Computers \& Industrial Engineering, Volume 48, pp. 377-394.

Kakabadse, N., and A. Kakabadse (2000), "Critical Review - Outsourcing: A Paradigm Shift," The Journal of Management Development, Volume 19, Number 8, pp. 670728.

Kasi, V. (2005), "Systematic Assessment of SCOR for Modeling Supply Chain," Proceedings of the $38^{\text {th }}$ Hawaii International Conference on Systems Sciences, pp. 110.

Kengpol A. and M. Touminen (2006), "A Framework for group decision support systems: An Application in the Evaluation of Information Technology for Logistics Firms," International Journal of Production Economics, Volume 101, pp. 159-171.

Kerr, J. (2002), "What Does “Lean” Really Mean?," Logistics Management, Volume 45, Number 5, pp 29- 34.

Kole, M. A. (1983), "Go Outside for MIS Implementations," Information and Management, Volume 6, Number 5, pp. 261-268.

Kosanke, K., and M. Zelm (1999), "CIMOSA Modelling Process," Computers in Industry, Volume 40, pp. 141-153. 
Kosanke, K., F. Vernadat, and M. Zelm (1999), "Enterprise Engineering and Integration," Computers in Industry, Volume 40, pp. 83-97.

La Londe, B. J. and J. M. Masters (2004), "Emerging logistics strategies: Blueprints for the next century," International Journal of Physical Distribution \& Logistics, Volume 24, Number 7, pp. 35-47.

Lambert, D. M., M. C. Cooper, and J. D. Pagh (1998), "Supply Chain Management: Implementation Issues and Research Opportunities," International Journal of Logistics Management, Volume 9, Number 2, pp. 1-19.

Lambert, D. M. and T. L. Pohlen (2001), "Supply Chain Metrics," International Journal of Logistics Management, Volume 12, Number 1, pp. 1-19.

Lawes, Aidan (2006), "Making Best Practices Work for You," Computer Weekly, 5/9/2006, p. 24.

Lee, H. L., V. Padmanabhan and S. Whang (1997), "The Bullwhip Effect in Supply Chains," MIT Sloan Mangement Review, Volume 38, Number 3, pp. 93-102.

Li, H., and T. J. Williams (2002), "Management of complexity in Enterprise Integration Projects by the PERA Methodology," Journal of Intelligent Manufacturing, Volume 13, Number 6, pp. 417-427.

Li, Z., A. Kumar, and Y. G. Lim (2002), "Supply Chain Modeling: A Coordination Approach," Integrated Manufacturing Systems, Volume 13, Number 8, pp. 551-561.

Lin, F., M. Yang, and Y. Pai (2002), "A Generic Structure for Business Process Modeling," Business Process Management Journal, Volume 8, Number 1, pp. 19-41.

Linstone, H. A. and M. Turoff (1975), The Delphi Method: Techniques and Applications, Addison-Wesley, London.

Lockamy III, A., and K. McCormack (2004), “The Development of a Supply Chain Management Process Maturity Model Using Concepts of Business Process Orientation," Supply Chain Management: An International Journal, Volume 9, Number 4, pp. 272-278.

Lockamy III, A., and K. McCormack (2004b), "Linking Score Planning Practices to Supply Chain Performance: An Exploratory Study," International Journal of Operations \& Production Management, Volume 24, Number 12, pp. 1192-1218.

Lummus, R. R., D. W. Krumwiede, and R. J. Vokurka (2001), "The Relationship of Logistics to Supply Chain Management: Developing a Common Industry Definition," Industrial Management and Data Systems, Volume 101, Number 8, pp. 426-431. 
Markus, M.L., M. Tanniru, and P. C. Van Fenema (2000), "Multisite ERP Implementations", Communications of the ACM, Volume 43, Number 4, p. 42.

McCormack K. P., W. C. Johnson with W. T. Walker (2002), Supply Chain Networks and Business Process Orientations, Boca Raton, Florida, The St. Lucie Press/APICS Series on Resource Management.

McGuire E. G. and K. A. McKeown (2001) "5 Critical Steps for Adopting CMM in an ISO Environment," International Conference on Management of Engineering and Technology, Volume 1, pp. 430-431.

Mentzer, J. T., W. DeWitt, J. S. Keebler, S. Min, N. W. Nix, C. D. Smith, and Z. G. Zacharia (2001), "Defining Supply Chain Management," Journal of Business Logisitcs, Volume 22, Number 2, pp. 1-25.

Mertins K., and R. Jochem (2005), “Architectures, Methods and Tools for Enterprise Engineering," International Journal of Production Economics, Volume 98, 2005

Miller, G. D. (2004), "Common Mistakes in Supply Chain Buying," Frontline Solutions, Volume 5, Number 9, pp. 42-43.

Motwani, J., M. Madan, A. Gunasekaran (2000), "Information Technology in Managing Global Supply Chains," Logistics Information Management, Volume 13, Number 5, pp. 320-327.

Mullen, P. M. (2003), “Delphi: Myths and Reality," Journal of Health Organization and Management, Volume 17, Number 1, pp. 37-52.

Murugappan, M. and G. Kenni (2003), "Blending CMM and Six Sigma to Meet Business Goals," IEEE Software, Volume 20, Number 2, pp. 42-48.

National Institute of Standards and Technology (NIST) (1999), "Interoperability Cost Analysis of the US Automotive Supply Chain," Prepared by S. B. Brunnermeier and S. A. Martin, Research Triangle Institute, Strategic Planning and Economic Assessment office.

Neely, A., M. Gregory, and K. Platts (1997), "Performance Measurement Systems Design a Literature Review and Research agenda," International Journal of Operation and Production Management, Volume 15, Number 4, pp. 80-116.

Noran O. (2003), “An Analysis of the Zachman Framework for Enterprise Architecture from the GERAM Perspective," Annual Review in Control, Volume 27, pp. 163-183.

Okoli, C., and S. D. Pawlowski (2004), "The Delphi Method as a Research Tool: An Example, Design Considerations and Applications," Information \& Management, Volume 42, pp. 15-29. 
Pereira C. M., and P. Sousa (2004), "A Method to Define an Enterprise Architecture Using the Zachman Framework," Proceedings of the 2004 ACM Symposium on Applied Computing, ACM Press New York, N. Y., pp. 1366-1371.

Phelps T., M. Smith, and T. Hoenes (2004), "Building a Lean Supply Chain," Manufacturing Engineering, Volume 132, Number 5, pp. 107-113.

Porter, M.E. (1985), Competitive Advantage: Creating and Sustaining Superior Performance, The Free Press, New York, NY.

Rollins, R. P., K. Porter, and D. Little (2003), "Modelling the Changing Apparel Supply Chain," International Journal of Clothing Science and Technology, Volume 15, Number 2, pp. 140-156.

Saenz O. A., and C. Chen (2004), "A Framework for Enterprise Systems Engineering," Proceedings of the Second LACCEI International Latin American and Caribbean Conference for Engineering and Technology, Information Technology Track, paper number 033.

Samaranayake, P. (2005), "A Conceptual Framework for Supply Chain Management: A Structural Integration," Supply Chain Management: An International Journal, Volume 10, Number 1, pp. 47-59.

Sengupta, S. (2004), "The Top 10 Supply Chain Mistakes," Supply Chain Management Review, Volume 8, Number 5, pp. 42-49.

Shapiro, J. F. (2001), "Modeling and IT Perspectives on Supply Chain Integration," Information Systems Frontiers, Volume 3, Number 4, pp 455-464.

Siau, K. and Y. Tian (2004), "Supply Chains Integration: Architecture and Enabling Technologies," The Journal of Computer Information Systems, Volume 44, Number 3, pp. 67-72.

Stank, T. P., and T. J. Goldsby (2000), "A Framework for Transportation Decision Making in an Integrated Supply Chain," Supply Chain Management An International Journal, Volume 5, Number 2, pp. 71-77.

Stevens, G. (1989), "Integrating the Supply Chain," International Journal of Physical Distribution and Logistics Management, Volume 19, Number 8, pp. 3-8.

Stewart, G. (1997), "Supply Chain Operations Reference (SCOR): The first Crossindustry Framework for Integrated Supply Chain Management," Logistic Information Management, Volume 10, Number 2, pp. 62-67. 
Stock, J.R. (1990), "Logistics Thought and Practice: a Perspective," International Journal of Physical Distribution \& Logistics Management, Vol. 20 No. 1, p. 5.

Stock, J. R. (1997). "Applying Theories from Other Disciplines to Logistics," International Journal of Physical Distribution and Logistics, Volume 27, Number 9/10, pp. 515-539.

Svensson, G. (2002), "The Theoretical Foundation of Supply Chain Management: A Functionalist Theory of Marketing," International Journal of Physical Distribution and Logistics, Volume 32, Number 9, pp. 734-754.

Svensson, G. (2003), "Holistic and Cross-Disciplinary Deficiencies in the Theory Generation of Supply Chain Management," Supply Chain Management: An International Journal, Volume 8, Number 4, pp. 303-316.

Timm, R. (1993), "Outsourcing Can Be a Productivity Solution for the 90's," HR Focus, Volume 70, Number 11, p. 23.

Turoff, M. (1970), "The Design of a Policy Delphi," Technological Forecasting and Social Change, Volume 2, Number 2, pp 149-171.

Tyndall, G., C. Gopal, W. Partsch, and J. Kamauff (1998), Super-charging Supply Chains: New Ways to Increase Value through Global Operational Excellence, New York, N.Y., John Wiley \& Sons.

Van der Vorst, J. G. A. J., and A. J. M. Beulens (2002), "Identifying Sources of Uncertainty to Generate Supply Chain Redesign Strategies," International Journal of Physical Distribution \& Logistics Management, Volume 32, Number 6, pp. 409-430.

Van der Zee, D. J., and J. G. A. J. Van der Vorst (2005), “A Modeling Framework for Supply Chain Simulation: Opportunities for Improved Decision Making," Decision Sciences, Volume 36, Number 1, pp. 65-95.

Verhagen A. P., A. P., H. C. W. de Vet, R. A. de Bie, A. G. H. Kessels, M. Boers, L. M. Bouter, and P. G. Knipschild (1998), "The Delphi List: A Criteria List for Quality Assessment of Randomized Clinical Trials for Conducting Systematic Reviews Developed by Delphi Consensus," Journal of Clinic Epidemiology, Volume 51, Number 12, pp. 1235-1241.

Vitasek K., K. B. Manrodt, J. Abbott (2005), "What Makes a LEAN Supply Chain?," Supply Chain Management Review, Volume 9, Number 7, pp. 39-45.

White R. E., and J. N. Pearson (2001), "JIT, System Integrations and Customer Service," International Journal of Physical Distribution and Logistics Management, Volume 31, Number 5, pp. 313-333. 
Whitman L., K. Ramachandran, V. Ketkar (2001), "A Taxonomy of a Living Model of the Enterprise," Proceedings of the 2001 Winter Simulation Conference, B. A. Peters, J. S. Smith, D. J. Medeiros, and M. W. Rohrer eds., pp. 848-855.

Williams, T. J. (1998), Handbook of Life-cycle Engineering: Concepts, Models, and Technologies, Molina, A., A. Kusiak, and J. M. Sanchez eds., Dordrecht, the Netherlands, Kluwer Academic Publisher.

Yoo, C., J. Yoon, B. Lee, C. Lee, J. Lee, S. Hyun, and C. Wu (2004), "An Integrated Model of ISO 9001:2000 and CMMI for ISO Registered Organizations," Proceedings of the 11th Asia-Pacific Software Engineering Conference, pp. 150-157.

Yu, B., J. A. Harding, and K. Popplewell (2000), "A Reusable Enterprise Model," International Journal of Operations \& Production Management, Volume 20, Number 1, pp. 50-69.

Yu, B., J. A. Harding, and K. Popplewell (2000b), "Supporting Enterprise Design Through Multiple Views," International Journal of Agile Management Systems, Volume 2, Number 1, pp. 71-82.

Zachman, J. A. (1999), "A Framework for Information Systems Architecture," IBM Systems Journal, Volume 38, Number 2/3, pp. 454-470.

Zülch,G., A. Rinn, and O. Strate (2001), "Dynamic analysis of changes in decisional structures of production systems," International Journal of Production Economics, Volume 69, pp. 239-252. 


\section{APPENDICES}

APPENDIX 1: INVITATION LETTER FOR THE FIRST ROUND AT STAGE I

Date: XXXX

To: XXXX

By this mean, I like inviting you to participate in a research project about supply chain management. The objective of this research is to define a five levels maturity model to assess the enterprise's supply chain processes. The model development implies to collect and analyze the opinion of several experts in the supply chain field. As you are considering an expert by your experience and recognition in supply chain or related fields, your participation is worthwhile to us. The research process involves two rounds of questions. All the answers provided in the first round will be compiled and summarized. After you will be receiving a second questionnaire designed to go in depth in the findings obtained from the first round of answers. I will really appreciate your time and cooperation.

Sincerely

XXXX 
Name

Company

Position

Years of experience in the supply chain field or similar

Please answer the following open-end questions.

1. What do you understand by supply chain management?

2. According to the following taxonomy:

Level one: an enterprise with poor supply chain development

Level two: ------

Level three: ------

Level four: ------

Level five: an enterprise leader on the market (benchmarking)

What characteristics have an enterprise in each one of these level? 
ApPENDIX 2: Delphi SuRVEY FOR THE SECOND Round AT THE STAGE I

Second Round

Date XXXX

\section{To XXXX}

I appreciate your previous participation in the first round. This time I like inviting you to answer this second survey. The objectives of this second round are to improve and to validate the supply chain definition generated from the first round of results and to identify the key elements at each maturity level, according to the taxonomy defined in the previous survey. Thanks again for your time and participation.

\section{Sincerely}

XXXX

Name

Company

Position

Years of experience in the supply chain field or similar 
After reviewing the data obtained from the first round of results, the following definition was established:

"Supply chain is a network of enterprises, which integrates all processes from the supply and procurement of raw materials to delivering a finished good. The supply chain involves all processes oriented to improve logistics and productivity”.

1. Select from the following options how much you agree with this definition.

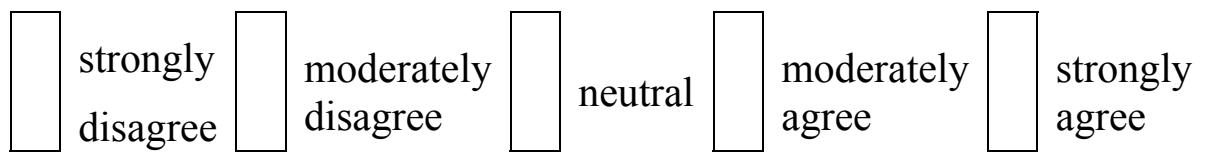

2. Include your comments in order to improve the definition. What is missing?

The following list of supply chain elements was generated from the data obtained in the first round. According to you, which of them are key factors for each maturity level? It can be selected as many as you consider relevant for each maturity level. Consider level one as an enterprise with a poor supply chain development and level five as an enterprise leader on the market (benchmarking). 


$\begin{array}{lll}\text { 1. Company Objectives, } & \text { 10. ISO } & \text { 19. Product } \\ \text { vision and mission } & \text { 11. KPI } & \text { 20. Product Distribution } \\ \text { 2. Cost } & \text { 12. Lead Time } & \text { 21. Production } \\ \text { 3. Customer requirements } & \text { 13. Logistics } & \text { 22. Quality } \\ \text { 4. Customer Service } & \text { 14. Optimization processes } & \text { 23. Raw materials } \\ \text { 5. Defects/reworks/scrap } & \text { 15. Organization structure } & \text { procurement } \\ \text { 6. Demand Forecasting } & \text { 16. Procedures } & \text { 24. Change Response Time } \\ \text { 7. Demand Management } & \text { 17. Process Capability } & \text { 25. Shipping } \\ \text { 8. Enterprise Policies } & \text { 18. Processes } & \text { 26. Suppliers } \\ \text { 9. Inventory Management } & \text { Synchronization } & \text { 27. Warehousing }\end{array}$

3. Include a brief explanation of any other element does not listed. 


\section{APPENDix 3: InVITATION LETTER FOR THE FiRST Round AT STAGE II}

\section{First Round}

Date: XXXX

\section{To: XXXX}

By this mean, I like inviting you to participate in a research project about supply chain management. The objective of this research are to define a five level model of supply chain development and identify tools, techniques, methodologies, etc. available to improve the supply chain from one maturity level to the next one. The model development implies to collect and analyze the opinion of several experts in the supply chain field. As you are considering an expert by your experience and recognition in supply chain or related fields, your participation is worthwhile to us. The research process involves two rounds of questions. All the answers provided in the first round will be compiled and summarized. After you will be receiving a second questionnaire designed to go in depth in the findings obtained from the first round of answers. I will really appreciate your time and cooperation.

\section{Sincerely}

XXXX 
Name

Company

Position

Years of experience in the supply chain field or similar

\section{Section One: Supply Chain definition}

Please read the following supply chain definition

"Supply Chain is a system which manages and controls the use of facilities, processes, resources, and supplies in order to improve the logistic productivity in the enterprise. All the processes of the supply chain system have the objective of promoting products and/or services with value to their customers. This goal is achieved through the coordination among all the supply chain stakeholders. All supply chain processes are based on the knowledge and satisfaction of the customer requirements regarding quality, time response, cost, flexibility, and innovation".

Considering this definition, select how much you agree with each of the segments using the provided scale.

1. Supply Chain is a system which manages and controls the use of facilities, processes, resources, and supplies in order to improve the logistic productivity in the enterprise.

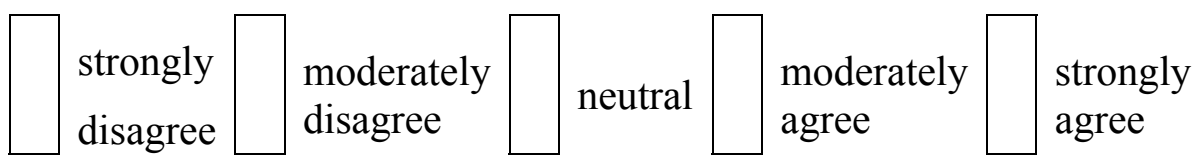


2. All the processes of the supply chain system have the objective of promoting products and/or services with value to their customers. This goal is achieved through the coordination among all the supply chain stakeholders.

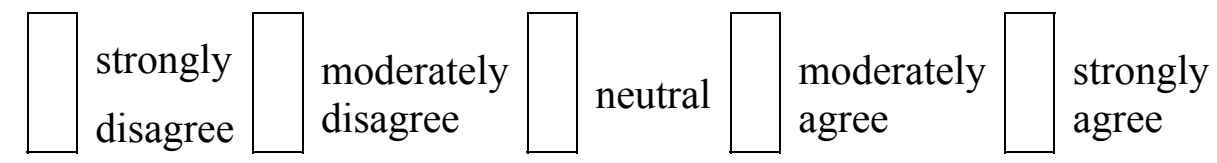

3. All supply chain processes are based on the knowledge and satisfaction of the customer requirements regarding quality, time response, cost, flexibility, and innovation.

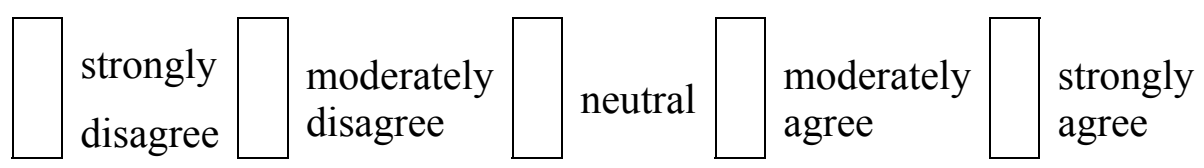

\section{Section Two: Maturity level definition}

Please read the following enterprise's characteristics of each maturity level. Considering these definitions, selects form the following options your agreement level using the provided scale.

Maturity level one (undefined). This is an enterprise with no process documentation or standardization; there is lack of knowledge about the enterprise's processes, activities, and tasks; the enterprise primarily reacts to the environment instead of planning; the enterprise remains in the market by a small advantage on sale price, location, or customer relationship in comparison with the competition; there is no continuous improvement plan defined; all the improvements are reached by individual and isolated efforts; the productive processes are focused on completing the customer orders; however, they may 
experience frequent problems in meeting customers' expectations; the enterprise does not have a defined vision or mission.

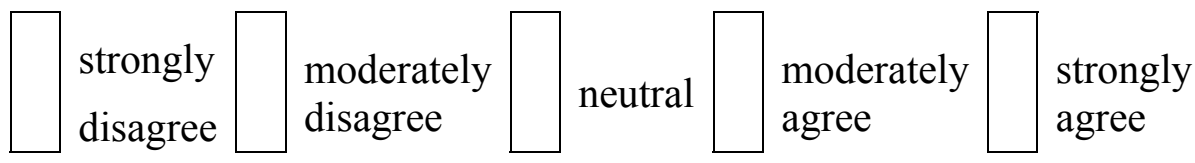

Provide any comment and suggestion to improve this definition.

Maturity level two (Defined). This is an enterprise which recognizes the value of defining its vision and mission; at this level the enterprise starts to consider the strategic market elements such as price fluctuations, new products, tendencies, etc; there is lack of documentation at all the enterprise levels; the enterprise has not defined a target market to which offer a wide catalog of products, even though many of the products imply losing money; the first attempts to develop customer loyalty and suppliers appear; the enterprise has basic and generic office software without specialized software for the industry or functions; the enterprise starts to collect data and use them to generate information useful to making decisions; there are no performance measurement systems; and the improvement efforts are still unorganized.

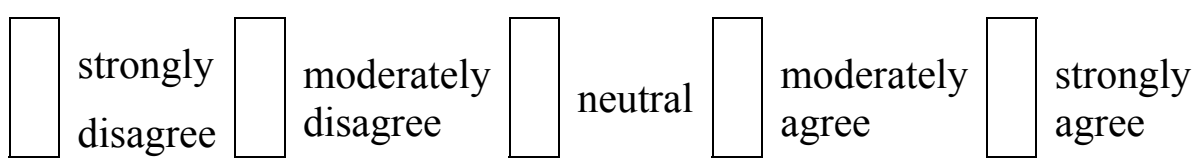


Provide any comment and suggestion to improve this definition.

Maturity level three (Manageable). The enterprise is searching a target market, the first attempt to integrate processes is made; the enterprise starts to deploy continuous improvement plans with special focus on process documentation and standardization; the personnel is induced to an organizational culture oriented to customer satisfaction and personal development; there are closer negotiations with suppliers regarding policies, times and costs; the improvement process applied a set of tools or techniques instead of a single one; there are isolated information systems useful to measure, control, and make decisions oriented to processes improvement.

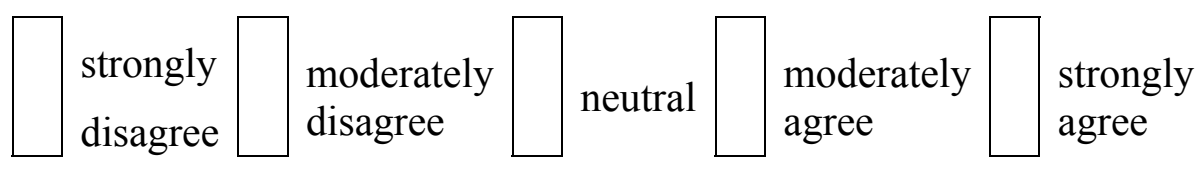

Provide any comment and suggestion to improve this definition. 
Maturity level four (Collaborative). An enterprise at this level has defined collaboration strategies oriented to integrate customers and suppliers; there is clear orientation to satisfy the customer's expectations; there are several improvement processes related to the knowledge of customers' needs; there are integrated information systems, which provide a technological platform for data exchange among suppliers, company, and customers, generating key information about the market and the competence; there are several measurements and evaluation related to the supplier's performance; there is a better selection of suppliers; the enterprise uses more complex improvement processes due to the holistic project focus; there is in depth knowledge of all the enterprise's processes.

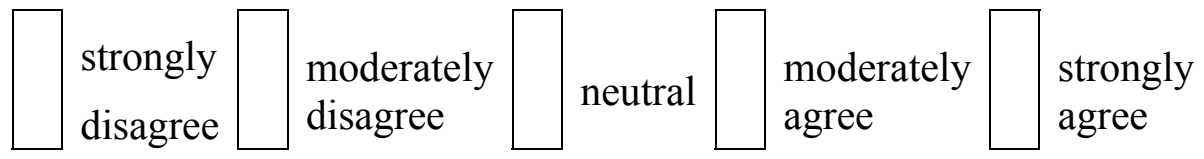

Provide any comment and suggestion to improve this definition.

Maturity level five (Leading). An enterprise in this maturity level will be able to innovate, develop, and transfer the best practices; this type of enterprises has a strong influence over suppliers and customers regarding their work culture and methods, information systems, continuous improvement processes etc; key processes and functions 
are aligned to the enterprise's mission and corporative strategy; the personnel is aware about the value that they add to the product with their activities, such that they are looking for more efficient and effective ways to do them. Information systems integrate suppliers, company, and customers' key information, which is available to everyone who needs it; there is a strong dependence of technological solutions.

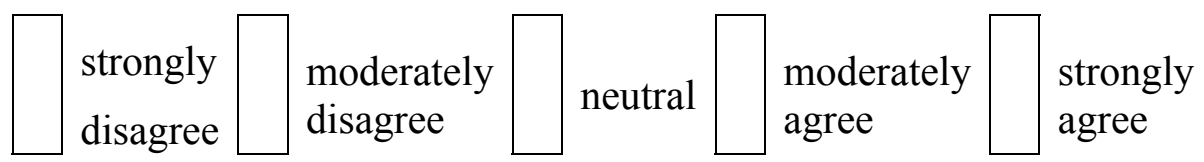

Provide any comment and suggestion to improve this definition. 


\section{To XXXX}

I appreciate your previous participation in the first round. This time I like inviting you to answer this second survey. The objective of this second survey is to collect a set of tools useful to improve a supply chain from one maturity level to the next one. The maturity levels are defined according to the answer obtained from the first round. Thanks again for your time and participation.

\section{Sincerely}

XXXX

Name

Company

Position

Years of experience in the supply chain field or similar 


\section{Section One: Maturity Levels definitions}

Due the definitions of the maturity levels were accepted in a general sense, the final definition for each level is as follows:

\section{Maturity Level: Undefined}

This is an enterprise with no process documentation or standardization; there is lack of knowledge about the enterprise's processes, activities, and tasks; the enterprise primarily reacts to the environment instead of planning; the enterprise remains in the market by a small advantage on sale price, location, or customer relationship in comparison with the competition; there is no continuous improvement plan defined; all the improvements are reached by individual and isolated efforts; the productive processes are focused on completing the customer orders; however, they may experience frequent problems in meeting customers' expectations; the enterprise does not have a defined vision or mission.

\section{Maturity Level: Defined}

This is an enterprise which recognizes the value of defining its vision and mission; at this level the enterprise starts to consider the strategic market elements such as price fluctuations, new products, tendencies, etc; there is lack of documentation at all the enterprise levels; the enterprise has not defined a target market to which offer a wide catalog of products, even though many of the products imply losing money; the first attempts to develop customer loyalty and suppliers appear; the enterprise has basic and generic office software without specialized software for the industry or functions; the enterprise starts to collect data and use them to generate information useful to making 
decisions; there are no performance measurement systems; and the improvement efforts are still unorganized.

\section{Maturity Level: Manageable}

The enterprise is searching a target market, the first attempt to integrate processes is made; the enterprise starts to deploy continuous improvement plans with special focus on process documentation and standardization; the personnel is induced to an organizational culture oriented to customer satisfaction and personal development; there are closer negotiations with suppliers regarding policies, times and costs; the improvement process applied a set of tools or techniques instead of a single one; there are isolated information systems useful to measure, control, and make decisions oriented to processes improvement.

\section{Maturity Level: Collaborative}

An enterprise at this level has defined collaboration strategies oriented to integrate customers and suppliers; there is clear orientation to satisfy the customer's expectations; there are several improvement processes related to the knowledge of customers' needs; there are integrated information systems, which provide a technological platform for data exchange among suppliers, company, and customers, generating key information about the market and the competence; there are several measurements and evaluation related to the supplier's performance; there is a better selection of suppliers; the enterprise uses more complex improvement processes due to the holistic project focus; there is in depth knowledge of all the enterprise's processes. 


\section{Maturity Level: Leading}

An enterprise in this maturity level will be able to innovate, develop, and transfer the best practices; this type of enterprises has a strong influence over suppliers and customers regarding their work culture and methods, information systems, continuous improvement processes etc; key processes and functions are aligned to the enterprise's mission and corporative strategy; the personnel is aware about the value that they add to the product with their activities, such that they are looking for more efficient and effective ways to do them. Information systems integrate suppliers, company, and customers' key information, which is available to everyone who needs it; there is a strong dependence of technological solutions.

Considering these definitions provide a set of tools, techniques, work philosophies, methodologies etc. useful to advance from one maturity level to the next one.

\section{Section Two: Tools, techniques, methodologies etc.}

Regarding the definition of each maturity level, list the tools, techniques, methodologies, philosophies etc. useful to pass from one level to the next one.

From level one to level two 
From level two to level three

From level three to level four

From level four to level five

To keep level five 


\section{ApPendix 5: The Five Levels of the S(CM ${ }^{2}$}

Maturity Level: Undefined

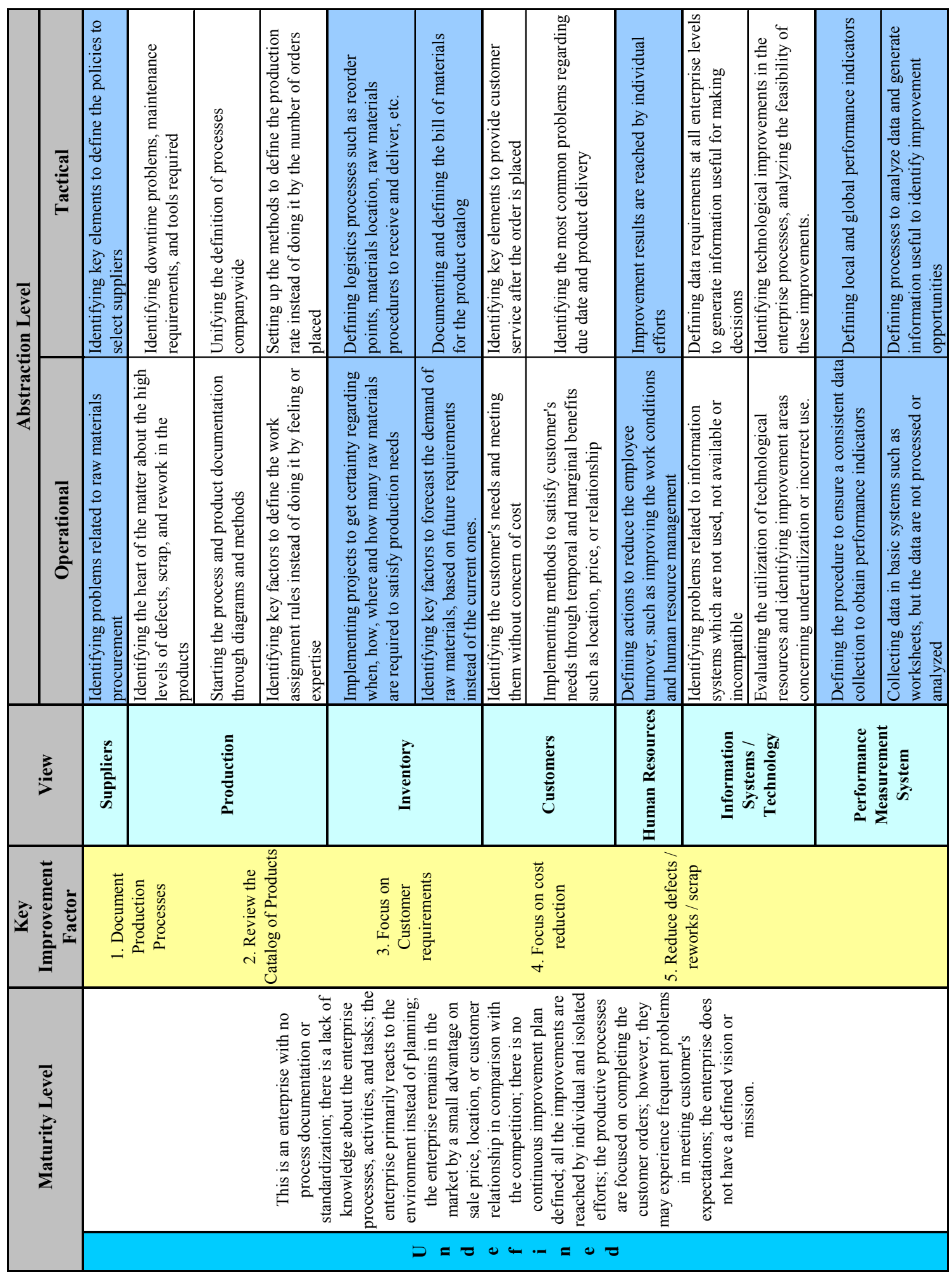


Maturity Level: Undefined (continuation)

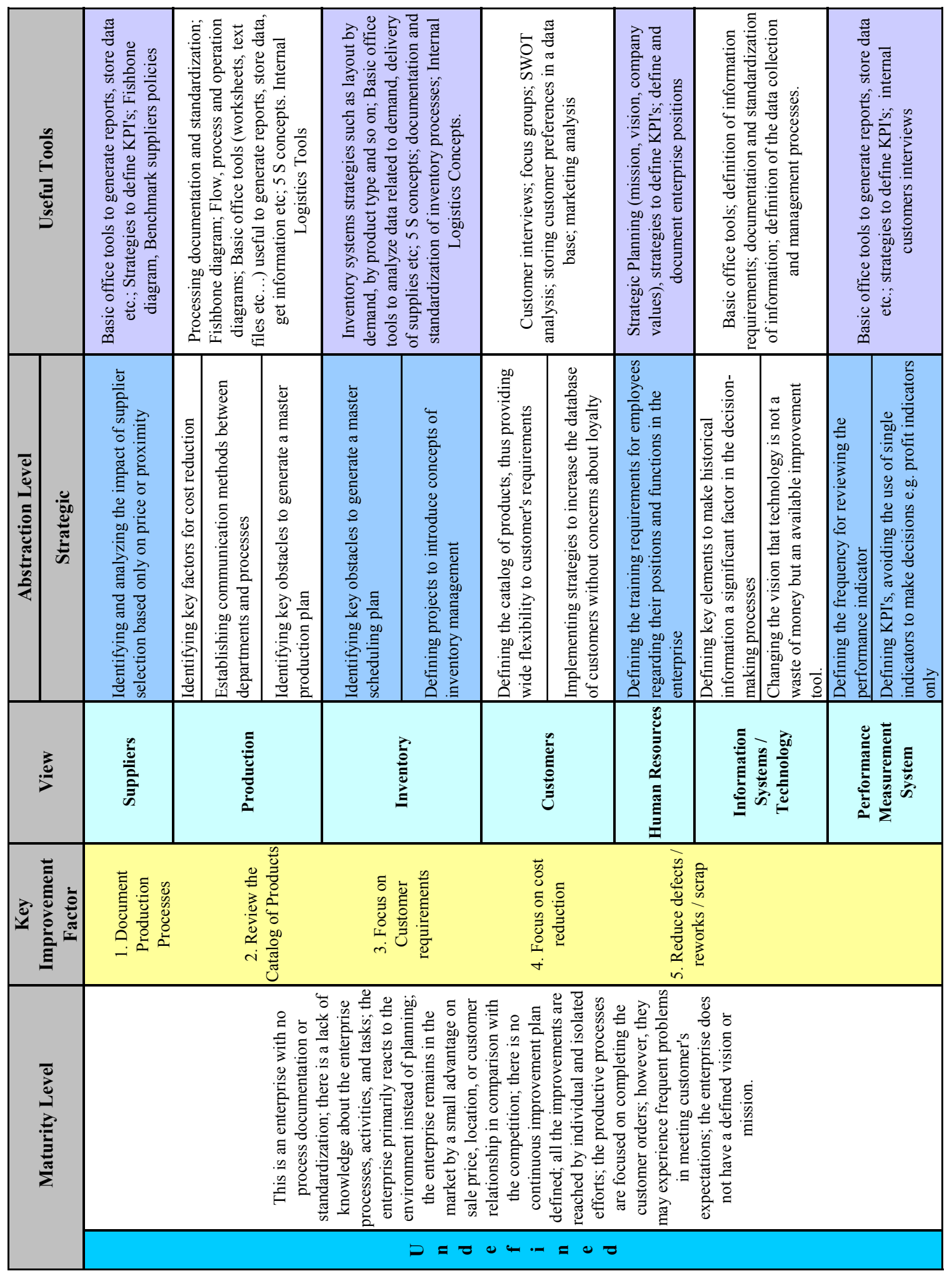




\section{Maturity Level: Defined}

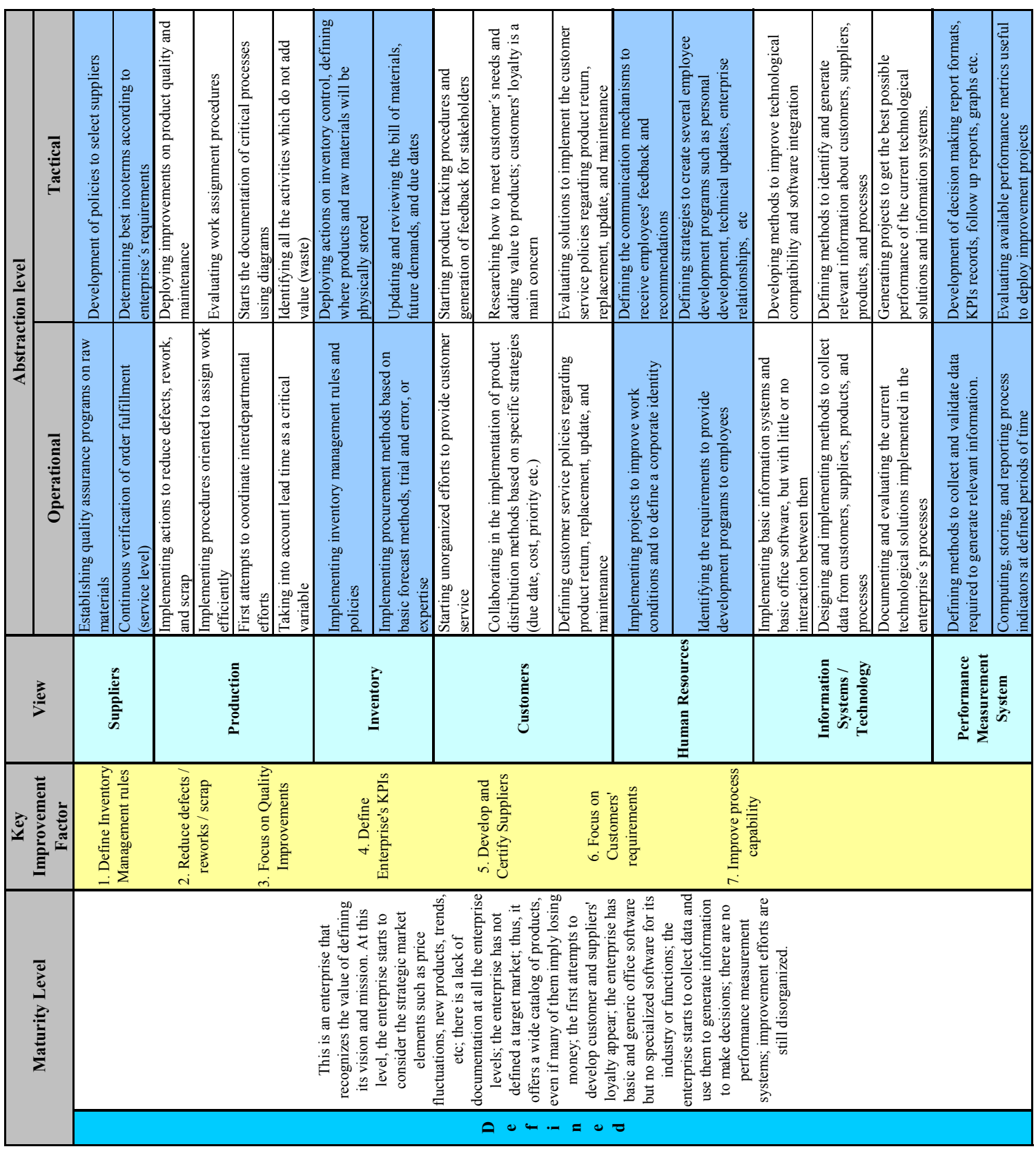


Maturity Level: Defined (continuation)

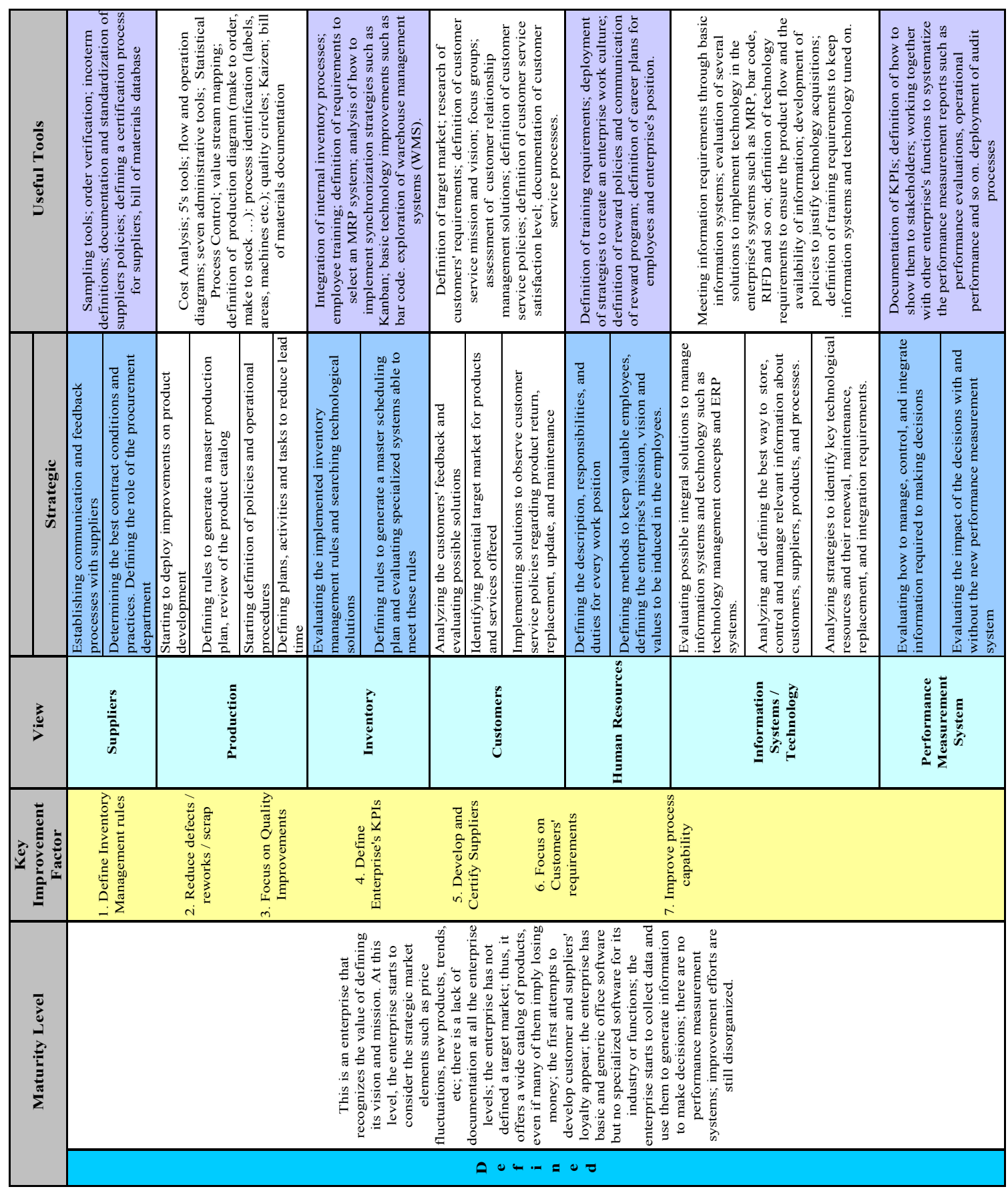




\section{Maturity Level: Manageable}

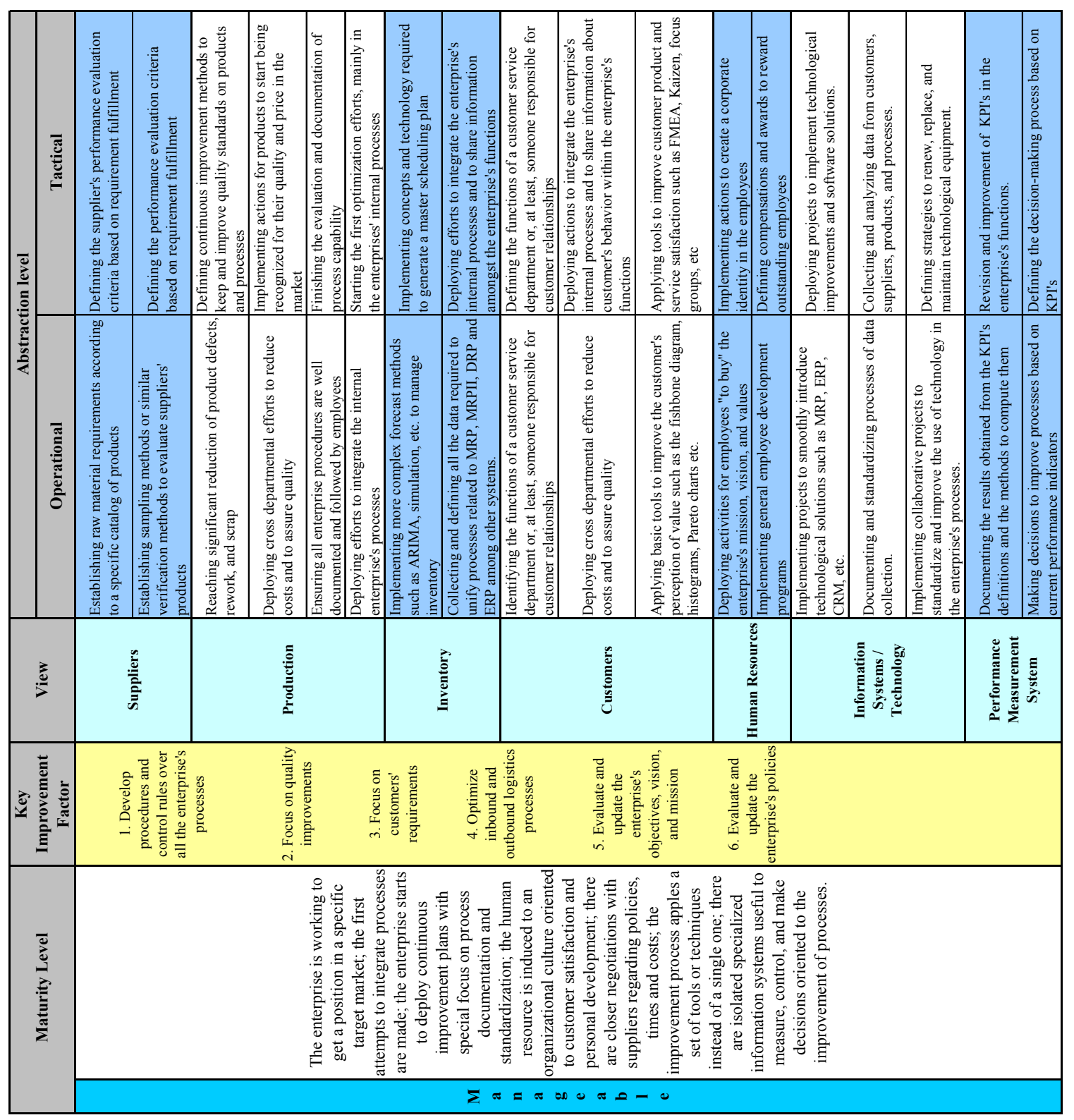




\section{Maturity Level: Manageable (continuation)}

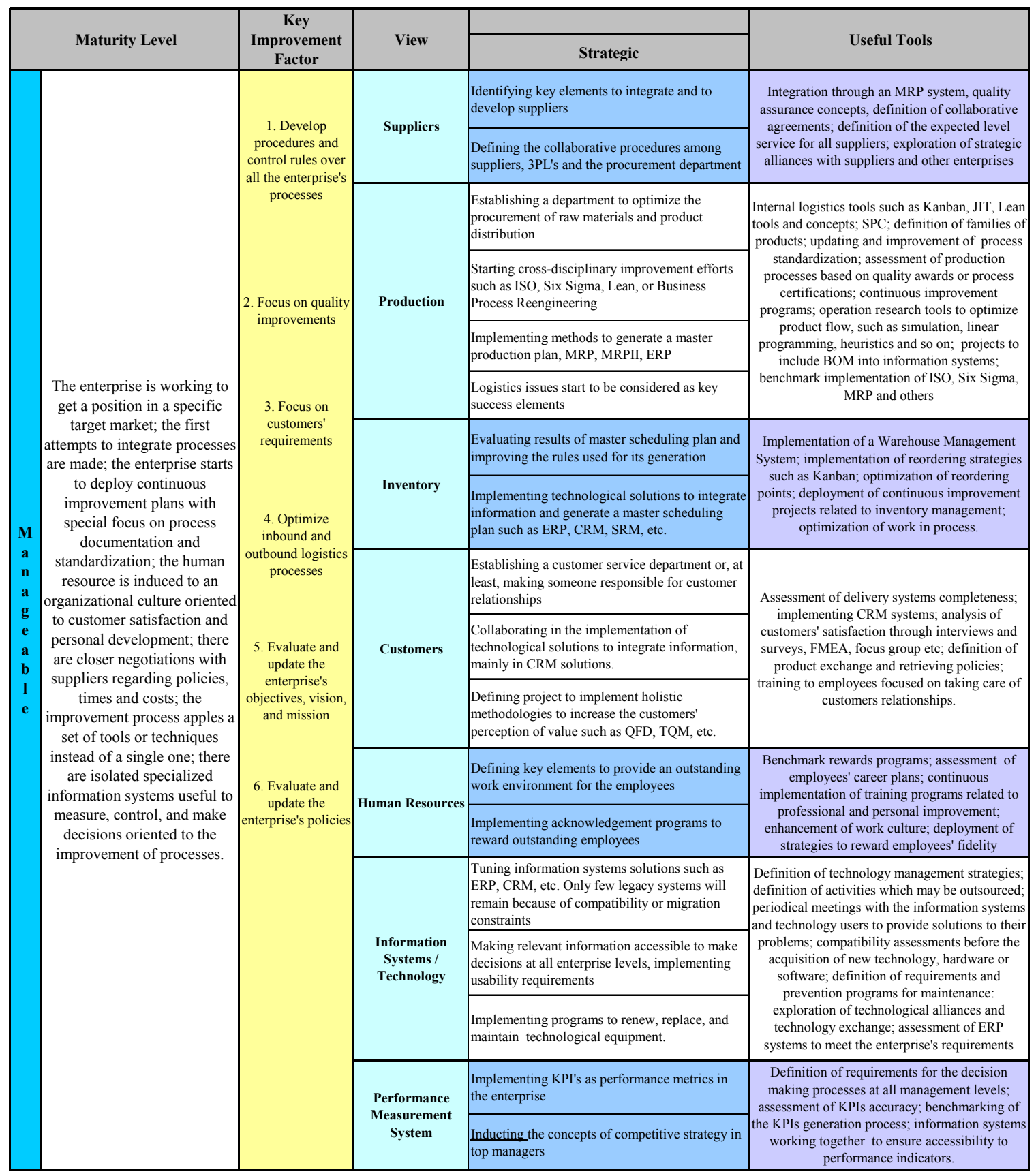




\section{Maturity Level: Collaborative}

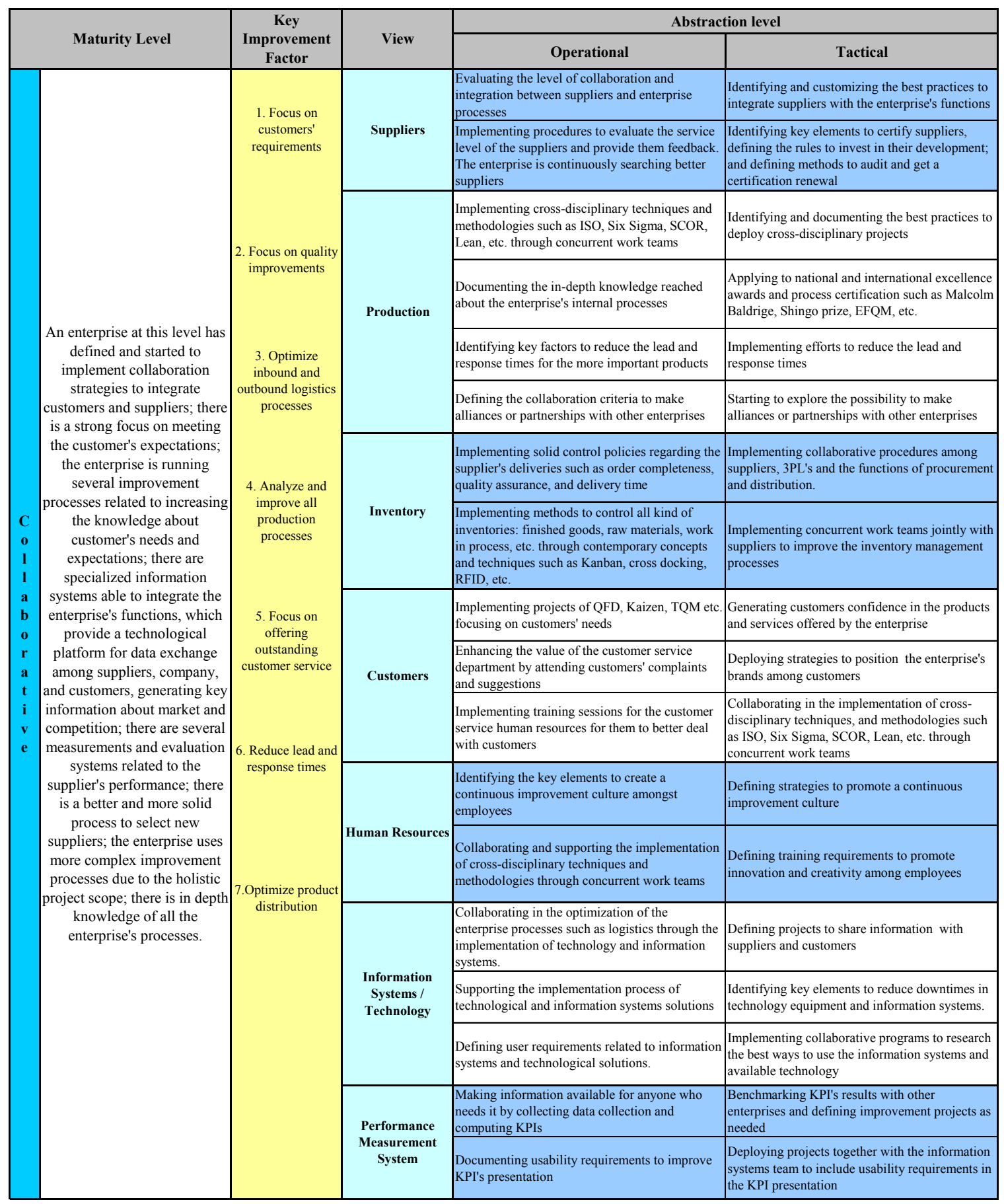




\section{Maturity Level: Collaborative (continuation)}

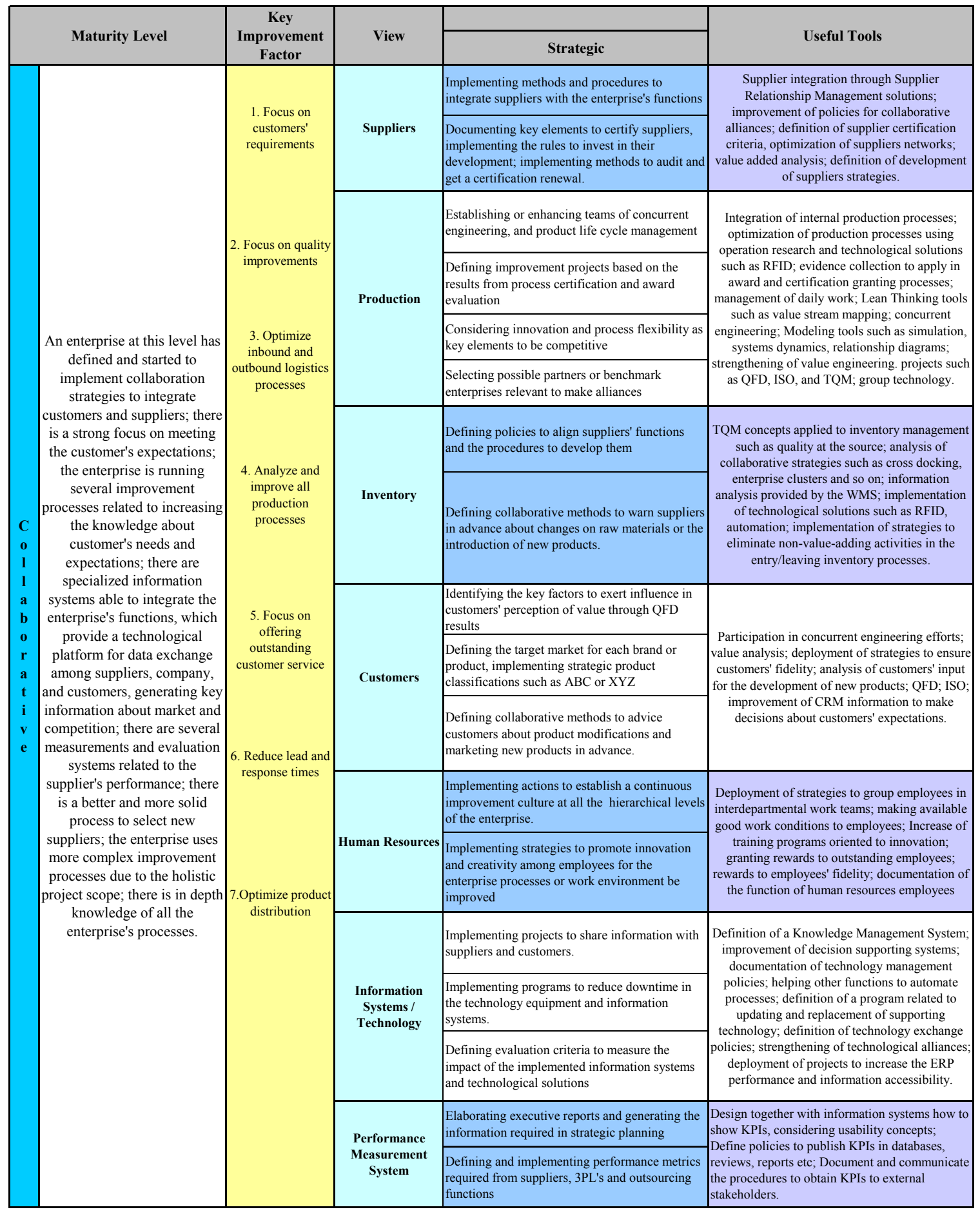




\section{Maturity Level: Leading}

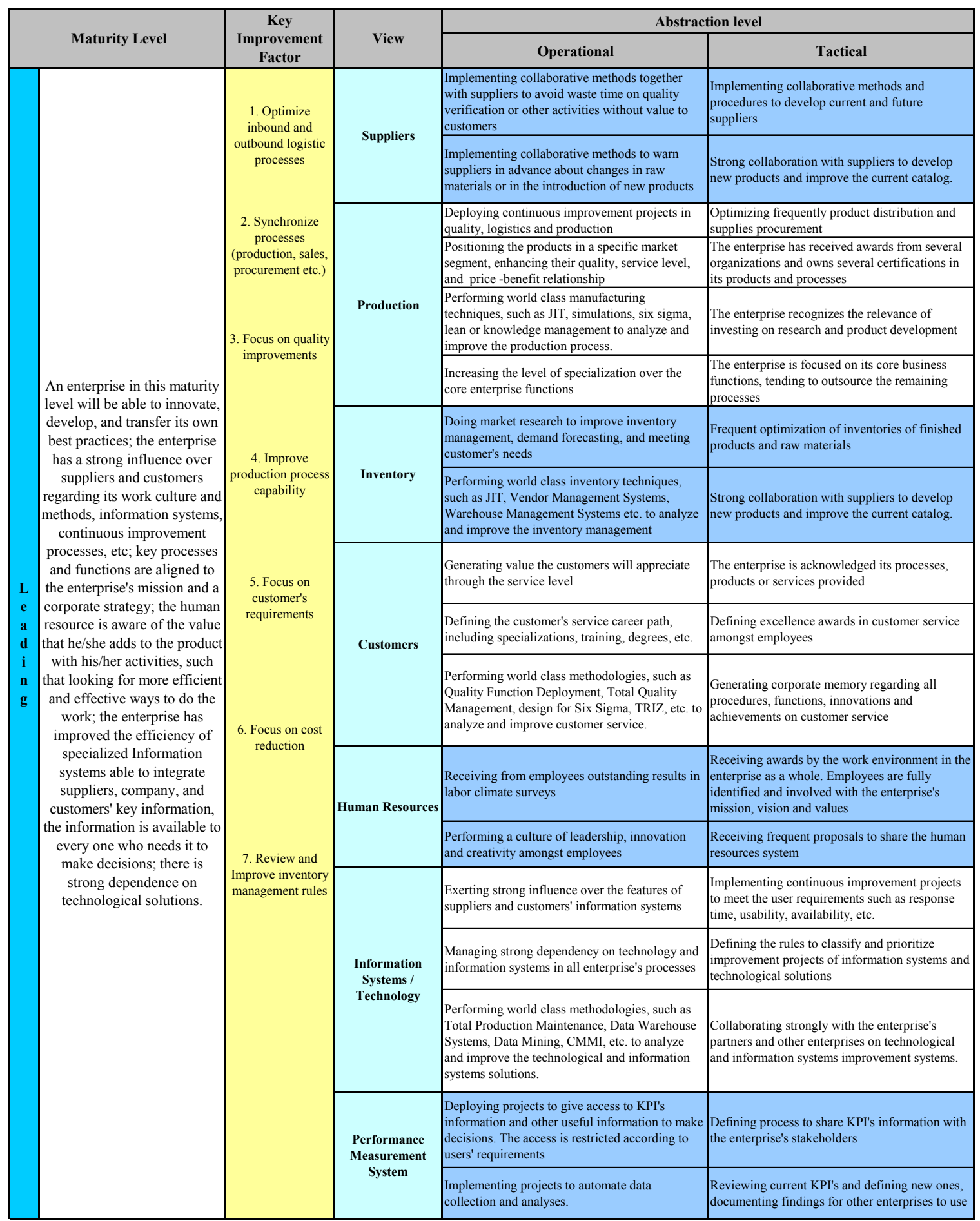




\section{Maturity Level: Leading (continuation)}

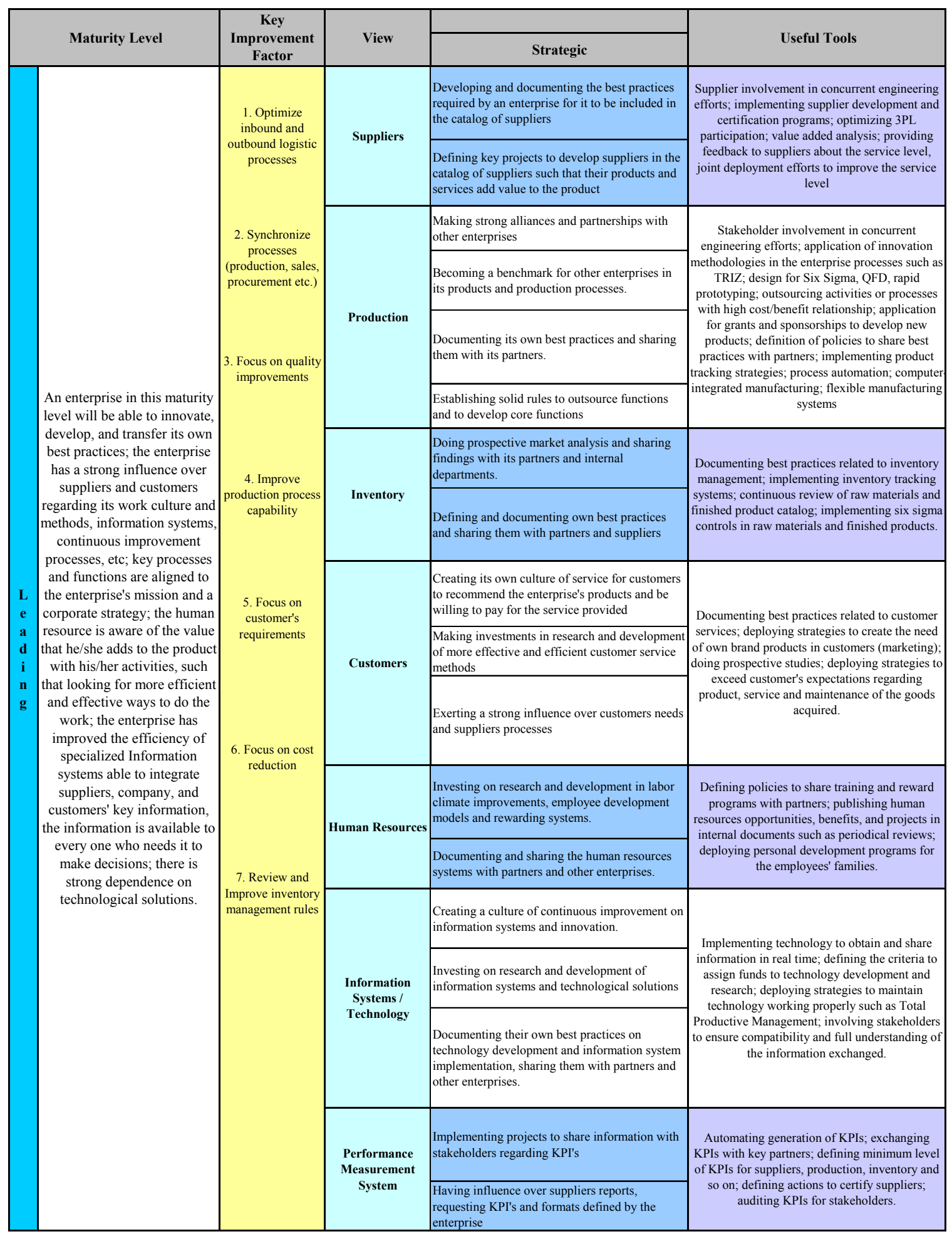


APPENDIX 6: S(CM) ${ }^{2}$ VALIDATION SHEET

\section{$\underline{\text { General Information }}$}

Date:

Name:

Position:

Business Type:

Years of Experience in Supply Chain or related field:

Academic Credentials:

After reviewing the model, please answer the following open-end questions

1. What advantages can you identify in the model?

2. What improvement opportunities can you identify in the model?

3. This model was developed to assess the processes in a supply chain and defining an improvement road map. Do you consider this model meet this goal? Yes/No/Why? 
The following case of study belongs to a research about a model useful to assess and improve the enterprise supply chain processes. The model classifies the maturity level of the processes according to seven views named: Suppliers, Production, Inventories, Customers, Human Resources, Information Systems \& Technology, and Performance Measurement Systems. The maturity levels are defined as Undefined, Defined, Manageable, Collaborative, and Leading. The definition of each maturity level is the following:

Undefined: ......

Defined: .......

Manageable: ......

Collaborative: .......

Leading: .......

The following are two assessment reports; these reports are based on findings regarding the supply chain processes of the Enterprise X and the Enterprise Y. Please classify the enterprise views regarding the definitions provided by each maturity level.

\section{Enterprise $X$ report}

Description of the supply chain processes for the enterprise X. These reports are based directly on the reference actions included in the model. 


\begin{tabular}{|c|c|c|c|}
\hline View & Maturity Level & View & Maturity Level \\
\hline Suppliers & & Human Resources & \\
\hline Production & & $\begin{array}{c}\text { Information Systems and } \\
\text { Technology }\end{array}$ & \\
\hline Inventories & & $\begin{array}{c}\text { Performance } \\
\text { Measurement Systems }\end{array}$ & \\
\hline Customers & & & \\
\hline
\end{tabular}

\section{Enterprise Y report}

Description of the supply chain processes for the enterprise Y. These reports are based directly on the reference actions included in the model.

\begin{tabular}{|c|c|c|c|}
\hline View & Maturity Level & View & Maturity Level \\
\hline Suppliers & & Human Resources & \\
\hline Production & & $\begin{array}{c}\text { Information Systems and } \\
\text { Technology }\end{array}$ & \\
\hline Inventories & & $\begin{array}{c}\text { Performance } \\
\text { Measurement Systems }\end{array}$ & \\
\hline Customers & & & \\
\hline
\end{tabular}

\section{General Information:}

Date:

Name:

Position:

Business Type:

Academic Credentials: 
VITA

HERIBERTO GARCIA

\section{$\underline{\text { ACADEMIC DEGREES }}$}

2009 Florida International University, Miami, FL

Doctoral Candidate in Industrial and Systems Engineering, Spring 2009

2007 Instituto Tecnológico y De Estudios Superiores de Monterrey, Nuevo León, Mx Master of Science in Industrial Engineering (MSIE)

1996 Instituto Tecnológico y De Estudios Superiores de Monterrey, Nuevo León, Mx Master of Science in Quality Systems (MSQS)

1993 Instituto Tecnológico y De Estudios Superiores de Monterrey, Nuevo León, Mx Bachelor of Science in Mechanical Engineering (BSME)

\section{PUBLICATIONS AND PRESENTATIOSN}

Enhancing Simulation as Improvement and Decision Support System Tool, Winter Simulation Conference, December 2008

Decision Making training tool for a Manufacturing Line using Simulation, Fifth LACCEI International Latin American and Caribbean Conference for Engineering and Technology (LACCEI'2007), May 2007

Modeling and Analysis of an Oil Platform Evacuation Logistic System using Simulation, Fifth LACCEI International Latin American and Caribbean Conference for Engineering and Technology (LACCEI'2007), May 2007

Simulation and Analysis of systems using ProModel, García Eduardo, H. García, L. E. Cárdenas, Prentice Hall, 2006

\section{SOCIETIES AND ORGANIZATIONS}

Institute of Industrial Engineering

Institute for the Operations Research and Management Sciences

Omega Rho, Honor Society for Operations Research

Council of Supply Chain Management and Professionals 